\title{
Applications of Metal-Organic Frameworks Featuring
}

\section{multi-Functional Sites}

\author{
Baiyan Li, Matthew Chrzanowski, Yiming Zhang and Shengqian Ma* \\ Department of Chemistry, University of South Florida, 4202 E. Fowler Ave, Tampa, Florida \\ 33620, USA \\ Tel: +1-813-974-5217, Fax: +1-813-974-3203 \\ Email address: sqma@usf.edu
}

\section{Contents}

1. Introduction

2. Application of MFS-MOFs in catalysis

2.1 Multi-functional catalytic sites on both organic ligands and metal clusters

2.2 Multi-functional catalytic sites in organic ligands

2.3 Multi-functional catalytic sites in framework and guest moiety separately

2.4 Combine MFS of two guest components

3. Application of MFS-MOFs in gas adsorption/separation

$3.1 \mathrm{CO}_{2}$ adsorption.

3.1.1 $\mathrm{CO}_{2}$ adsorption by multifunctional non-metal sites.

3.1.2 $\mathrm{CO}_{2}$ adsorption by combination of non-metal sites and open metal sites

3.2 Hydrocarbon separation.

4. Application of MFS-MOFs in optics.

5. Application of MFS-MOFs in proton conduction. 
6. Conclusion and outlook

Acknowledgments

References

\begin{abstract}
Metal-organic frameworks (MOFs), a class of porous materials bring great promise for a diverse array of applications ranging from gas storage and separation to heterogeneous catalysis. The ability to incorporate multiple functional sites into a single system enhances the interest seen in MOFs. The solid, well-defined nature of MOFs allow for the engineering of materials capable of performing multiple functions through multiple independent processes or cooperative and synergetic interactions or pathways. In this review, we aim to encompass and summarize research that introduces techniques and strategies to incorporate multiple functional sites within a single MOF system, highlight exceptional examples of work that exploits MFS-MOFs to perform noteworthy processes, and give direction to further enhance our ability to move MFSMOFs forward in a way that addresses current problems faced by our society.
\end{abstract}

\title{
Abbreviations
}

AB, ammonia borane; ad, adenine; adp, adipic acid; ATA, 2-aminoterephthalate; Atz, 3-amino1,2,4-triazole; bdc- $\mathrm{NH}_{2}$, 2-amino-benzene-1,4-dicarboxylate; BA, benzaldehyde; bpy, 2,2'bipyridine; BTC, 1,3,5-benzenetricarboxylate; CCR, concentration-controlled reduction; DFT, density functional theory; DMATA, dimethyl 2-aminoterephthalate; DMBDC, 2,5-dimethoxy1,4-benzenedicarboxylate; DMF N,N-Dimethylformamide; $\quad \operatorname{dobpdc}^{4-}, \quad 4,4^{\prime}$-dioxido-3,3'biphenyldicarboxylate; DPBDPM, dipyridyl boron dipyrromethene; DSM, double solvents 
method; ee, enantiomeric excess; HA, heptanal; $\mathrm{H}_{4} \mathrm{BDCPPI}, \quad \mathrm{N}, \mathrm{N}$ '-bis(3,5dicarboxyphenyl)pyromellitic diimide; $\mathrm{H}_{4}$ BPTCA, biphenyl-3,3',5,5' -tetracarboxylic acid; $\mathrm{H}_{2}$ btz, 1,5-bis(5-tetrazolo)-3-oxapentane; $\quad \mathrm{H}_{2} \mathrm{DBTCPB}, \quad$ 1,4-dibromo-2,3,5,6-tetrakis(4carboxyphenyl)benzene; $\mathrm{H}_{2}$ ndc, 1,4-naphthalenedicarboxylate; HPLC, high-performance liquid chromatography; $\mathrm{H}_{4}$ tactmb, 1,4,7,10-tetrazazcyclododecane-,N',N', ,N', '-tetra-p-methylbenzoic acid; $\quad \mathrm{H}_{4} \mathrm{TCPP}, \quad$ 5,10,15,20-tetrakis(4-carboxyphenyl)-porphyrin; $\mathrm{H}_{6} \mathrm{TDPAH}, \quad$ 2,5,8-tris(3,5dicarboxylphenylamino)-s-heptazine; $\mathrm{H}_{6}$ TDPAT, 2,4,6-tris(3,5-dicarboxylphenylamino)-1,3,5triazine; IAST, Ideal Adsorbed Solution Theory; JA, jasminaldehyde; MeCN, acetonitrile; MeIM, 2-methylimidazolate; MOF, Metal-organic framework; MFS, Multi-functional sites; mmen, N,N-dimethylethylenediamine; MNP, metal nanoparticle; NMR, nuclear magnetic resonance; $\mathrm{NP}$, nanoparticle; 4-NPh, 4-nitrophenol; OMS, open metal site; ox, oxalic acid; PCP, porous coordination polymer; ppy, 2-phenylpyridine; PSM, post-synthetic modification; PYI, pyrrolidin-2-ylimidazole; TCA, 4,4',4''-tricarboxyltriphenylamine; TEOA, triethanolamine; TON, turnover number.

Keywords: metal-organic framework; multi-functional sites; catalysis; gas adsorption/separation; optics; proton conductivity

\section{Introduction}

Metal-organic frameworks (MOFs), an emergent class of porous materials, attract broad interests that arise from viewing MOFs as an adaptable platform capable of contributing to investigations in research ranging from exploring our fundamental understandings of surface chemistry to highly applied research [1-10]. The true power of MOFs, a class of porous coordination polymers (PCPs), derives from researchers' abilities to engineer properties into 
MOFs using a bottoms-up approach, taking advantage of geometric, chemical, and electronic features presented in the organic and inorganic building blocks [11-15]. The ultrahigh porosity and extraordinary surface area exhibited by MOFs make the materials promising for applied research, addressing issues found in gas storage and separation [16-20], catalysis [21-24], sensing [25-27], proton conduction [28-31], and drug delivery [32-34]. Researchers achieve further functionalization of MOF materials using a number of strategies including post-synthetic modification (PSM) [35-39] of organic ligands or metal clusters, constructing frameworks using functional ligands or metal clusters, and embedding useful molecules including organometallic molecules [40-43], enzymes [44-47], metal nanoparticles (NPs) [8,48-50], heteropoly acids [5153] within the pores. The diverse and immense number of species, including organic ligands, inorganic metal ions/clusters, and guests, used to construct MOFs materials lead to MOFs materials possessing phenomenal properties. Multi-functional sites (MFSs) achieved through the inclusion of multiple mono- or multi-functional species or the inclusion of a single multifunctional species further enhance interest in MOFs materials. MFSs behave either cooperatively or independently to further appreciate the functionality of MOFs materials. To date, MFS-MOFs synthesis results from one of four well established techniques highlighted in this review: (1) use organic ligands possessing multiple functional sites (Scheme 1a) [54-58]; (2) use both organic ligands and metal clusters possessing functional sites (Scheme 1b) [59-65]; (3) introduce multiple guest components as functional sites (Scheme 1c) [98-108]; (4) construct a framework with functional sites and include guest molecules with another functional sites (Scheme 1d) [8896]. These strategies make MOFs an optimal platform to design and synthesize functionally tailored materials. This review aims to focus on the application of MFS-MOFs while illustrating 
the cooperative or separate roles of these functional sites in the application of catalysis, gas adsorption and separation, optics and proton conduction application.

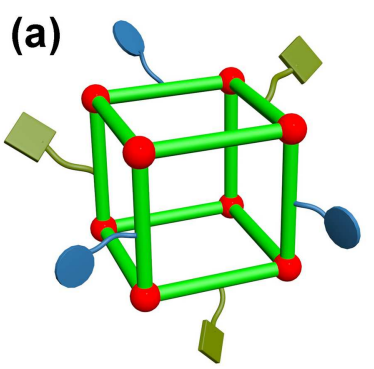

(c)

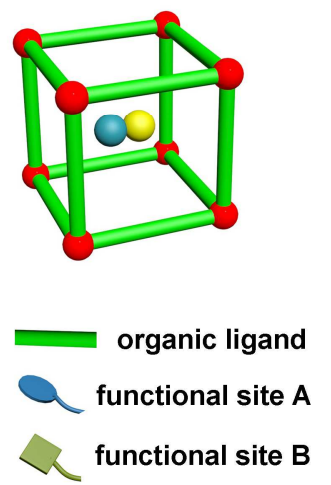

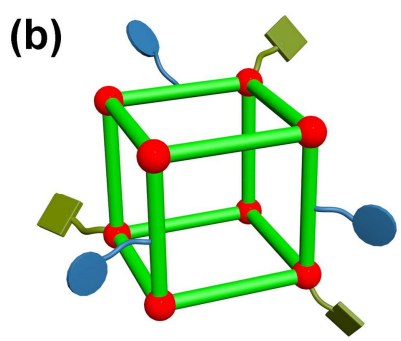

(d)

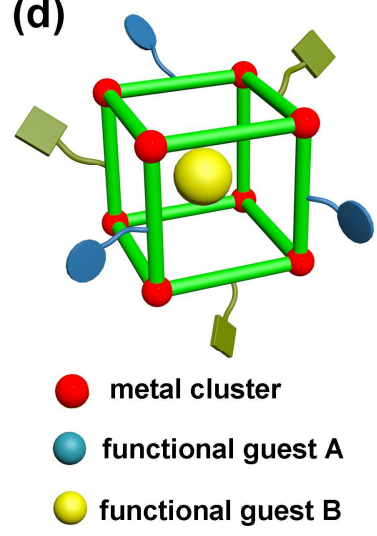

Scheme 1. The synthetic strategies of MFS-MOFs.

Four separate sections compose this article with each section focusing on separate and unique applications. In the first section, we present current technologies and knowledge that exploit MFS-MOFs for catalysis applications. We classify recent research into three categories based off the nature of the multifunctional sites: the first classification presents examples of MOFs that include functional sites on the organic ligand and metal center, the second gives research that present strategies for including MFS in MOFs within only the organic ligand, and the third introduces the concept of combining functional guests with functional sites on the framework. The second section of this review aims to provide a summary of current research, technologies, and knowledge that capitalizes on MFS-MOFs for the purpose of gas separation and storage. We broke this section up into two distinct branches, $\mathrm{CO}_{2}$ adsorption and 
hydrocarbon separation. We found numerous examples of $\mathrm{CO}_{2}$ adsorption technologies using MFS-MOFs and thus separated that section into two subsections based on the species forming the MFSs (organic and OMS functionality, multiple organic functionalities). Finally, we conclude this review with a brief overview of MFSs applied for optics technology and for proton conduction. We focus our review on providing publications that present strategies to incorporate MFSs on MOFs, providing chemists with a toolbox to further exploit the fantastic properties MOFs possess.

\section{Application of MFS-MOFs in catalysis}

Compared with other porous material based catalysts, MOF catalysts show several advantageous features: (1) the extra high surface area of MOFs facilitate the contact of substrate and catalytic active site resulting in improved catalytic reactivity; (2) the uniformity and tunability of MOFs' pores benefit the catalytic selectivity; (3) facile functionalization and incorporation of catalytic active sites into MOFs enhance researchers' abilities to manipulate the nano-environment to further enhance catalytic activity. In this section, we aim to present several strategies to enhance heterogeneous catalytic activity of MOFs by incorporating multiple catalytic sites within the framework confines.

\subsection{Multi-functional catalytic sites on both organic ligands and metal clusters}

Biological systems (such as enzymes or enzyme complexes) accelerate and control the selectivity of chemical transformations by precise control of the local environments around active centers [59]. Immobilizing different catalytically active sites on a substrate maintains the independent function while allowing cooperative or independent catalysis of a single step or multiple steps in a reaction sequence [60-61]. As an illustration, organic and biological systems commonly catalyze reactions using both acid and base catalytic sites. Development of a singly 
homogeneous system containing both acidic and basic catalytic sites introduces an issue in that the acidic and basic components of the homogenous system would neutralize each other, resultantly quenching the activity of catalyst. Immobilizing an acidic and basic catalytic site prevents the two catalysts from physically interacting and neutralizing each other ultimately preserving activity of multifunctional catalysts [62-63]. In MOFs materials, the distinct and regular arrangement of the organic ligand and inorganic metal ion or metal clusters provides the chance to construct multifunctional catalysts by modifying the organic ligand and metal cluster.

Researchers have demonstrated Lewis acid catalytic activity stemming from open metal sites (OMS) in MOFs. By judiciously selecting MOF materials that possesses OMS and functionalizing an organic ligand with an organic basic group, the resultant materials exhibits both basic and acidic functional sites. De Vos and co-workers reported a multi-functional MOF UiO-66 $\left(\mathrm{NH}_{2}\right) \quad\left[\mathrm{Zr}_{6} \mathrm{O}_{4}(\mathrm{OH})_{4}\left(\mathrm{O}_{2} \mathrm{C}-\mathrm{C}_{6} \mathrm{H}_{3} \mathrm{NH}_{2}-\mathrm{CO}_{2}\right)_{6}\right]$ constructed by using $\mathrm{Zr}_{6} \mathrm{O}_{4}(\mathrm{OH})_{4}$ clusters with an amine-functionalized organic ligand [64]. The $\mathrm{Zr}(\mathrm{IV})$ OMS behaves as a Lewis acid site whereas the amino group derived from organic ligand behaves as a basic functional site. The acid-base bifunctional MOF UiO-66 $\left(\mathrm{NH}_{2}\right)$ catalyzes cross-aldol reaction of heptanal $(\mathrm{HA})$ and benzaldehyde (BA) to obtain jasminaldehyde (JA) (Scheme 2) with high conversion (67\%) and selectivity (91\%). Control experiments illustrate that UiO-66 without amino group result in a lower conversion (30\%) and selectivity (82\%). The results suggest that the combination of acid and base sites catalyze the cross-aldol reaction superior to materials containing only Lewis acid sites. De Vos et al. claim the $\mathrm{Zr}$ sites activate benzaldehyde by increasing its polarity, while the proximal amino groups activate the methylenic group in the aliphatic aldehyde. The compounding catalytic activity of the Lewis acid site and Lewis base site leads to the superior selectivity and demonstrate the feasibility of multifunctional, synergetic catalysis. 


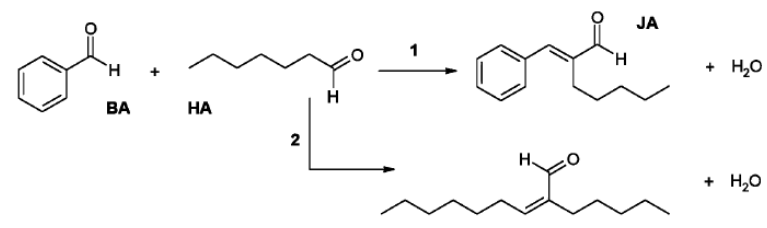

Scheme 2. The catalytic reaction of heptanal and benzaldehyde to obtain jasminaldehyde.

Reprinted with the permission from ref. 64, Copyright 2010, Royal Society of Chemistry.

The Kim group reported another multifunctional acid-base MOF [65]. Using Al(III) sites as Lewis acid groups and an amino- substituted ligand as a Lewis base, Kim et al. constructed the MOF $\mathrm{NH}_{2}-\mathrm{MIL}-101(\mathrm{Al})\left[\mathrm{Al}_{3} \mathrm{O}(\mathrm{Cl}, \mathrm{OH})\left(\mathrm{H}_{2} \mathrm{O}\right)_{2}\left(\mathrm{O}_{2} \mathrm{C}-\mathrm{C}_{6} \mathrm{H}_{3} \mathrm{NH}_{2}-\mathrm{CO}_{2}\right)_{3}\right]$ (Fig.1A and 1B). Due to the well-defined and isolated acid-base sites, the two active sites cannot quench each other, thus preserving individual functions (Fig.1C). $\mathrm{NH}_{2}-\mathrm{MIL}-101(\mathrm{Al})$ catalyzes tandem Meinwald rearrangement-Knoevenagel condensation (Scheme 3) with high conversion $(80 \%)$ and yield (70\%). Control experiments suggest that Lewis acid catalyst such as $\mathrm{AlCl}_{3}$, possessing only mono-acidic sites, catalyzes only the first step of tandem the reaction converting the epoxide to an aldehyde while failing to condense the aldehyde and form the final alkene product. When only dimethyl 2-aminoterephthalate (DMATA) was used as catalyst, the reaction failed to proceed due to the lack aldehyde formation, a product of the first reaction step. A homogeneous mixture of $\mathrm{AlCl}_{3}$ and DMATA results in the quenching of DMATA activity. This drawback highlights the advantage of site-separate acid-base catalysts in $\mathrm{NH}_{2}-\mathrm{MIL}-101(\mathrm{Al})$. Horiuchi, Matsuoka and coworkers further tested the catalytic capabilities of $\mathrm{NH}_{2}-\mathrm{MIL}-101(\mathrm{Al})$ in deacetalizationKnoevenagel condensation reaction (Scheme 4), converting benzaldehyde dimethylacetal and malononitrile to form benzylidenemalononitrile [66]. $\mathrm{NH}_{2}-\mathrm{MIL}-101(\mathrm{Al})$, the OMS, behaving as a Lewis acid, catalyzes the first step, the deacetalization reaction while the Lewis base amino 
group catalyzes the Knoevenagel reaction, the second step in the reaction sequence. The examples presented highlight the concept of using multi-functional MOFs materials as a platform to catalyze a cascade of reactions for single-pot, multistep, complex organic reactions.

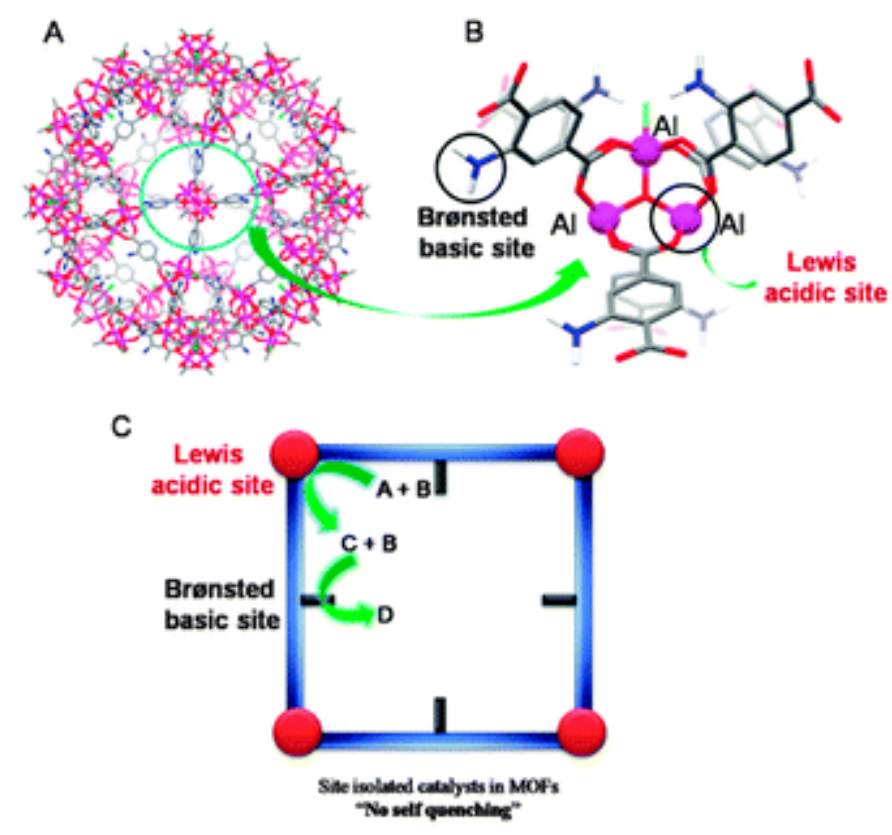

Fig.1. (A) A large cage in $\mathrm{NH}_{2}-\mathrm{MIL}-101(\mathrm{Al})$; (B) Lewis acidic sites ( $\mathrm{Al}^{3+}$ centers) and Lewis basic sites (aminoterephthalate linkers); (C) schematic representation of tandem organic reactions using a site-isolated heterogeneous catalyst. Reprinted with the permission from ref. 65, Copyright 2012, Royal Society of Chemistry.

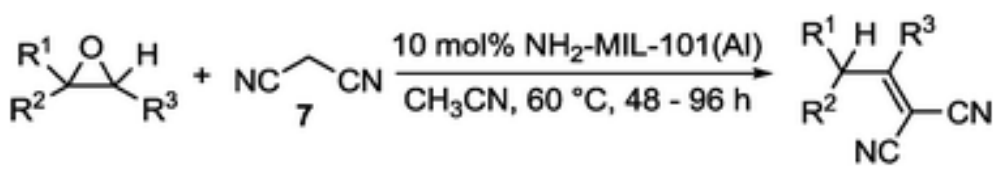

Scheme 3. Meinwald rearrangement-Knoevenagel condensation. Reprinted with the permission from ref. 65, Copyright 2012, Royal Society of Chemistry.<smiles>CCCNC=Cc1ccccc1</smiles> 
Scheme 4. One-pot deacetalization-Knoevenagel condensation reaction. Reprinted with the permission from ref. 66, Copyright 2013, Royal Society of Chemistry.

The metal clusters of MOFs materials have been shown to exhibit photocatalytic activity in addition to Lewis acid catalytic activity. $\mathrm{Li}$ and co-workers use $\mathrm{Ti}_{8} \mathrm{O}_{8}(\mathrm{OH})_{4}\left(\mathrm{O}_{2} \mathrm{C}-\mathrm{C}_{6} \mathrm{H}_{3} \mathrm{NH}_{2-}\right.$ $\left.\mathrm{CO}_{2}\right)_{6}\left(\mathrm{NH}_{2}\right.$-MIL-125(Ti)) framework to photocatalyze the reduction of $\mathrm{CO}_{2}$ under visible light irradiation (Fig.2) [67]. Using MIL-125(Ti), the same framework lacking amino-groups, and the mixture of $\mathrm{TiO}_{2}$ and ATA as controls, $\mathrm{Li}$ and co-workers demonstrate the necessary role compounding catalytic activity from separate multi-functional sites plays in promoting the observed photocatalytic behavior. The authors indicate that the introduction of the amino group in organic ligands result in light absorption in visible light region. Beyond the observed photocatalytic activity, an interesting photochromic phenomenon was observed during the photocatalytic reaction. When the suspension of $\mathrm{NH}_{2}$-MIL-125(Ti) and TEOA in MeCN was irradiated with visible light in the presence of $\mathrm{N}_{2}$, the reaction suspension changed from the bright yellow to green. Upon the introduction of $\mathrm{CO}_{2}$ or $\mathrm{O}_{2}$, the suspension gradually changed from green back to the original yellow (Fig.3). The studies on $\mathrm{NH}_{2}-\mathrm{MIL}-125$ (Ti) ascribe the photochromic phenomenon to the presence of the intervalence electron transfer from $\mathrm{Ti}$ (III) to Ti(IV) sites in the titanium oxo-clusters. The result suggests that the titanium oxo-clusters act as the catalyst for the photocatalytic reaction. The amine-functionalized organic ligand adsorbs visible light, playing the role of antenna. The proposed mechanism highlights the roles separate, multi-functional sites on $\mathrm{NH}_{2}$-MIL-125(Ti) play. Light absorption by $\mathrm{NH}_{2}$-BDC in the LMCT band results in an electron transfer from the organic ligand to $\mathrm{Ti}^{4+}$ (Scheme 5). TEOA also functions as an electron donor, aiding in the reduction of $\mathrm{Ti}^{4+}$ to $\mathrm{Ti}^{3+}$. The $\mathrm{Ti}^{3+}$ reduces $\mathrm{CO}_{2}$ to $\mathrm{HCOO}^{-}$. Likewise, the reduction of $\mathrm{Ti}^{4+}$ to $\mathrm{Ti}^{3+}$ in the presence of visible light radiation and the 
subsequent oxidation of $\mathrm{Ti}^{3+}$ back to $\mathrm{Ti}^{4+}$ explain the observed color changes. This example highlights the ability to tune band gaps and exploit LMCT using separated multi-functional sites on MOFs to promote photocatalysis in MOFs materials.

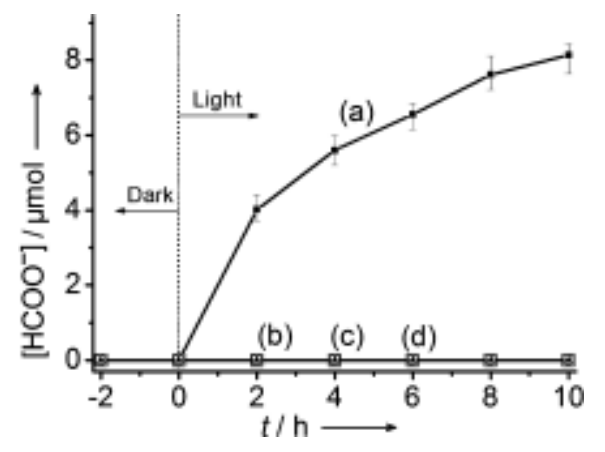

Fig.2. The amount of $\mathrm{HCOO}^{-}$produced as a function of the time of irradiation over a) $\mathrm{NH}_{2}$-MIL125(Ti) (•), b) MIL-125(Ti) $(\square)$, c) a mixture of $\mathrm{TiO}_{2}$ and $\mathrm{H}_{2} \mathrm{ATA}(19 \mathrm{mg}+32 \mathrm{mg})(\bigcirc)$, and d) visible light irradiation without a sample (₫). Reprinted with the permission from ref. 67, Copyright 2012 WILEY-VCH Verlag GmbH \& Co. KGaA, Weinheim.

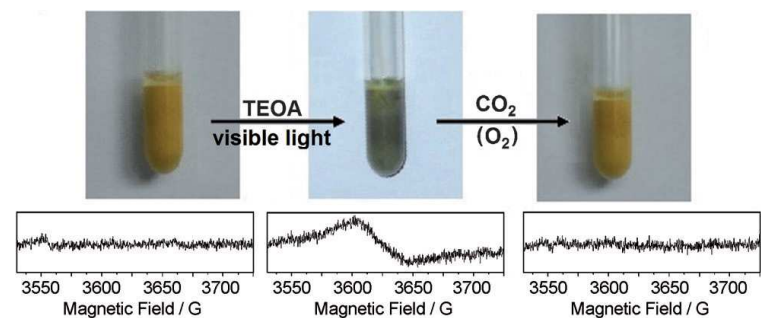

Fig.3. Photos and corresponding ESR spectra of $\mathrm{NH}_{2}-\mathrm{MIL}-125$ (Ti) under different conditions: a) fresh $\mathrm{NH}_{2}$-MIL-125(Ti), b) TEOA, visible light, and $\mathrm{N}_{2}$ and c) after the introduction of $\mathrm{CO}_{2}$ (or $\mathrm{O}_{2}$ ). Reprinted with the permission from ref. 67, Copyright 2012 WILEY-VCH Verlag GmbH \& Co. KGaA, Weinheim. 


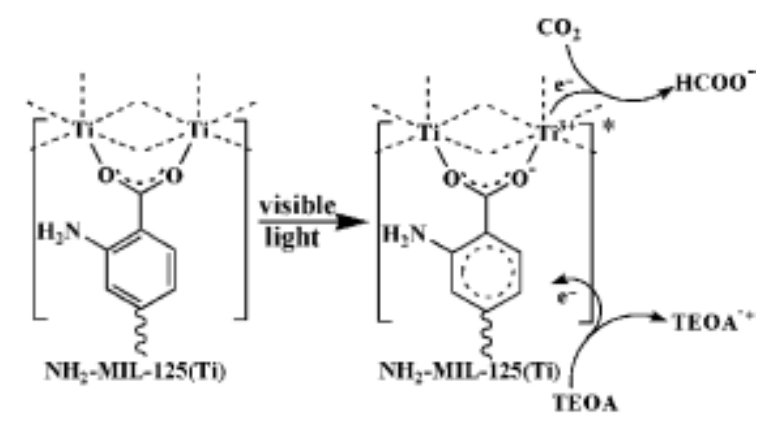

Scheme 5. Proposed mechanism for the photocatalytic $\mathrm{CO}_{2}$ reduction over $\mathrm{NH}_{2}-\mathrm{MIL}-125(\mathrm{Ti})$ under visible light irradiation. Reprinted with the permission from ref. 67, Copyright 2012 WILEY-VCH Verlag GmbH \& Co. KGaA, Weinheim.

Horiuchi, Matsuoka and coworkers report another approach to synthesize the multifunctional photocatalytic MOFs, focusing on only the metal cluster as the photocatalytic active center and the organic linker behavior as another function [68]. The first step in the cascade reaction involves the oxidation of benzyl alcohol into benzaldehyde using the photo-active $\mathrm{Zr}$ oxo clusters of the UiO-66- $\mathrm{NH}_{2}$ framework. The amine-functionalized ligands then catalyze the second step of cascade reaction, the Knoevenagel condensation (Scheme 6).

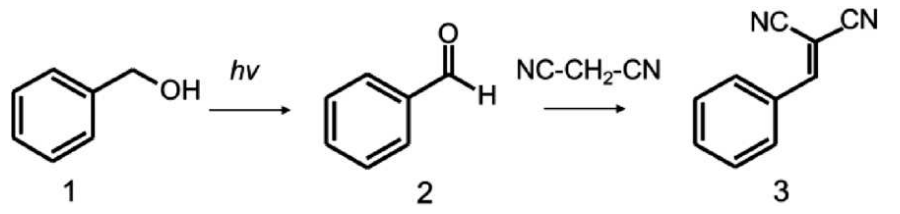

Scheme 6. One-pot sequential photocatalytic oxidation and Knoevenagel condensation reaction over Zr-MOF-NH 2 . Reprinted with the permission from ref. 68, Copyright 2013 Royal Society of Chemistry.

Ma and co-workers present a unique perspective and strategy in forming multi-functional MOFs materials by inserting additional OMS into the ligand of the framework [69]. Our group used a macrocyclic ligand, $\mathrm{H}_{4}$ tactmb, and copper paddlewheel clusters to construct MMCF-2 $\left[\mathrm{Cu}_{2}(\mathrm{Cu}\right.$-tactmb $\left.)\left(\mathrm{H}_{2} \mathrm{O}\right)_{3}\left(\mathrm{NO}_{3}\right)_{2}\right] \quad\left(\mathrm{H}_{4}\right.$ tactmb $=$ 1,4,7,10-tetrazazcyclododecane-N,N',N', ,N', '- 
tetra-p-methylbenzoic acid), a MOF possessing nbo topology. The OMS in the axial positions of the copper paddlewheel clusters behave as Lewis acid sites as does the $\mathrm{Cu}$ (II) metalated azamacrocycle (Fig.4). MMCF-2 catalyzes the cycloaddition of $\mathrm{CO}_{2}$ and epoxides, forming cyclic carbonates at room temperature and 1 atm pressure. Compared with other similar MOFs, the introduction of extra Lewis acid sites in organic ligand increases the activity of MMCF-2. We make the claim that increasing additional Lewis acid sites increases the density of catalytic active centers within the MOF framework, resulting in higher catalytic activity.

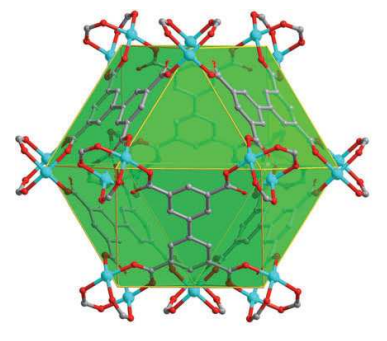

(a)

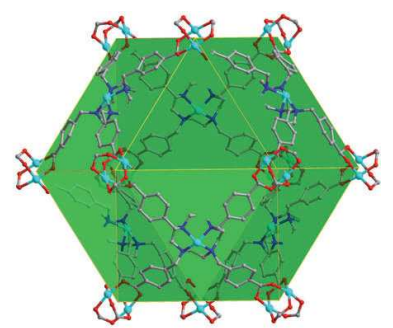

(b)

Fig.4. The cuboctahedral cage of (a) MOF-505 and (b) MMCF-2. Reprinted with the permission from ref. 69, Copyright 2014 WILEY-VCH Verlag GmbH \& Co. KGaA, Weinheim.

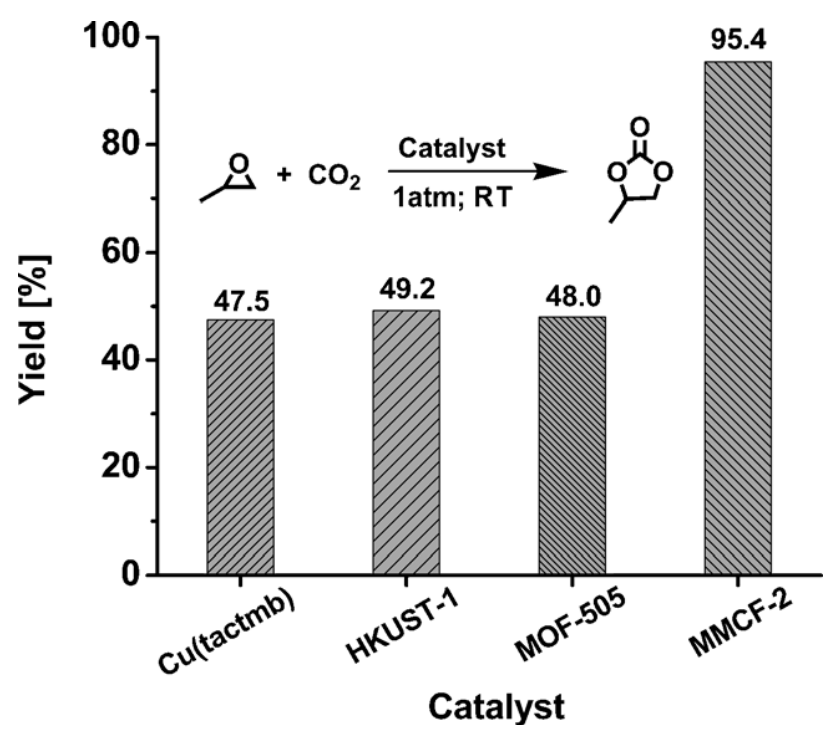

Fig.5. The yield of propylene carbonate from cycloaddition of propylene oxide and $\mathrm{CO}_{2}$ catalyzed by $\mathrm{Cu}($ tactmb), HKUST-1, MOF-505, and MMCF-2 after $48 \mathrm{~h}$ at room temperature 
under $1 \mathrm{~atm} \mathrm{CO}_{2}$ pressure. Reprinted with the permission from ref. 69, Copyright 2014 WILEYVCH Verlag GmbH \& Co. KGaA, Weinheim.

To further the previous investigation, we designed and synthesized a MOF $\mathrm{Cu}_{6}\left(\mathrm{CuC}_{76} \mathrm{H}_{36} \mathrm{~N}_{4} \mathrm{O}_{16}\right)\left(\mathrm{HCO}_{2}\right)_{4}\left(\mathrm{H}_{2} \mathrm{O}\right)_{6}$ (MMPF-9) possessing an entirely new smy topology [70]. MMPF-9 was synthesized using tetrakis(3,5-dicarboxybiphenyl)-porphine (tdcbpp) as a ligand and copper paddlewheel clusters (Fig.6). MMPF-9 interestingly has two distinct channels, a truncated triangular channel with nine copper OMS pointing toward the middle of the channel, and a larger hexagonal channel with nine copper OMS oriented, likewise, toward the center of the channel. MMPF-9 exhibits similar catalytic activity as MMCF-2 in the cycloaddition of $\mathrm{CO}_{2}$ and epoxides. The previous two examples demonstrate the ability to effectively introduce multiple functional sites into MOFs through the addition of OMS within the ligand.

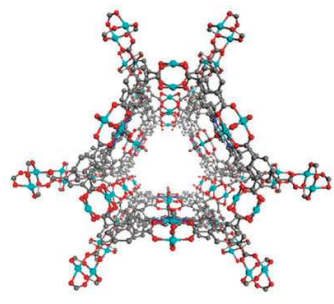

(a)

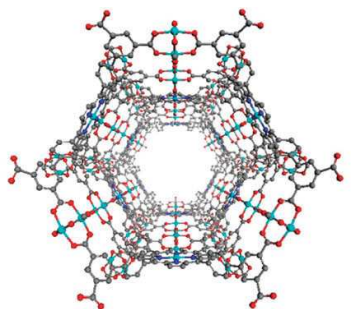

(b)

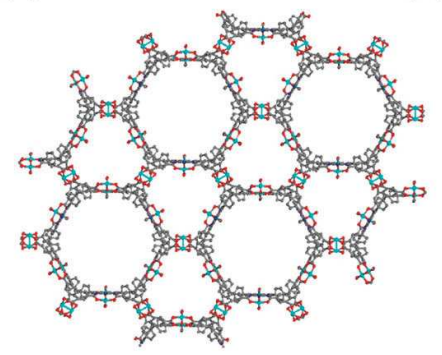

(c)

Fig.6. (a) The truncated triangular channel, (b) the hexagonal channel, and (c) the extended channels of MMPF-9 viewed along the c direction. Reprinted with the permission from ref. 70 , Copyright 2013 Royal Society of Chemistry.

\subsection{Multi-functional catalytic sites in organic ligands}


Both pre-synthetic methods and post-synthetic modifications present a facile methodology for introducing multifunctional sites into MOFs. Shi and co-wokers [71] developed a strategy to construct organo-bifunctional catalyst by modifying both the metal clusters and ligands (Scheme 7). Li et al. obtained the organo-bifunctional catalyst MIL-101-SO ${ }_{3} \mathrm{H}-\mathrm{NH}_{2}$ and demonstrated its capabilities to catalyze one-pot deacetalization-nitroaldol reaction with excellent yield (97\%) (Table 1). The work presents an intuitive strategy of incorporating three distinct steps to graft and functionalize multiple groups on the framework: first grafting a protected amine-group onto the metal centers, followed by sulfonation of the aromatic ligands and then deprotection of the amine functionalized metal centers. Sulfonate functionalized Brønsted acid exhibits stronger acidity and catalytic activity when compared with Lewis acid catalytic sites. The presented strategy further allows tuning of the Lewis base site by exchanging the amine-functional group. Where monofunctional materials only catalyze a single step in cascade reactions (Table 1), bifunctional MOFs materials such as MIL-101- $\mathrm{SO}_{3}-\mathrm{NH}_{2}$ efficiently produce complex products requiring a cascade of multiple steps in a single reaction pot. The combination of two hostile catalysts in a single homogenous catalytic system results in a significant depression of catalytic activity whereas the immobilization of two hostile functional sites on a heterogeneous catalyst prevents quenching of the catalyst, highlighting a major benefit of this class of materials.

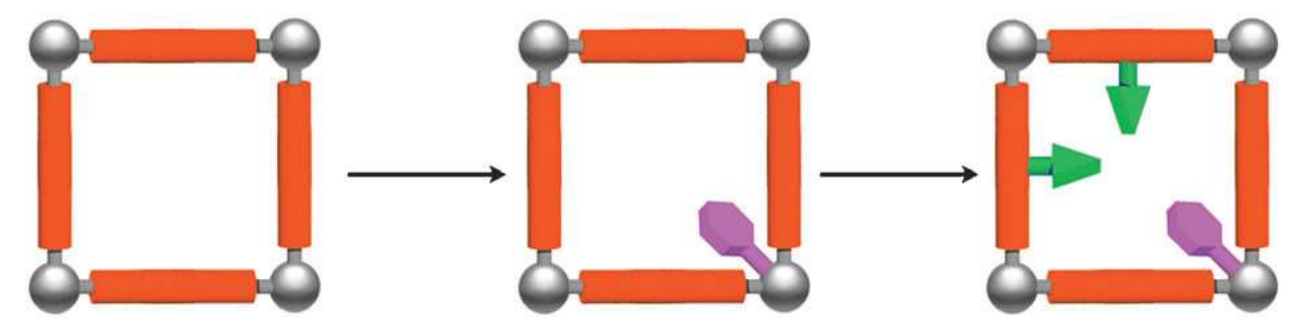

Scheme 7. The generic procedure for synthesizing bifunctional MOFs by grafting the functional groups onto both organic ligands and OMSs, respectively (grey ball: metal or metal cluster; 
orange pillar: organic ligand; green, and lavender bar: functional groups). Reprinted with the permission from ref. 71, Copyright 2012 Royal Society of Chemistry.

Table 1. One pot deacetalization-nitroaldol reaction. ${ }^{[a]}$ Reprinted with the permission from ref. 71, Copyright 2012 Royal Society of Chemistry.

\begin{tabular}{|c|c|c|c|c|}
\hline & 2 & & & 3 \\
\hline Entry & Catalyst & $\begin{array}{c}\text { conv. of } \\
1[\%]\end{array}$ & $\begin{array}{c}\text { yield of } \\
2[\%]\end{array}$ & $\begin{array}{c}\text { yield of } \\
3[\%]\end{array}$ \\
\hline 1 & MIL-101- $\mathrm{SO}_{3} \mathrm{H}-\mathrm{NH}_{2}$ & 100 & 3 & 97 \\
\hline 2 & MIL-101-SO ${ }_{3} \mathrm{H}-\mathrm{NHBOC}$ & 100 & 100 & trace \\
\hline 3 & MIL-101- $\mathrm{NH}_{2}$ & trace & trace & trace \\
\hline 4 & MIL-101- $\mathrm{SO}_{3} \mathrm{H}$ & 100 & 100 & 0 \\
\hline 5 & $\begin{array}{l}\mathrm{MIL}-101-\mathrm{SO}_{3} \mathrm{H}-\mathrm{NH}_{2}+\mathrm{p}- \\
\text { toluene sulfonic acid }\end{array}$ & 100 & 95.5 & 4.5 \\
\hline 6 & $\begin{array}{c}\mathrm{MIL}-101-\mathrm{SO}_{3} \mathrm{H}-\mathrm{NH}_{2}+ \\
\text { ethylamine }\end{array}$ & trace & trace & trace \\
\hline 7 & $\begin{array}{c}\text { p-toluene sulfonic acid }+ \\
\text { ethylamine }\end{array}$ & trace & trace & trace \\
\hline
\end{tabular}

In 2012, Duan and co-workers [72] reported a method to incorporate functionalization onto MOFs materials via using pre-synthesized functional organic ligands. The publication introduces two chiral MOFs, Zn-PYI1 and Zn-PYI2 (Zn-PYI = $\mathrm{Zn}_{2} \mathrm{H}_{2} \mathrm{O}(\mathrm{OH})\left(\mathrm{C}_{21} \mathrm{H}_{12} \mathrm{NO}_{6}\right)\left(\mathrm{C}_{8} \mathrm{H}_{13} \mathrm{~N}_{3}\right)$, that incorporate stereoselective organocatalysts L- or Dpyrrolidin-2-ylimidazole (PYI) and a triphenylamine photoredox group (Scheme 8). The triphenylamaine moiety initiates a photoinduced electron transfer, creating an active intermediate for the $\alpha$-alkylation. The chiral PYI moieties behave as cooperative organocatalytic active sites driving asymmetric catalysis, resulting in significant stereoselectivity. Zn-PYI1 catalyzes the coupling of aliphatic aldehydes and diethyl 2-bromomalonate under a fluorescent lamp (26 W) generating the desired product with excellent enantioselectivity (86-92\% ee) and moderate yield (65-84\%) (Table 2). Control experiments suggest both photosensitizing triphenylamine moiety 
and chiral organocatalyst D-/L-PYI moiety are necessary for the light-driven $\alpha$-alkylation reactions. The authors propose a photoinduced electron transfer occurs with electrons transferring from $\mathrm{Zn}-\mathrm{PYI}{ }^{*}$ to diethyl 2-bromomalonate molecules. This suggestion arises from the observation that the adsorption of 2-bromomalonate in MOFs Zn-PYI1 results in a depression of both luminescent intensity and fluorescent lifetime. The same quenching of luminescence and decline in fluorescence lifetime was observed in Ho-TCA, a third MOF synthesized specifically to further investigate photocatalytic capabilities, loaded with 2bromomalonate and triphenylamine. The results illustrate that the triphenylamine moiety plays a key role in catalyzing the coupling reaction. The authors propose the excited state of triphenylamine acts as a reductant in a single-electron transfer from the framework to diethyl 2bromomalonate, creating a radical anion that rapidly undergoes $\sigma$-bond cleavage. Importantly, the enantioselectivity of both Zn-PYI1 and Zn-PYI2 (78-92\%) exceed that of the mixtures of MOFs and PYI (Ho-TCA/L-PYI, Ho-TCA/D-PYI, MOF-150/L-PYI, and MOF-150/D-PYI) (2024\%). This work combines two functional catalytic sites that cooperatively interact to restrict substrate within pores of frameworks, controlling the product stereochemistry, and harvest and transfer electrons to promote catalysis. 


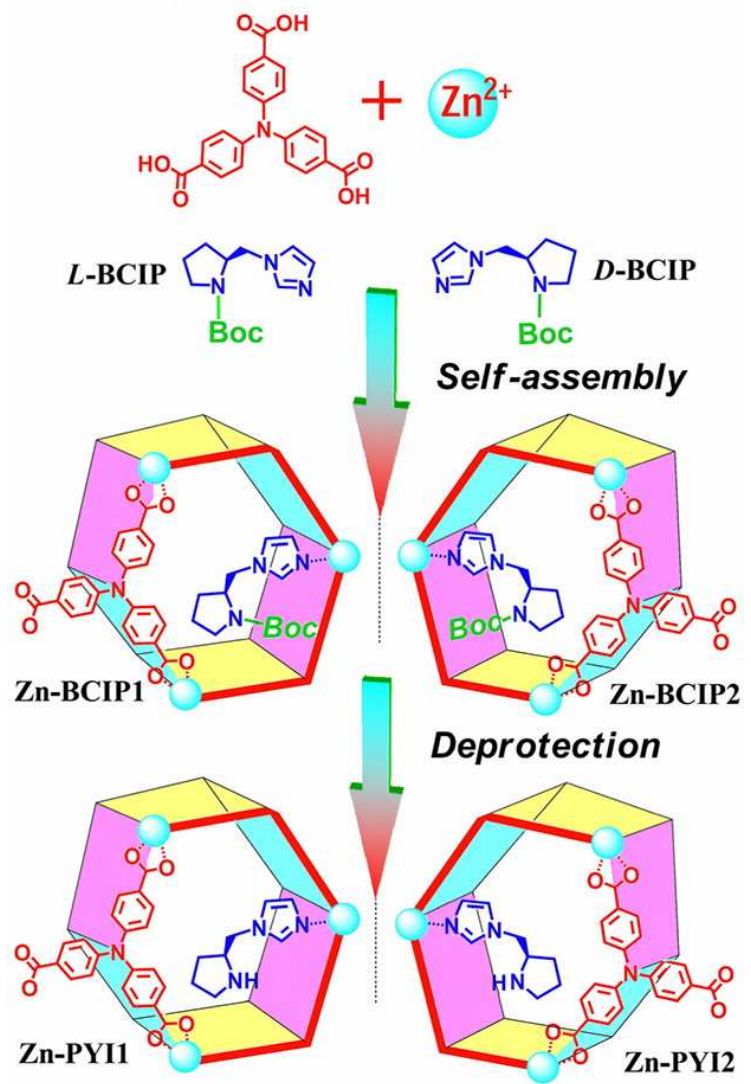

Scheme 8. Schematic Representation of the Mirror Image Structures of Zn-BCIP1 and Zn-BCIP2 and Their Deprotected Forms Zn-PYI1 and Zn-PYI2, Showing the Photosensitizer, 4,4',4”-Nitrilotribenzoic Acid (Red or Simply Drawn as Block Red Bars), and the Chiral Organocatalytic Moiety, L- or D-Proline Derivatives (Blue). Reprinted with the permission from ref. 72, Copyright 2012 American Chemical Society.

Table 2. Conversions and ee Values (in Parentheses) of the Photocatalytic $\alpha$-Alkylation of Aliphatic Aldehydes. Reprinted with the permission from ref. 72, Copyright 2012 American Chemical Society. 


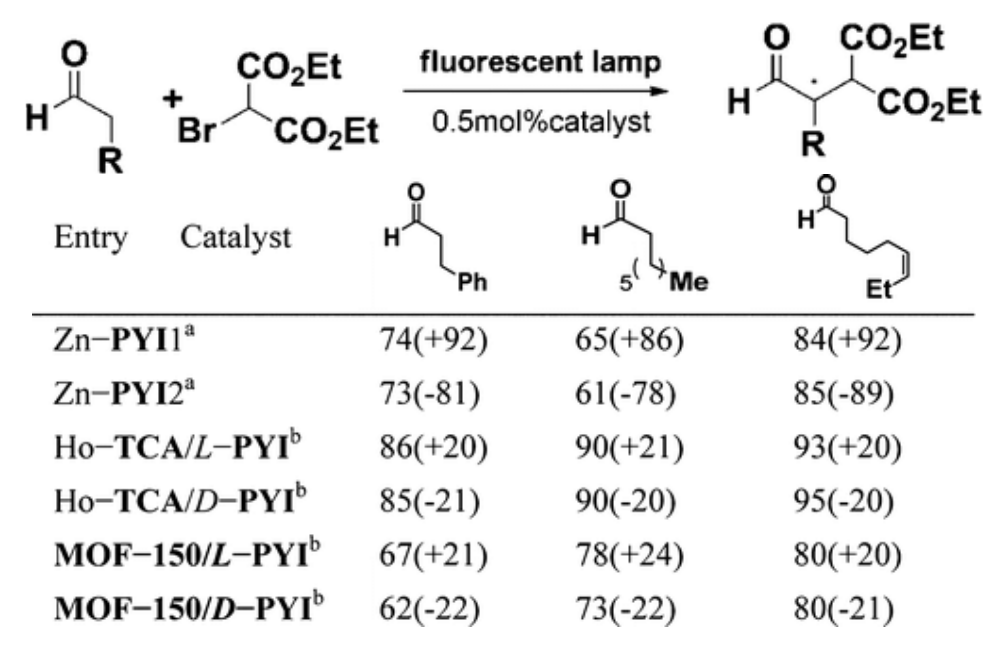

${ }^{a}$ Reaction conditions: diethyl 2-bromomalonate, $0.385 \mathrm{mmol}$; aliphatic aldehyde, $0.769 \mathrm{mmol}$; 2,6-lutidine, $0.769 \mathrm{mmol}$; catalyst, $1.9 \mu \mathrm{mol}(0.5 \mathrm{~mol} \%)$ per triphenylamine moiety; $26 \mathrm{~W}$ fluorescent lamp, room temperature under $\mathrm{N}_{2}$ for $24 \mathrm{~h}$. ${ }^{\mathrm{b}}$ In the presence of additional chiral D-/LPYI $(76.9 \mu \mathrm{mol})$.

\subsection{Multi-functional catalytic sites in framework and guest moiety separately}

The large void space MOFs materials possess bring about the ability to accommodate guest species such as nanoparticle [8,48-50,73-83], heteropoly acid [51-53,84-86] and metalorganic molecules $[40-43,87]$. Thus, MOFs present themselves as an ideal platform to complement functional sites from the framework with guest molecules.

Interest lies in incorporating small metal nanoparticles (MNPs) within MOFs materials because MOFs pores provide the ability to stabilize MNPs without interfering with the surface of MNPs, as ligands do. The well-defined pores of MOFs also allow MOFs to template and control the growth of nanoparticles. Furthermore, the close proximity of MNPs to MOFs surfaces allows researchers to exploit synergistic interactions between MOFs and NPs. Treating metal clusters as Lewis acid catalytic sites, in 2010, He, Li and coworkers [88] encapsulated metal nanoparticles within MOFs by synthesizing Pd@MIL-101 $\left\{\right.$ MIL-101 $\left.=\mathrm{Cr}_{3}(\mathrm{~F})\left(\mathrm{H}_{2} \mathrm{O}\right)_{2} \mathrm{O}\left[\left(\mathrm{O}_{2} \mathrm{C}\right) \mathrm{C}_{6} \mathrm{H}_{4}\left(\mathrm{CO}_{2}\right)\right]_{3}\right\}$. The researchers incorporate multiple functional sites within the framework with the MIL-101's 
OMS behaving as Lewis acid sites while the guest Pd nanoparticles catalyze hydrogenation reactions (Scheme 9). Beyond simply enhancing the catalytic abilities of the two different components, $\mathrm{He}, \mathrm{Li}$ et al. demonstrate that incorporating nanoparticles within the pores prevent metal agglomeration and stabilize the Pd nanoparticles. The Corma group furthered previous investigations by studying Pd@MIL-101's ability to cyclize citronellal into isopulegol. Corma et al. [89] also demonstrated the materials' ability to perform a one-pot tandem isomerization/hydrogenation of citronellal to menthol yielding excellent conversion (>99\%) and selectivity $(86 \%)$.

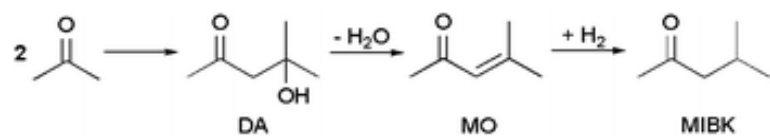

Scheme 9. Synthesis of (methyl isobutyl ketone) MIBK from acetone and $\mathrm{H}_{2}$. Reprinted with the permission from ref. 88, Copyright 2010 Royal Society of Chemistry.

The Huang group [90] furthered previous research incorporating Pd nanoparticles as a guest molecule by developing the multifunctional framework Pd@UiO-66- $\mathrm{NH}_{2}$ (Scheme 10). The catalyst performs a multi-step reaction where the guest Pd nanoparticles catalyze the oxidation of benzyl alcohol to benzaldehyde followed by the Lewis acid metal clusters catalyzing the formation of ethylene acetal with extra high conversion (99.9\%) and selectivity $(99.0 \%)$.

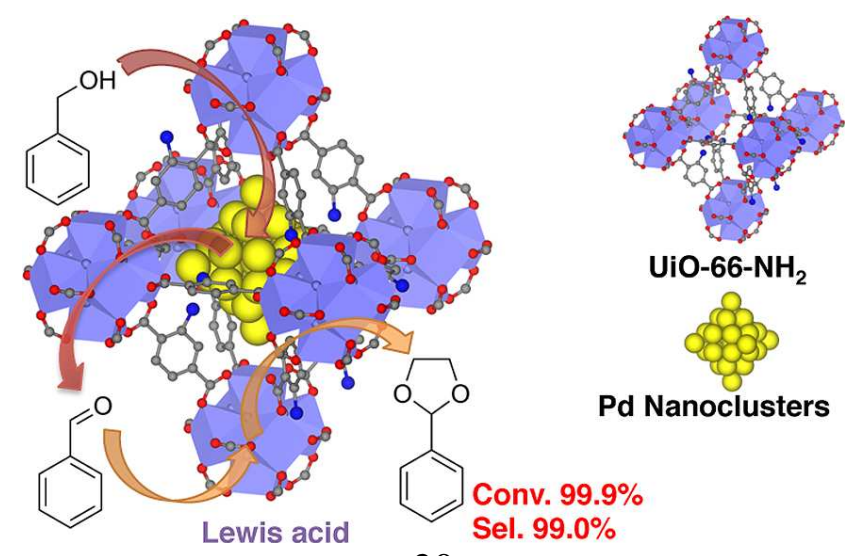


Scheme 10. The cascade reaction catalyzed by Pd@UiO-66- $\mathrm{NH}_{2}$. Reprinted with the permission from ref. 90, Copyright 2014 American Chemical Society.

Similar to functionalizing metal SBUs to complement the function of guest species, organic ligands present another platform for modification to form synergy with guest species. Recently, Tang's group [91] reported an interesting and efficient approach to enhance the properties of guest species and MOFs, synthesizing core-shell nanoparticle@MOFs composites Pd@IRMOF-3 [IRMOF-3 $=\mathrm{Zn}_{4} \mathrm{O}\left(\mathrm{O}_{2} \mathrm{C}-\mathrm{C}_{6} \mathrm{H}_{3} \mathrm{NH}_{2}-\mathrm{CO}_{2}\right)_{3}$ ] (Scheme 11a). The approach uses amino functionalized ligands to construct the MOF shell around Pd nanoparticles. The in situ encapsulation of Pd nanoparticles combines the basic properties of amino-functionalized ligands with the hydrogenation capabilities of Pd nanoparticles to perform Knoevenagel condensation and the subsequent selective hydrogenation (Scheme 11b) yielding extra high conversion (100\%) and superior selectivity (86\%) for the desired product (Table 3). Control experiments indicate core-shell Pd@IRMOF-3 exhibits two-step catalytic activity. The monofunctional counterparts perform a single step in the cascade reaction. Supported Pd/IRMOF-3 samples show lower selectivity to the final desired product when compared with core-shell Pd@IRMOF-3 catalyst. Experimental evidence and theoretical calculations elucidate the high catalytic activity and unique hydrogenation selectivity to the $-\mathrm{NO}_{2}$ group over the $\mathrm{C}=\mathrm{O}$ and $\mathrm{C}=\mathrm{C}$ groups. DFT calculations reveal group-selective adsorption of the substrate. The $-\mathrm{NH}_{2}$ groups on the surface of IRMOF-3 cause the substrate molecules to enter the MOFs pores with the $-\mathrm{NO}_{2}$ group leading and the $\mathrm{C}=\mathrm{O}$ group trailing. The pore dimensions then restrict the free rotation of the converted substrate, positioning the nitro group near the Pd nanoparticles where selective hydrogenation occurs. Tang et al. showed the effect pore size has on selectivity by testing the catalytic activity and selectivity of 4-nitro-1-butene $(0.87 \times 0.53 \mathrm{~nm})$ and 4-nitrocinnamaldehyde $(1.28 \times 0.72 \mathrm{~nm})$. 
The authors saw a significant decrease in selectivity for the desired product when 4-nitro-1butene was used and an increased selectivity, reaching over 96\% for 2-(3-(4aminophenyl)allylidene.

a)
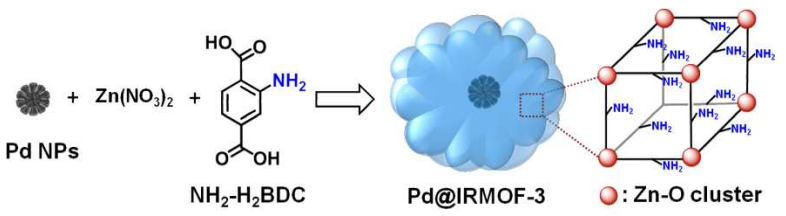

b)

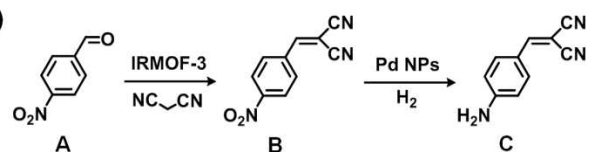

Scheme 11. (a) Synthetic route for the core-shell Pd@IRMOF-3 hybrids via the mixed solvothermal method and (b) model cascade reactions involving Knoevenagel condensation of A and malononitrile via the IRMOF-3 shell and subsequent selective hydrogenation of intermediate product B to C via the Pd NP cores. Reprinted with the permission from ref. 91, Copyright 2014 American Chemical Society.

Table 3. Cascade reactions of Knoevenagel condensation coupling with selective hydrogenation reactions catalyzed by different catalysts ${ }^{\mathrm{a}}$. Reprinted with the permission from ref. 91 , Copyright 2014 American Chemical Society.

\begin{tabular}{|c|c|c|c|c|c|c|}
\hline \multirow{2}{*}{ samples } & \multirow[b]{2}{*}{$\begin{array}{l}\text { Aconv. } \\
(\%)\end{array}$} & $\begin{array}{l}\text { form. } \\
(\%)\end{array}$ & $\begin{array}{l}\text { conv. }^{\mathrm{c}} \\
(\%)\end{array}$ & \multicolumn{3}{|c|}{ sel. (\%) } \\
\hline & & & B & $\mathrm{C}$ & $\mathrm{D}$ & E \\
\hline Pd@IRMOF-3 & 100 & 100 & 100 & 86 & 8 & 6 \\
\hline Pd/IRMOF-3 & 100 & 100 & 100 & 71 & 24 & 5 \\
\hline IRMOF-3 & 100 & 100 & 0 & 0 & 0 & 0 \\
\hline $\mathrm{Pd} \mathrm{NPs}^{\mathrm{d}}$ & 26 & 26 & - & - & - & - \\
\hline $\mathrm{Pd} \mathrm{NPs}^{\mathrm{e}}$ & - & - & 86 & 68 & 32 & 0 \\
\hline blank $^{\mathrm{f}}$ & 26 & 26 & - & - & - & - \\
\hline
\end{tabular}

${ }^{\mathrm{a}}$ Reaction conditions: A $(0.2 \mathrm{mmol})$, malononitrile $(0.21 \mathrm{mmol})$, catalyst $(10 \mathrm{mg}) .{ }^{\mathrm{b}} \mathrm{B}$ is formed via the condensation reaction. ${ }^{\mathrm{c}}$ Formed $\mathrm{B}$ is converted via the hydrogenation reaction. ${ }^{\mathrm{d}}$ For 
Knoevenagel condensation alone. ${ }^{\mathrm{e}} 0.2 \mathrm{mmol} \mathrm{B}$ is used as the raw material for the hydrogenation reaction. ${ }^{\mathrm{f}}$ No catalysts are used for the cascade reactions.

Multifunctional MOFs provide far greater potential beyond use solely in catalyzed cascade reaction. Lin and co-workers [92] demonstrate the ability to use a framework as a photosensitizer, harvesting photons and transferring electrons, while guest Pt nanoparticles act as a catalyst. Synergistic hydrogen evolution systems bring about great potential for hydrogen and clean energy production. Lin's group took a unique approach synthesizing a system incorporating Pt nanoparticle within the photoactive $\left[\operatorname{Ir}(\mathrm{ppy})_{2}(\mathrm{bpy})\right] \mathrm{MOF}$ frameworks (Scheme 12). Pt NPs are synthesized in situ within the pores of MOF powder. To catalyze hydrogen evolution, Pt@MOF assemblies were exposed to visible light (>420 nm). Using triethylamine to mediate photoreduction of $\left[\operatorname{Ir}^{\mathrm{III}}(\mathrm{ppy})_{2}\left(\mathrm{bpy}^{*^{-}}\right)\right]$, electrons efficiently transfer to Pt NPs which then reduce protons evolving hydrogen gas. TONs for the systems investigated reach 1.5 and 4.7 times the values of homogeneous controls (Fig.7). Since Lin's initial work, a number of other groups have applied this strategy to a number of other systems and reactions. The Matsuoka group [93] reported a hydrogen evolution system that used Pt nanoparticle functionalized $\mathrm{NH}_{2^{-}}$ MIL-125(Ti), replacing $\left[\operatorname{Ir}(\mathrm{ppy})_{2}(\mathrm{bpy})\right]$ as the photo-antenna responsible for transferring electrons to Pt nanoparticles. Sun et al. [94] extended Matsuoka's work by entrapping Pt and Au nanoparticles on $\mathrm{NH}_{2}$-MIL-125(Ti) to photocatalytically reduce $\mathrm{CO}_{2}$. Wu and coworkers [95] applied the same philosophies to the $\mathrm{UiO}-66\left(\mathrm{NH}_{2}\right)$ platform, synthesizing and characterizing Pd@UiO-66( $\left.\mathrm{NH}_{2}\right)$ 's ability to degrade organic pollutants. The presented research exemplifies the concept of using MOFs as photosensitizers to enhance the catalytic activity and stability of guest nanoparticles. 

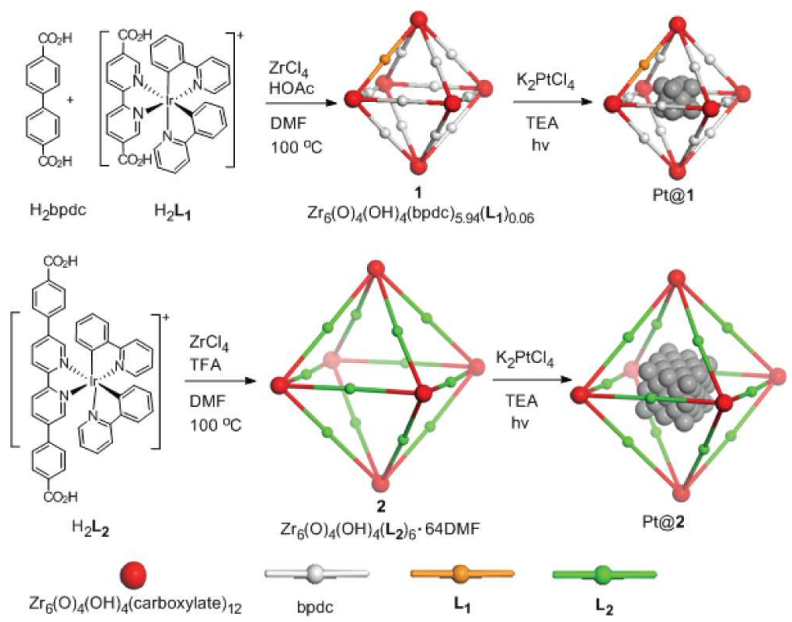

Scheme 12. Synthesis of phosphorescent Zr-Carboxylate MOFs (1 and 2) of the fcu topology and subsequent loading of Pt NPs inside MOF cavities via MOF-mediated photoreduction of $\mathrm{K}_{2} \mathrm{PtCl}_{4}$ to form the Pt@1 and Pt@2 assemblies. Reprinted with the permission from ref. 92, Copyright 2012 American Chemical Society.
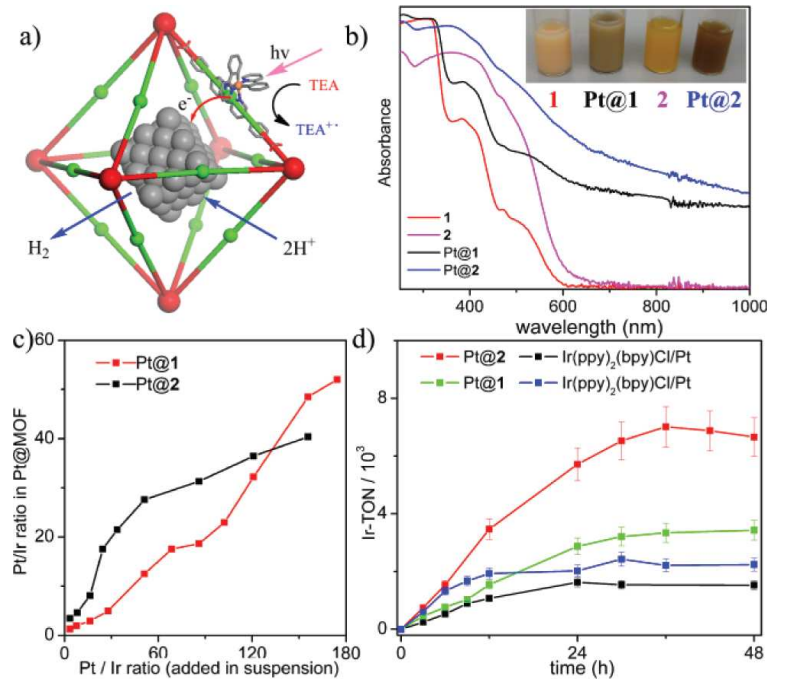

Fig.7. (a) Scheme showing the synergistic photocatalytic hydrogen evolution process via photoinjection of electrons from the lightharvesting MOF frameworks into the Pt NPs. The red balls represent $\mathrm{Zr}_{6}(\mathrm{O})_{4}(\mathrm{OH})_{4}(\text { carboxylate })_{12}$ cores, while the green balls represent the Irphosphor ligand of the MOF. (b) Diffuse reflectance spectra of 1 (red), Pt@ 1 (black), 2 (purple), and Pt@2 (blue). A photograph of suspensions of these samples is shown in the inset. (c) 
Relationship between the amount of $\mathrm{K}_{2} \mathrm{PtCl}_{4}$ added in the reaction solution and the amount of $\mathrm{Pt}$ deposited inside the MOF (normalized to the amount of) for Pt@1 (red) and Pt@2 (black). (d) Time-dependent hydrogen evolution curves of Pt@1 (green), Pt@2 (red), and homogeneous control [Ir(ppy) $\left.)_{2}(\mathrm{bpy})\right] \mathrm{Cl} / \mathrm{K}_{2} \mathrm{PtCl}_{4}$ (blue and black for different $\mathrm{Pt} / \mathrm{Ir}$ ratios) under optimized conditions. Reprinted with the permission from ref. 92, Copyright 2012 American Chemical

\section{Society.}

Duan et al. [96] introduce the concept of using a chiral catalyst species with an inorganic catalyst to synergistically combine two uniquely functioning components into a single system capable of efficient asymmetric catalysis. The authors aimed to exploit the redox properties of the oxygen rich Keggin-type $\left[\mathrm{BW}_{12} \mathrm{O}_{40}\right]^{5-}$ polyoxometlate (POM) to drive precursors to active intermediates while the chiral PYIs enhance the activity of the oxidant and drives asymmetrical catalysis. In introducing the two catalytic centers, Duan and coworkers tune the hydrophilic/hydrophobic properties within the MOF to benefit the amphipathic epoxidation processes. The authors build a chiral MOF, Ni-PYI1, by using the asymmetric organocatalytic molecule, PYI, Keggin-type $\left[\mathrm{BW}_{12} \mathrm{O}_{40}\right]^{5-}, \mathrm{Ni}(\mathrm{II})$ ion and 4,4-bipyridine molecule (Scheme 13). The $\left[\mathrm{BW}_{12} \mathrm{O}_{40}\right]^{5-}$ anion and protonated PYI molecules embed themselves within the MOF's. The obtained guest exchanged Ni-PYI1 catalyzes the asymmetric dihydroxylation of aryl olefins with high conversion (75-79\%) and enantioselectivity (67-95\%) (Table 4). In addition, the authors observed high substrate size selectivity. In the reaction, the chiral MOF framework directs chirality, controlling the asymmetric catalytic environment while the $\left[\mathrm{BW}_{12} \mathrm{O}_{40}\right]^{5-}$ guest anions catalyze the dihydroxylation reaction. The work by Duan and coworkers demonstrates the ability to exploit local nano-environments within pores in combination with large inorganic catalytically active species embedded within pores to control and promote asymmetric catalysis. 


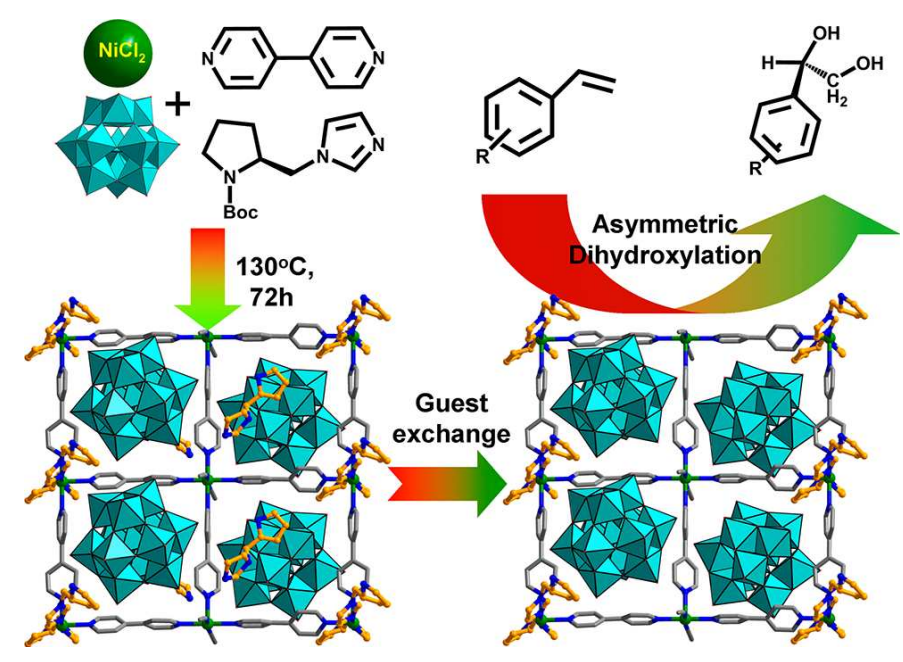

Scheme 13. Synthetic procedure of Ni-PYI1, showing the guest exchange and the potential amphipathic channel for the asymmetric olefin dihydroxylation. Reprinted with the permission from ref. 96, Copyright 2013 American Chemical Society.

Table 4. Yields and enantiomeric excess (ee) values of the asymmetric dihydroxylation about the aryl olefins ${ }^{\mathrm{a}}$. Reprinted with the permission from ref. 96, Copyright 2013 American Chemical Society.

$\begin{array}{clcc}\text { substrate } & \text { conversion (\%) } & \text { ee (\%) } \\ \text { entry } \\ 1 & \text { styrene (1) } & 75 & >95 \\ 2 & \text { 2-chlorovinylbenzene (2) } & 76 & 67 \\ 3 & \text { 3-chlorovinylbenzene (3) } & 79 & >95 \\ 4 & \text { 4-chlorovinylbenzene (4) } & 75 & >95 \\ 5 & \text { 3,5-di-tert-butyl-4'-vinylbiphenyl (5) } & <10 & \text { nd }\end{array}$

${ }^{\mathrm{a}}$ Reaction conditions: olefin, $55 \mathrm{mmol}$; ex-Ni-PYI1, $0.04 \mathrm{mmol} ; \mathrm{H}_{2} \mathrm{O}_{2}$ (15\%), $15 \mathrm{~mL} ; \mathrm{CH}_{2} \mathrm{Cl}_{2}, 5$ $\mathrm{mL} ; 40{ }^{\circ} \mathrm{C} ; 60 \mathrm{~h}$. ${ }^{\mathrm{b}}$ The conversions were determined by ${ }^{1} \mathrm{H}$ NMR spectroscopy of crude products. ${ }^{\mathrm{c}}$ The ee value was determined by chiral HPLC on a Chiralcel OD-H column.

\subsection{Combine MFS of two guest components}


Bimetallic nanoparticles attract growing attention due to the unique catalytic properties and great potential [97]. R. A. Fischer [98] reported the first encapsulation of bimetallic nanoparticles in MOF systems, focusing the publication on developing protocol to encapsulate preformed NPs. The Xu group [99] reported the first catalytic activity of bimetallic nanoparticle encapsulated MOF systems using a successive deposition-reduction approach to synthesize an $\mathrm{Au} / \mathrm{Ag}$ core-shell nanoparticle in the pores of ZIF-8 $\left[\mathrm{ZIF}-8=\mathrm{Zn}(\mathrm{MeIM})_{2} \cdot(\mathrm{DMF}) \cdot\left(\mathrm{H}_{2} \mathrm{O}\right)_{3}\right]$ (Scheme 14). Xu then studied the catalyst's activity towards the reduction of 4-nitrophenol (4$\mathrm{NPh}$ ) in water using $\mathrm{NaBH}_{4}$ as a reducing agent. The bimetallic Au@Ag NPs improve the catalytic activity compared to monometallic and alloy NPs composed of the core-shell nanoparticles (Fig.8). Xu's group [100] extends the previous work by reporting another bimetallic system composed of Au/Pd immobilized on a highly porous MOF ED-MIL-101. The system exhibits the superior catalytic activity, demonstrating the applicability of MOF-supported metal NP systems towards hydrogen generation from hydrogen storage materials (Fig.9). These works present the methodologies to efficiently enhance the stability of bimetallic NPs within the porous structure of MOFs without hindering catalytic activity of unique NPs.

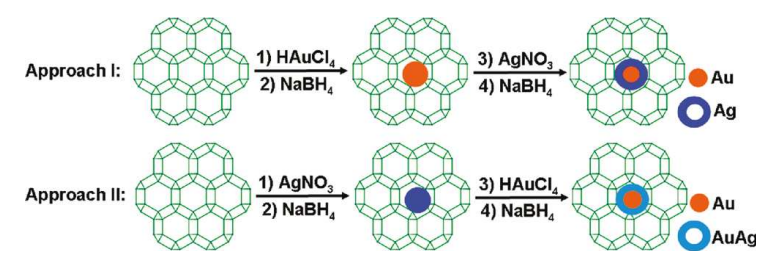

Scheme 14. Schematic Illustration for the Preparation Methods. Reprinted with the permission from ref. 99, Copyright 2011 American Chemical Society. 

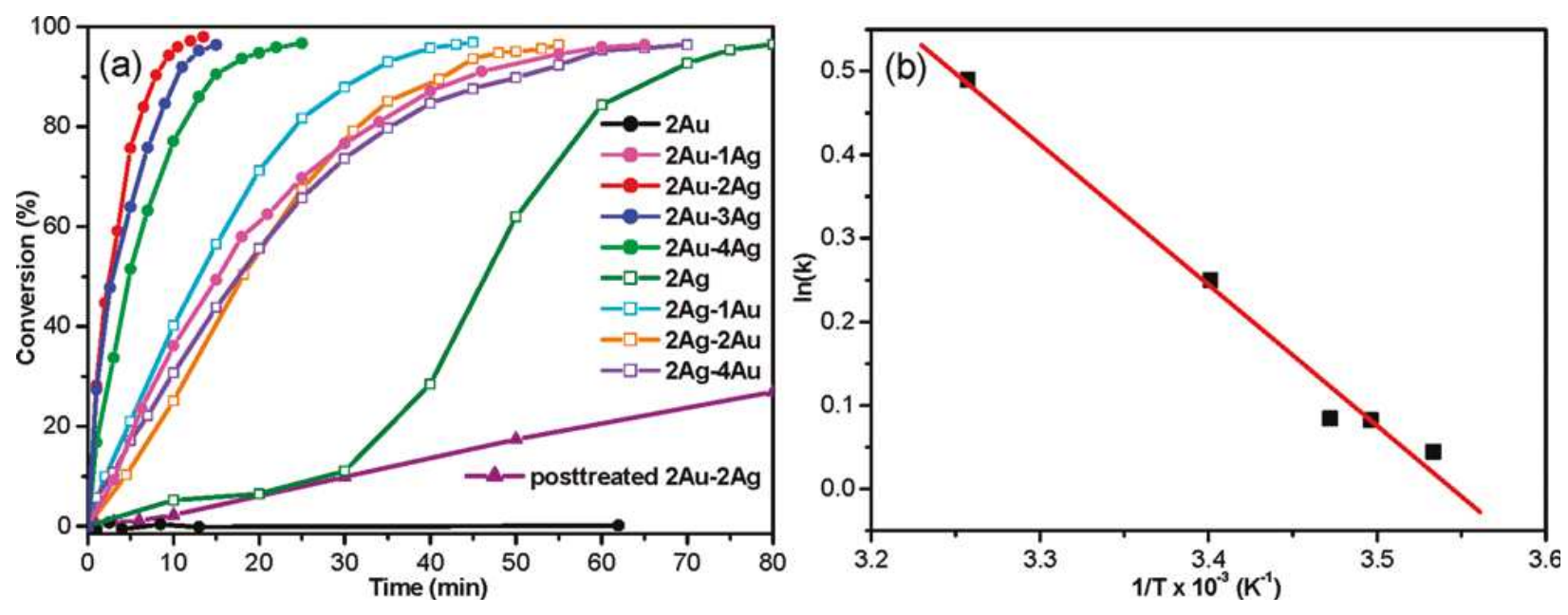

Fig.8. (a) Catalytic conversion of 4-NPh over ZIF-8 stabilized catalysts: $2 \mathrm{Au}\left(\mathrm{I}_{20}\right), 2 \mathrm{Au}-1 \mathrm{Ag}\left(\mathrm{I}_{21}\right)$, $2 \mathrm{Au}-2 \mathrm{Ag}\left(\mathrm{I}_{22}\right), 2 \mathrm{Au}-3 \mathrm{Ag}\left(\mathrm{I}_{23}\right), 2 \mathrm{Au}-4 \mathrm{Ag}\left(\mathrm{I}_{24}\right), 2 \mathrm{Ag}\left(\mathrm{II}_{02}\right), 2 \mathrm{Ag}-1 \mathrm{Au}\left(\mathrm{II}_{12}\right), 2 \mathrm{Ag}-2 \mathrm{Au}\left(\mathrm{II}_{22}\right), 2 \mathrm{Ag}-$ $4 \mathrm{Au}\left(\mathrm{II}_{42}\right)$, and post treated $\mathrm{I}_{22}$. For the detailed denotations, see Table $\mathrm{S} 1$ in the Supporting Information. (b) Arrhenius plots of the rate constants of the reduction of 4-NPh over $\mathrm{I}_{22}$. Reprinted with the permission from ref. 99, Copyright 2011 American Chemical Society.

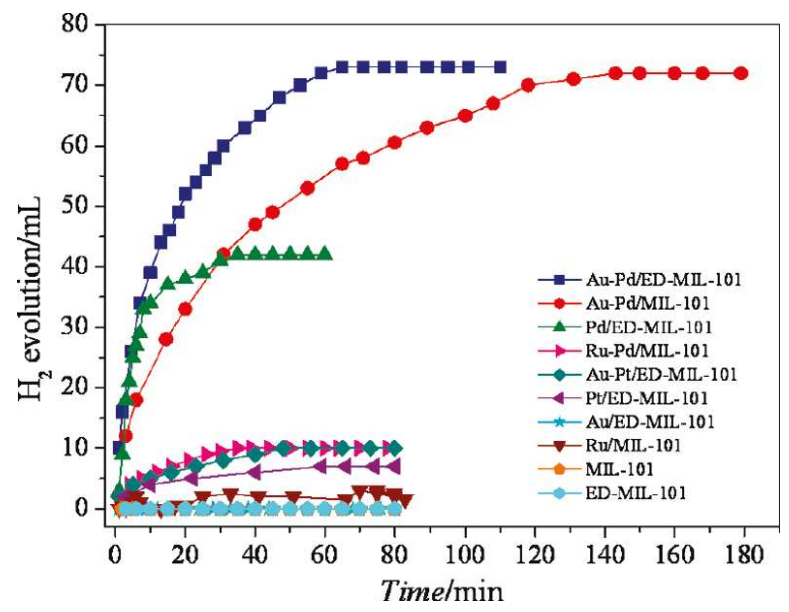

Fig.9. Time-course plots for hydrogen generation from formic acid in the presence of $20 \mathrm{mg}$ of different metal NP catalysts, $140 \mathrm{mg}$ of formic acid, $70 \mathrm{mg}$ of sodium formate, and $1.0 \mathrm{~mL}$ of water at $90^{\circ} \mathrm{C}$. Reprinted with the permission from ref. 100, Copyright 2011 American Chemical Society. 
The Kempe group [101] advanced Fischer's work, translating Fischer's metal-organic chemical vapor deposition technique to the significantly more stable MIL-101 system. In observing a direct correlation between MNP size and the window size rather than pore size, Kempe et al. took advantage of excess free space within the pores introducing a second metal and forming bimetallic NPs in the MOF's pores. Chemical vapor deposition produces undersized Pd NPs within the pores, leaving room to introduce a second metal resulting in bimetallic nanoparticles filling the pores (Fig.10). The Ni/Pd NP catalyst shows increased catalytic activity when compared to Pd or Ni NPs; however, there were no controls to show if the MIL-101 framework contributed any synergistic effect on the catalysis. In 2013, Xu group [102] reported another method for synthesizing bimetallic NPs within the pores of MOFs. The double solvent method developed by Xu exploits the hydrophilic nature of MIL-101's interior surface. By suspending MIL-101 in dry n-hexane along with a volume of aqueous metal precursors less than the pore volume, capillary action causes the diffusion of the aqueous solution into the MOFs pores, resulting in a reduction of external surface deposition. Ultrafine AuNi alloy NPs result when an overwhelming reduction approach is employed using a similar double solvent method to transport the reductant into the MOF's pores (Fig.11). The obtained catalysts exhibits excellent catalytic performance for hydrogen generation from the catalytic hydrolysis of ammonia borane (AB) (Fig.12). Since these germinal studies, encapsulation of bimetallic nanoparticles has expanded to include the successful encapsulation of $\mathrm{Au} / \mathrm{Co}$ [103], $\mathrm{Ag} / \mathrm{Pd}[104,105], \mathrm{Ni} / \mathrm{Pt}$ [106] and $\mathrm{Pd} / \mathrm{Co}$ [107] MNP systems. Although authors of these publications claim synergy, the synergy between the metal components within bimetallinc MNPs has been well established outside the field of MOFs. The field of MOFs has neglected exploiting the activity of the 
frameworks themselves, limiting the frameworks to a role controlling MNP size and enhancing stability rather than contributing towards the activity of the system.
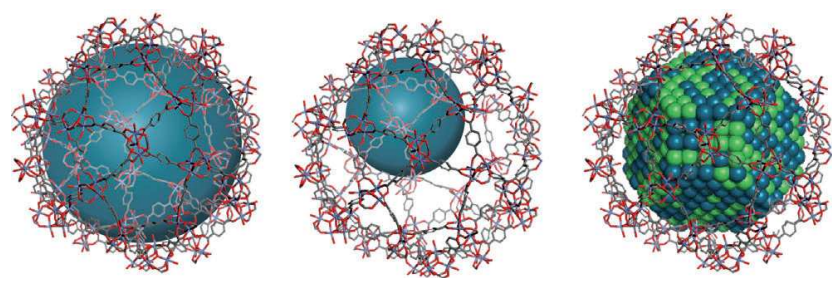

Fig.10. Size-selective cavity loading of MIL-101 (left: cavity-conform; center: undersized cavity loading; right: introduction of a second metal). Reprinted with the permission from ref. 101, Copyright 2012 WILEY-VCH Verlag GmbH \& Co. KGaA, Weinheim.

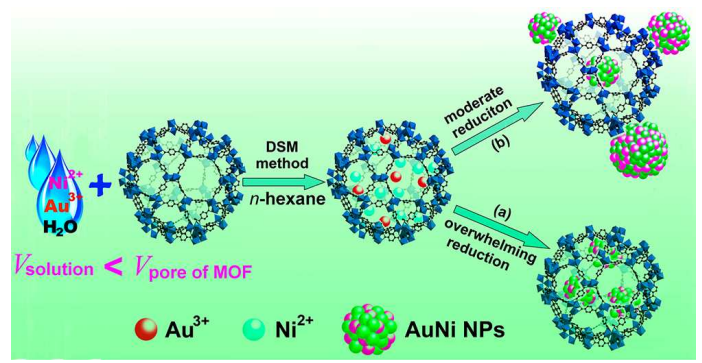

Fig.11. Schematic representation of immobilization of the AuNi nanoparticles by the MIL-101 matrix using the DSM combined with a liquid-phase CCR strategy. Reprinted with the permission from ref. 102, Copyright 2013 American Chemical Society.

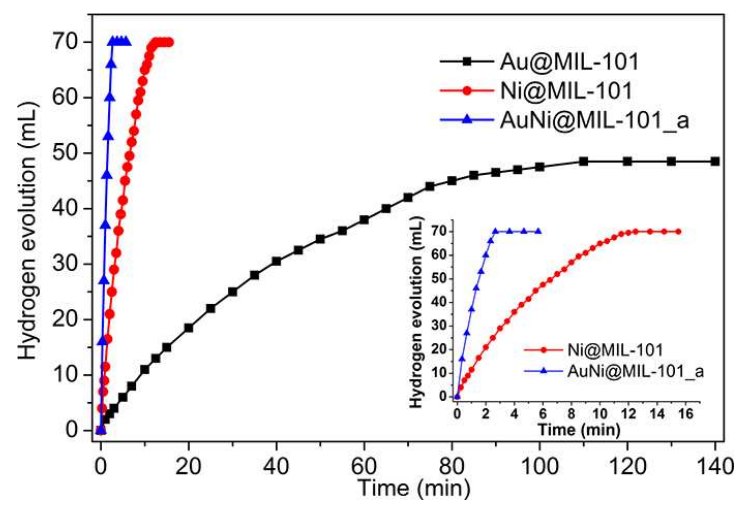

Fig.12. Plots of time vs volume of hydrogen generated from $\mathrm{AB}(1 \mathrm{mmol}$ in $5 \mathrm{~mL}$ water $)$ hydrolysis at room temperature catalyzed by the Au@MIL-101, Ni@MIL-101, and AuNi@MIL- 
101 as catalysts $(50 \mathrm{mg},(\mathrm{Au}+\mathrm{Ni}) / \mathrm{AB}($ molar ratio $)=0.017)$. Reprinted with the permission from ref. 102, Copyright 2013 American Chemical Society.

Besides the introduction of two guest species as multi-functional sites for synergy catalysis. The MOF pore can introduce two guest sites with different functions. Zhu and coworkers [108] reported a core-shell $\mathrm{Fe}_{3} \mathrm{O}_{4} @ \mathrm{Au}$ embedded into MOF using layer-by-layer assembly method in 2015. The authors demonstrate control over the MOF shell thickness by altering the number of assembly cycles. The core-shell magnetic catalysts exhibit excellent catalytic performance toward 4-nitrophenol reduction in the presence of $\mathrm{NaBH}_{4}$. The $\mathrm{Au}$ nanoparticle as active sites for catalytic reduction reaction in this multifunctional catalyst, while $\mathrm{Fe}_{3} \mathrm{O}_{4}$ nanoparticle as another functional sites play the role of magnetic recycle.

The advantageous features MOFs possess make them unique and powerful platforms to immobilize multiple functional sites within a single system. The works presented in this section identify several strategies to synthesize MFS-MOFs. Future research in these areas should aim to expand upon the tools (i.e. functional sites) and reactions capable of being catalyzed by MFSMOFs available to researchers. Additionally, in depth investigations into the synergy formed by MFS-MOFs could contribute to understanding and enhance our ability to design MFS-MOFs materials using a bottoms-up approach.

\section{Application of MFS-MOFs in gas adsorption/separation}

\section{1 $\mathrm{CO}_{2}$ adsorption.}

Emissions of carbon dioxide continue to receive worldwide attention because of the environmental and economic threats it presents [109-111]. Energy efficient, environmentally friendly adsorptive technologies utilizing porous materials such as MOFs attract much attention because of the materials' high surface area, and high porosity [17,112-116]. The ability to tune 
MOFs materials with desired functional groups further enhances interest in adsorption technologies as a means to capture $\mathrm{CO}_{2}$. Past research identifies a series of functional groups including OMS [117-118], - $\mathrm{NH}_{2}$ [119-120], $-\mathrm{OH}$ [121], $-\mathrm{CF}_{3}$ [122], and -CONH [123] that behave as $\mathrm{CO}_{2}$ binding sites, increasing the $\mathrm{CO}_{2}$ adsorption enthalpy. To date, our field has demonstrated MOF materials using a single functional adsorption site exhibit superior gas adsorption capabilities. Multifold weak interactions between one target molecule and multiple sites efficiently enhance our ability to capture $\mathrm{CO}_{2}$. Combining multiple functional sites into a single MOF system introduces new opportunities to further MOFs as a platform to selectively adsorb $\mathrm{CO}_{2}$. In the following, we will discuss the application of MOFs with multifunctional sites for $\mathrm{CO}_{2}$ adsorption.

\subsection{1 $\mathrm{CO}_{2}$ adsorption by multifunctional non-metal sites.}

In 2009, the Shimizu group [124] reported a multifunctional MOF, $\mathrm{Zn}_{2}\left(\mathrm{C}_{2} \mathrm{O}_{4}\right)\left(\mathrm{C}_{2} \mathrm{~N}_{4} \mathrm{H}_{3}\right)_{2}\left(\mathrm{H}_{2} \mathrm{O}\right)_{0.5}\left[\mathrm{Zn}_{2}(\mathrm{Atz})_{2}(\mathrm{ox})\right]$, constructed via solvothermal synthesis of zinc carbonate, 3-amino-1,2,4-triazole (Atz) and oxalic acid (ox) (Fig.13) The resulting $\mathrm{Zn}_{2}\left(\right.$ Atz) (ox) $^{(\mathrm{o}}$ exhibits high $\mathrm{CO}_{2}$ adsorption ability $\left(4.35 \mathrm{mmol} \mathrm{g}^{-1}\right.$, at 1.2 bar and $\left.273 \mathrm{~K}\right)$ and high adsorption enthalpy (40.8 $\mathrm{kJ} \mathrm{mol}^{-1}$ ), originally attributed to the small pores and favorable host-guest interactions (Fig.14). Shimizu, Vaidhyanathan and coworkers [125] furthered the report in 2010 by in-depth X-ray diffraction analysis and computational studies. Based on the structural analysis of a $\mathrm{CO}_{2}$ loaded sample, two $\mathrm{CO}_{2}$ adsorption sites were identified. Adsorbed $\mathrm{CO}_{2}$ molecules interact with the free amine group extended into the frameworks channels via $\mathrm{N}-\mathrm{H} \cdots \mathrm{O}$ hydrogen bonding and via an interaction between the $\mathrm{N}$ lone pair electrons and the $\mathrm{C}$ atom of $\mathrm{CO}_{2}$. Vaidhyanathan et al. also observed the interactions between $\mathrm{CO}_{2}$ molecules and $\mathrm{O}$ atoms of oxalic acid lingads as well as interactions between adjacent $\mathrm{CO}_{2}$ molecules. The combination of 
these multiple reactions contribute to $\mathrm{Zn}_{2}(\mathrm{Atz})_{2}(\mathrm{ox})$ 's high $\mathrm{CO}_{2}$ adsorption enthalpies, allowing strong cooperative and selective binding of $\mathrm{CO}_{2}$ over other gases $\left(\mathrm{N}_{2}, \mathrm{H}_{2}\right.$, Ar). The Denayer group [126] demonstrated another form of cooperative interactions for $\mathrm{CO}_{2}$ separation using amine-functionalized MIL-53(Al). The amino-MIL-53(Al) $\quad\left[\mathrm{Al}(\mathrm{OH})\left(\mathrm{O}_{2} \mathrm{C}-\mathrm{C}_{6} \mathrm{H}_{3} \mathrm{NH}_{2}-\mathrm{CO}_{2}\right)\right]$ exhibits an enhanced $\mathrm{CO}_{2}$ adsorption enthalpy of $38.4 \mathrm{~kJ} \mathrm{~mol}^{-1}$ compared to the adsorption enthalpy of $20.1 \mathrm{~kJ} \mathrm{~mol}^{-1}$ observed in unfunctionalized MIL-53(Al). The authors claim $\mathrm{CO}_{2}$ synergistically interacts with the $-\mathrm{NH}_{2}$ groups from the functionalized ligand and $-\mathrm{OH}$ groups extending from the $\mathrm{AlO}_{4}(\mathrm{OH})_{2}$ metal clusters into the pores. $\mathrm{CO}_{2}$ adsorption isotherms also interestingly show two plateaus. The second plateau is attributed to framework contraction at high $\mathrm{CO}_{2}$ concentrations; this contraction also contributes to high $\mathrm{CO}_{2}$ selectivity over $\mathrm{CH}_{4}$.

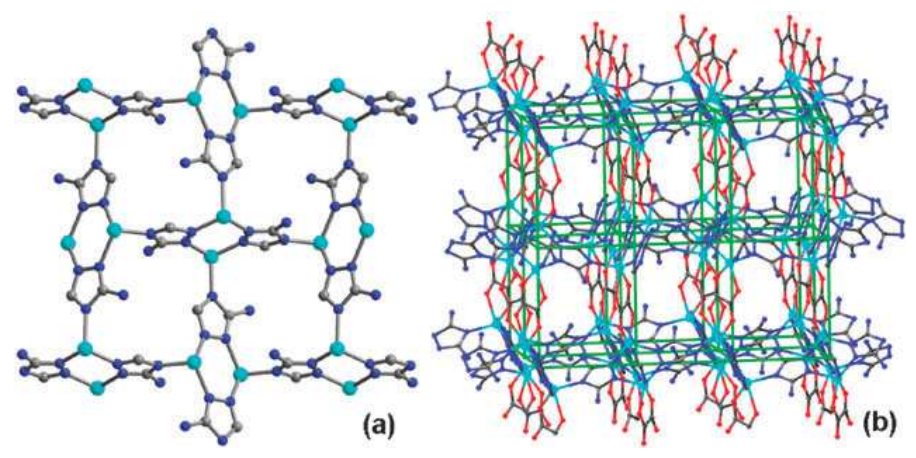

Fig.13. (a) $\mathrm{Zn}$-aminotriazolate layer in $\mathrm{Zn}_{2}(\mathrm{Atz})_{2}(\mathrm{ox})$. The layer is made up of $\mathrm{Zn}_{2}$ dimers rotated by $90^{\circ}$ with respect to each other. (b) The three dimensional structure formed by pillaring the above $\mathrm{Zn}$-aminotriazolate layers by oxalate units. Colour scheme: $\mathrm{Zn} —$ cyan; $\mathrm{N} —$ blue; O—red; $\mathrm{C}$ - grey. The cubic 6-connected network of $\mathrm{Zn}_{2}(\mathrm{Atz})_{2}(\mathrm{ox})$ is indicated as green grids. Reprinted with the permission from ref. 124, Copyright 2009 Royal Society of Chemistry. 


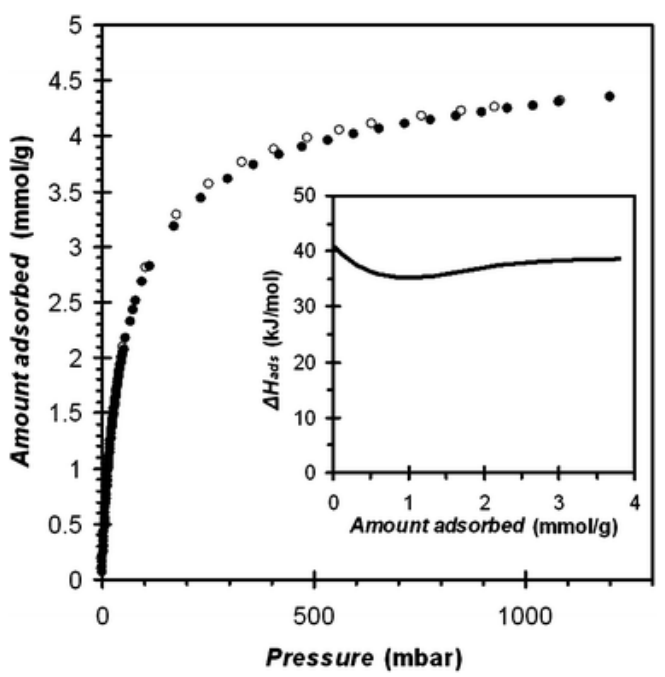

Fig.14. $\mathrm{CO}_{2}$ sorption isotherms of $\mathrm{Zn}_{2}(\mathrm{Atz})_{2}(\mathrm{ox})$ carried out at $273 \mathrm{~K}$, closed circles adsorption, open circles desorption. Inset shows the enthalpy of adsorption as a function of loading. Reprinted with the permission from ref. 124, Copyright 2009 Royal Society of Chemistry. Bio-MOF-11, a porous cobalt adeninate MOF $\mathrm{Co}_{2}(\mathrm{ad})_{2}\left(\mathrm{CO}_{2} \mathrm{CH}_{3}\right)_{2} \cdot 2 \mathrm{DMF} \cdot 0.5 \mathrm{H}_{2} \mathrm{O}$ (bioMOF-11) produced in 2010 by the Rosi group (Fig.15) [127], shows many favorable properties with respect to $\mathrm{CO}_{2}$ capture including high adsorption capacity with a maximum $\mathrm{CO}_{2}$ uptake of $4.1 \mathrm{mmol} \mathrm{g}^{-1}$ at $298 \mathrm{~K}$ and 1 bar (Fig.16), $\mathrm{CO}_{2} / \mathrm{N}_{2}$ selectivity of $75: 1$ at $298 \mathrm{~K}$ and adsorption enthalpy of $45 \mathrm{~kJ} \mathrm{~mol}^{-1}$. Rosi and co-workers credit the exposure of multiple functional sites, amino and pyramidal nitrogen atoms exposed in the pores, to the observed adsorption enthalpies and selectivities.
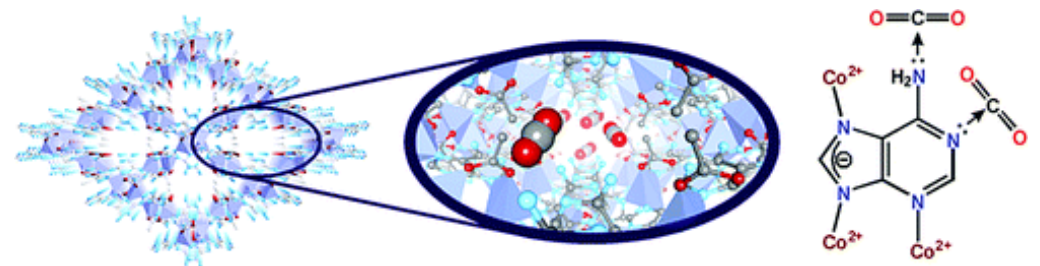

Fig.15. The structure of bio-MOF-11 and the binding sites of $\mathrm{CO}_{2}$ in bio-MOF-11. Reprinted with the permission from ref. 127, Copyright 2010 American Chemical Society. 

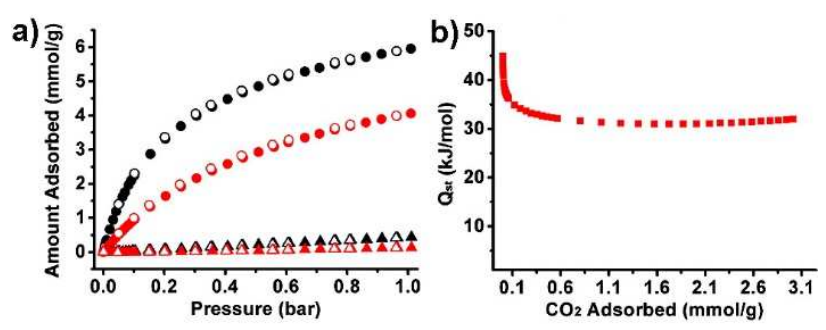

Fig.16. (a) Adsorption isotherms for $\mathrm{CO}_{2}$ (circles) and $\mathrm{N}_{2}$ (triangles) at 273 (black) and $298 \mathrm{~K}$ (red). (b) Isosteric heat of adsorption for $\mathrm{CO}_{2}$ at different $\mathrm{CO}_{2}$ loadings. Reprinted with the permission from ref. 127, Copyright 2010 American Chemical Society.

Stemming from inspiration of nature's use of multiple weak interactions to enhance binding energies between a molecule and binding site, Balbuena, Zhao and coworkers [128] constructed a microporous MOF $\left\{[\mathrm{Zn}(\mathrm{btz})] \cdot \mathrm{DMF} \cdot 0.5 \mathrm{H}_{2} \mathrm{O}\right\}_{n}(\mathrm{Zn}$-btz) using 1,5-bis(5-tetrazolo)3-oxapentane $\left(\mathrm{H}_{2}\right.$ btz) as a ligand (Fig.17). Zn-btz $\mathrm{CO}_{2}$ adsorption capacity reaches $4.99 \mathrm{mmol} \mathrm{g}^{-1}$ at $298 \mathrm{~K}$ and $1 \mathrm{~atm}$ while also exhibiting a high adsorption enthalpy of $31.2 \mathrm{~kJ} \mathrm{~mol}^{-1}$. Theoretical simulations of the system (Fig.18) indicates the observed $\mathrm{CO}_{2}$ adsorption capacity and enthalpy result from the multipoint interactions between the aromatic $\mathrm{N}$ atoms and methylene groups in the framework with $\mathrm{CO}_{2}$ molecules.

The works presented above highlight the ability to use cooperative interactions between organic functional groups to enhance gas uptake, adsorption enthalpies, and selectivity. The theoretical support provided offers insight into the types of interactions we researchers can exploit to solve the global $\mathrm{CO}_{2}$ crisis. 

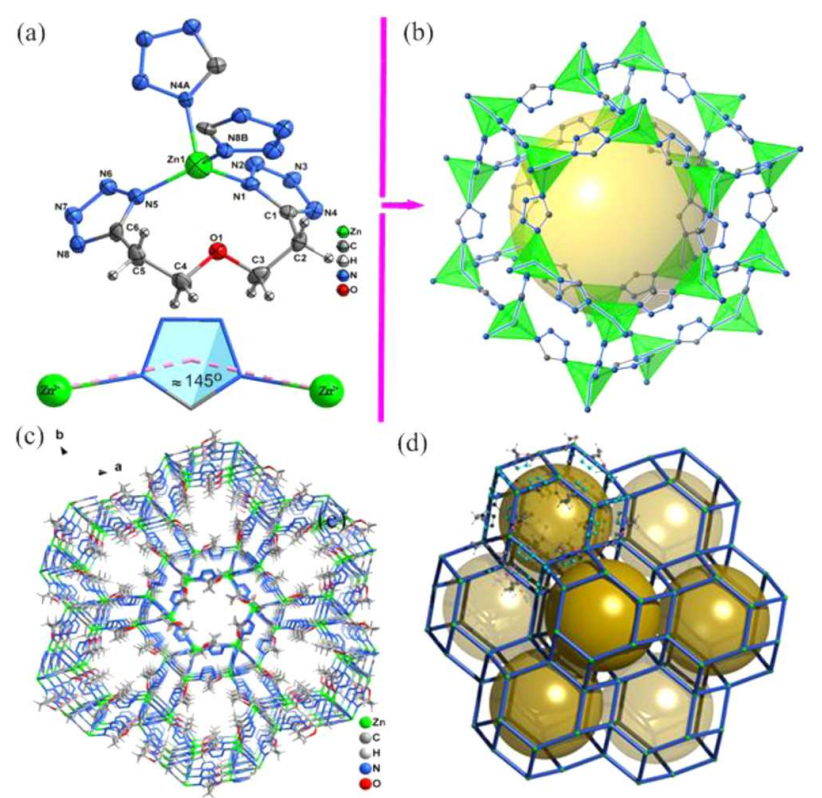

Fig.17. (a) $\mathrm{Zn}^{2+}$ ion coordination environment and $\mathrm{Tz}$ ring coordination mode. (b) $\mathrm{Zn}_{24}$ cage in

Zn-btz. (c) Perspective view of the framework structure of Zn-btz. (d) The sod topological net of Zn-btz. Reprinted with the permission from ref. 128, Copyright 2012 American Chemical Society.

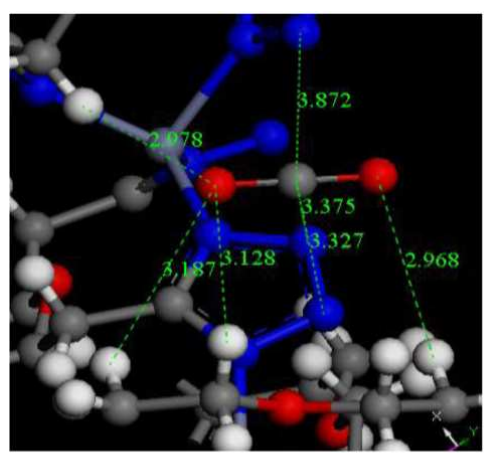

A

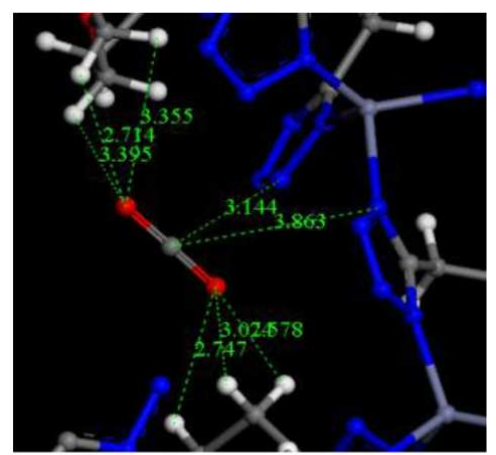

B

Fig.18. Preferred $\mathrm{CO}_{2}$ adsorption site configurations by annealing simulations. Close contact distances, in $\AA$, are marked. Reprinted with the permission from ref. 128, Copyright 2012 American Chemical Society.

\subsection{2 $\mathrm{CO}_{2}$ adsorption by combination of non-metal sites and open metal sites.}


Past research shows open metal sites strongly bind gas molecules; thus the combination of OMS with organic functional groups providing multiple binding sites cooperatively enhances the binding energy of gas molecules on MOFs materials. The Suh group [129] initiated the use of combined organic and metal binding sites to enhance gas adsorption capabilities by using N,N'bis(3,5-dicarboxyphenyl)pyromellitic diimide $\left(\mathrm{H}_{4} \mathrm{BDCPPI}\right)$ and $\mathrm{Cu}\left(\mathrm{NO}_{3}\right)_{2}$ to build $\left\{\left[\mathrm{Cu}_{2}(\text { bdcppi })(\mathrm{dmf})_{2}\right] \cdot 10 \mathrm{DMF} \cdot 2 \mathrm{H}_{2} \mathrm{O}\right\}_{\mathrm{n}}(\mathrm{SNU}-50)$ possessing an $\mathrm{NbO}$ net (Fig.19). The resulting $\left[\mathrm{Cu}_{2}(\text { bdcppi })\right]_{\mathrm{n}}\left(\mathrm{SNU}-50^{\prime}\right)$ crystals adsorb large amounts of $\mathrm{CO}_{2}$ with an excess adsorption of 64 wt $\%$ and a total uptake of $77 \mathrm{wt} \%$ at $298 \mathrm{~K}$ and 55 bar. The high $\mathrm{CO}_{2}$ uptake, although not thoroughly investigated, can be attributed to the presence of open metal site and imide groups simultaneously providing multiple binding sites for $\mathrm{CO}_{2}$.

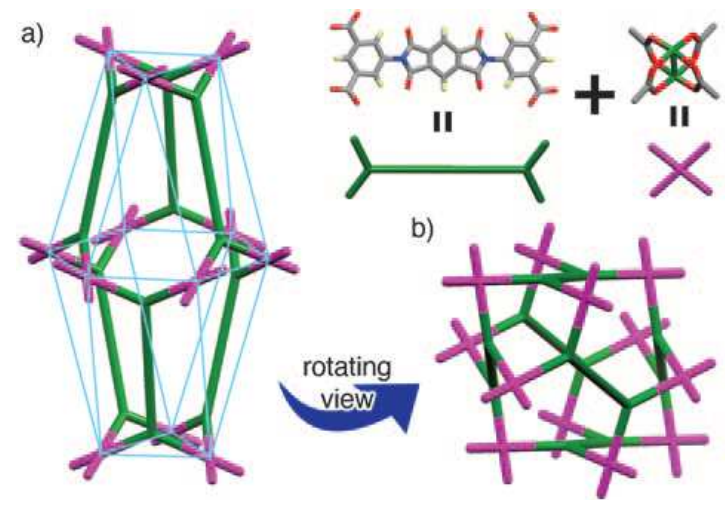

Fig.19. X-ray crystal structure of SNU-50. a) View showing a barrel like cage that consists of $\mathrm{Cu}_{24}(\mathrm{BDCPPI})_{6}$. Color scheme: $\left[\mathrm{Cu}_{2}(\mathrm{OOC})_{4}\right]$ paddlewheel units = purple, BDCPPI ligand $=$ green. b) Simplified view showing the NbO-type net. Reprinted with the permission from ref. 129, Copyright 2010 WILEY-VCH Verlag GmbH \& Co. KGaA, Weinheim. Zaworotko, Bai and coworkers [123] employed hexacarboxylate N,N',N',tris(isophthalyl)-1,3,5-benzenetricarboxamide (TPBTM), constructing an rht topology MOF $\left[\mathrm{Cu}_{24}\left(\mathrm{TPBTM}^{6-}\right)_{8}\left(\mathrm{H}_{2} \mathrm{O}\right)_{24}\right](\mathrm{Cu}-\mathrm{TPBTM})$ (Fig.20). The MOF exhibits two kinds of $\mathrm{CO}_{2}$ binding sites, OMS in the metal SBUs and acylamide sites from the ligand. Cu-TPBTM shows a high 
unsaturation excess $\mathrm{CO}_{2}$ uptake of $23.53 \mathrm{mmol} \mathrm{g}^{-1}$ at $298 \mathrm{~K}$ and 20 bar. Isoteric heats of $\mathrm{CO}_{2}$ adsorption for $\mathrm{Cu}$-TPBTM is higher than PCN-61, an isostructural MOF with similar ligand size but lacking multiple binding sites. The authors attribute the high adsorption enthalpy to the combination of two kinds of $\mathrm{CO}_{2}$ binding sites.

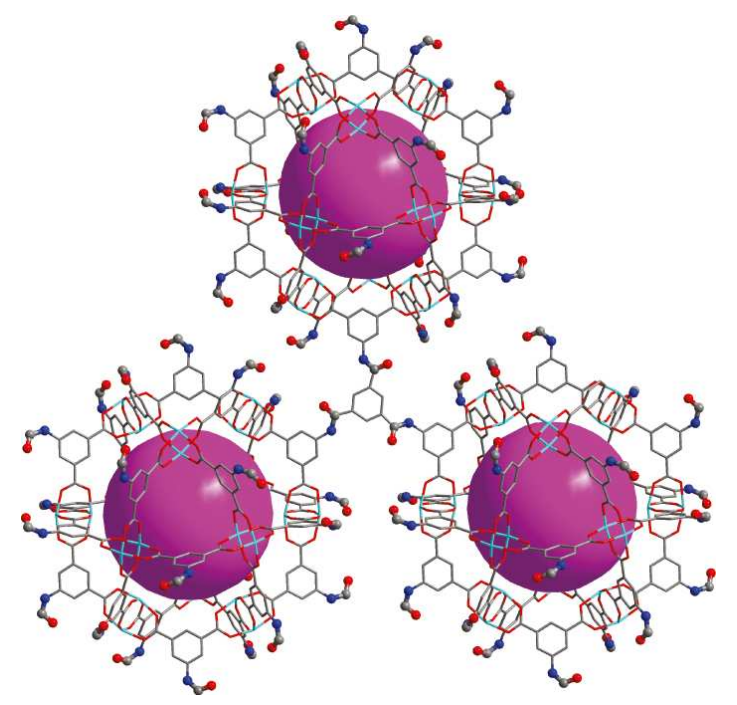

Fig.20. Portion of the structure of the $(3,24)$-connected rht-type framework of Cu-TPBTM showing surface decoration by acylamide groups. $\mathrm{Cu}$, blue-green; $\mathrm{C}$, gray; $\mathrm{O}$, red; $\mathrm{N}$, blue. Water molecules and $\mathrm{H}$ atoms have been omitted for clarity. Reprinted with the permission from ref.

123, Copyright 2011 American Chemical Society.

In 2012, Shi, Li and coworkers [130] introduced another class of functional sites introduced into MFS-MOFs. Li et al. prepared MOF Cu-TDPAT $\left\{\left[\mathrm{Cu}_{3}(\mathrm{TDPAT})\left(\mathrm{H}_{2} \mathrm{O}\right)_{3}\right] \cdot 10 \mathrm{H}_{2} \mathrm{O} \cdot 5 \mathrm{DMA}\right\}$, a MOF possessing an rht topology synthesized using the shortest reported hexacarboxylic acids ligand 2,4,6-tris(3,5-dicarboxylphenylamino)-1,3,5triazine (H6 $\mathrm{H}_{6}$ TDPT) (Fig.21), as also simultaneously synthesized by Eddaoudi and co-workers [131]. Cu-TDPAT exhibits higher density of Lewis basic sites and OMS when compared with other reported rht MOF because of the shortened ligand. The low-pressure $\mathrm{CO}_{2}$ adsorption shows that $\mathrm{Cu}$-TDPAT exhibits an extra high $\mathrm{CO}_{2}$ adsorption ability with $\mathrm{CO}_{2}$ uptake amount of 
$5.9 \mathrm{mmol} \mathrm{g}^{-1}$ at $298 \mathrm{~K}$ and $1 \mathrm{~atm}$ (Fig.22). The advantageous Lewis base sites and $\mathrm{OMS}$ in $\mathrm{Cu}-$ TDPAT selectively bind $\mathrm{CO}_{2}$ molecules over $\mathrm{N}_{2}$, with a selectivity of $79: 1$ calculated by the IAST method. The high adsorption enthalpy (42.2 $\mathrm{kJ} \mathrm{mol}^{-1}$ at zero loading), suggests strong adsorbate-adsorbent interactions. IR studies reveal interactions between $\mathrm{CO}_{2}$ molecules and the framework arise from N-rich Lewis base site and high density OMS. Li et al. show Cu-TDPAT effectively separates $\mathrm{CO}_{2} / \mathrm{N}_{2}$ gas mixtures using breakthrough experiments under kinetic flow conditions. Li's work introduces the triazine building block as an effective $\mathrm{CO}_{2}$ binding site and a way to condense the pore structure, thus increasing the density of binding sites per unit volume. After that, several papers [132-135] reported a series of MOFs based on N-rich ligands and OMS contained cluster, exhibiting the high $\mathrm{CO}_{2}$ adsorption abilities. The previous publications demonstrate the effectiveness of judiciously selecting a ligand that contains a secondary binding site.

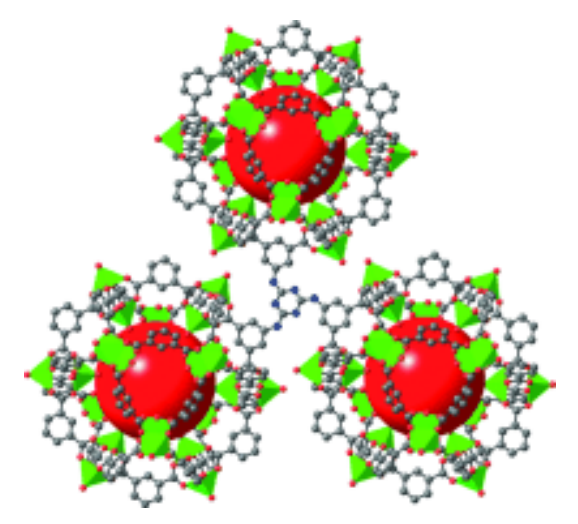

Fig.21. Structure of $\mathrm{Cu}$-TDPAT. A portion of the (3,24)-connected rht-net built on the shortest linker TDPAT is shown. Reprinted with the permission from ref. 130, Copyright 2012 WILEYVCH Verlag GmbH \& Co. KGaA, Weinheim. 


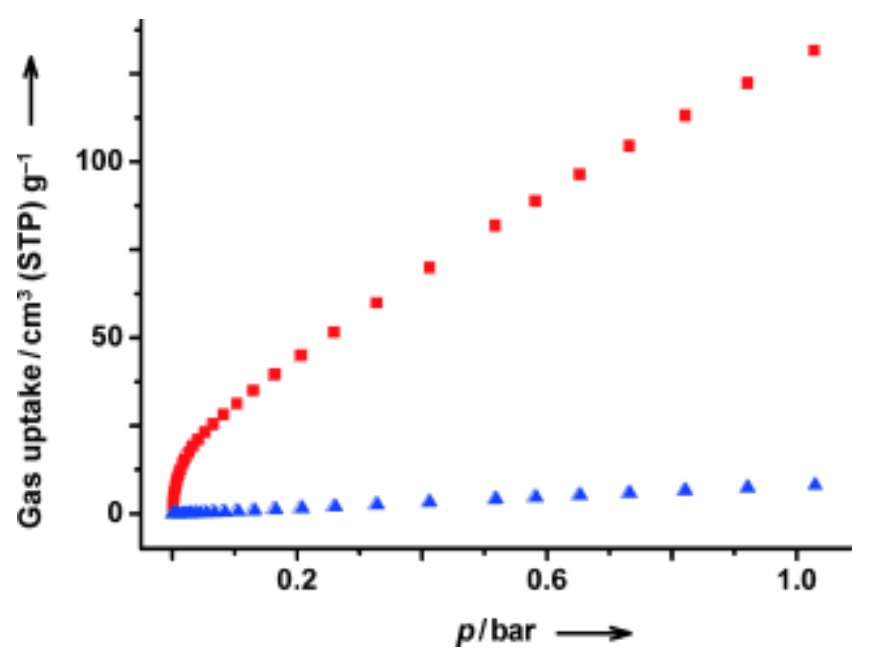

Fig.22. $\mathrm{CO}_{2}$ and $\mathrm{N}_{2}$ sorption isotherms of $\mathrm{Cu}$-TDPAT at $298 \mathrm{~K}$ (adsorption: filled; desorption: open; $\mathrm{CO}_{2}$ : red squares; $\mathrm{N}_{2}$ : blue triangles). Reprinted with the permission from ref. 130, Copyright 2012 WILEY-VCH Verlag GmbH \& Co. KGaA, Weinheim.

In 2012, the Long and Hong groups [136] demonstrated another strategy to use ligand$\mathrm{CO}_{2}$ interactions to enhance $\mathrm{CO}_{2}$ uptake and separation. Using dobpdc ${ }^{4-}=4,4^{\prime}$-dioxido-3,3'biphenyldicarboxylate ligand, Long and Hong synthesized an expanded MOF-74 structure type MOF via microwave reaction. Long et al. post-synthetically modified OMS with N,Ndimethylethylenediamine (mmen). The resulting $\mathrm{MOF} \mathrm{Mg}_{2}(\mathrm{dobpdc})-(\mathrm{mmen})_{1.6}\left(\mathrm{H}_{2} \mathrm{O}\right)_{0.4}($ mmen$\mathrm{Mg}_{2}$ (dobpdc) exhibits both Lewis base site and open metal sites (Fig.23). The researchers went through extensive analysis of $\mathrm{CO}_{2}$ adsorption on the framework, demonstrating the MOFs ability to adsorb high capacities of $\mathrm{CO}_{2}$ and efficiently separate $\mathrm{CO}_{2}$ at low and high coverage and ambient conditions. At $298 \mathrm{~K}$, mmen- $\mathrm{Mg}_{2}\left(\right.$ dobpdc) can absorb $\mathrm{CO}_{2}$ with $3.13 \mathrm{mmol} \mathrm{g}{ }^{-1}(12.1$ wt $\%)$ at 0.15 bar and $3.86 \mathrm{mmol} \mathrm{g}^{-1}(14.5 \mathrm{wt} \%)$ at 1 bar (Fig.24). In addition, mmen$\mathrm{Mg}_{2}$ (dobpdc) exhibits an extra high adsorption heats of $71 \mathrm{~kJ} \mathrm{~mol}^{-1}$. The authors find the low surface area, measured using $\mathrm{N}_{2}$ adsorption, fails to accurately reflect the surface area accessible to $\mathrm{CO}_{2}$. Interestingly, the framework shows a prominent step in isotherms at low pressures, 
unexpected in strongly adsorbing materials, especially materials that exhibits chemisorption. Logically, $\mathrm{CO}_{2}$ should preferentially adsorb to the free amines, the strongest adsorption sites in the framework. The authors hypothesize the large positive entropy associated with the reorganization of the mmen amines, required for chemical bonding with $\mathrm{CO}_{2}$, results in unfavorable $\mathrm{CO}_{2}$ adsorption onto mmen-2 at low concentrations. At these low localized concentrations, non-amine or weak-amine $\mathrm{CO}_{2}$ adsorption sites dominate $\mathrm{CO}_{2}$ adsorption; however, higher localized concentrations, or higher temperatures minimize the chemical potential required for amine reorganization. This interesting behavior results in an astounding molar selectivity estimated to be over 49,000 . This work presents a unique and extraordinarily effective approach, post-synthetically modifying the metal centers with an amine ligand, to introduce multiple functional sites within a MOF aimed at enhancing $\mathrm{CO}_{2}$ separation and adsorption.

Recently, the Yaghi group [137] introduces multifunctionality into MOFs via postsynthetic modification of IRMOF-74's ligand. The work, presented in 2014, shows an enhancement of $\mathrm{CO}_{2}$ adsorption by introducing flexible Lewis base sites on the ligand design. Moreover, the MOF with multifunctional non-metal sites and open metal sites have been extend to $\mathrm{OMS} /-\mathrm{CF} 3$ and $\mathrm{OMS} /-\mathrm{NHC}(\mathrm{O}) \mathrm{C}(\mathrm{O}) \mathrm{NH})$ - and a number of other functionalized ligands.

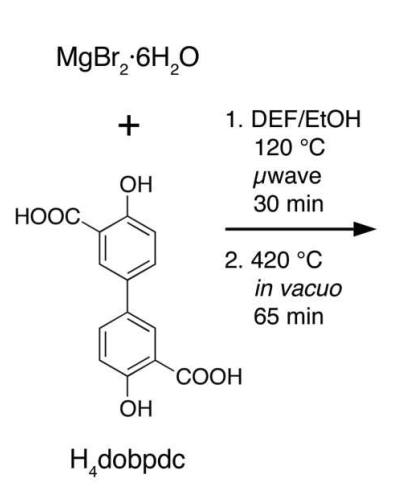

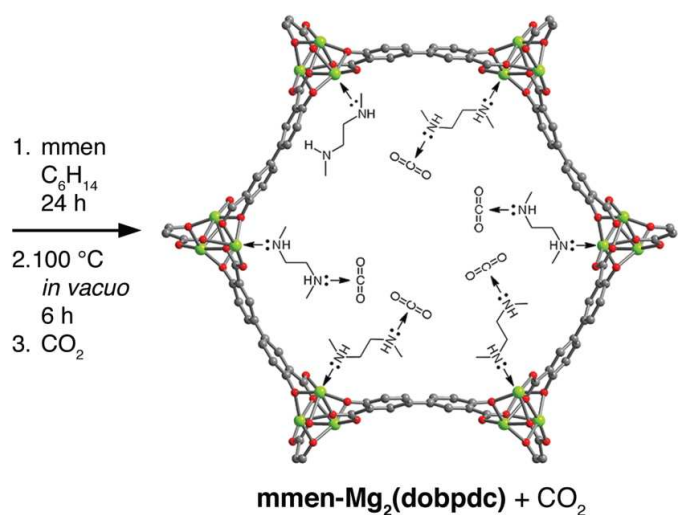


Fig.23. Synthesis of mmen- $\mathrm{Mg}_{2}$ (dobpdc). From the microwave reaction of $\mathrm{MgBr}_{2} \cdot 6 \mathrm{H}_{2} \mathrm{O}$ and $\mathrm{H}_{4} \mathrm{dobpdc}$ (left), $\mathrm{Mg}_{2}$ (dobpdc) (2) is obtained following evacuation of the as-synthesized solid at high temperatures (middle). Green, red, and gray spheres represent $\mathrm{Mg}, \mathrm{O}$, and $\mathrm{C}$ atoms respectively; $\mathrm{H}$ atoms are omitted for clarity. Addition of an excess of mmen to the evacuated framework yields the amine-appended $\mathrm{CO}_{2}$ adsorbent $\mathrm{Mg}_{2}($ dobpdc $)(\text { mmen })_{1.6}\left(\mathrm{H}_{2} \mathrm{O}\right)_{0.4}$ (right). Reprinted with the permission from ref. 136, Copyright 2012 American Chemical Society.

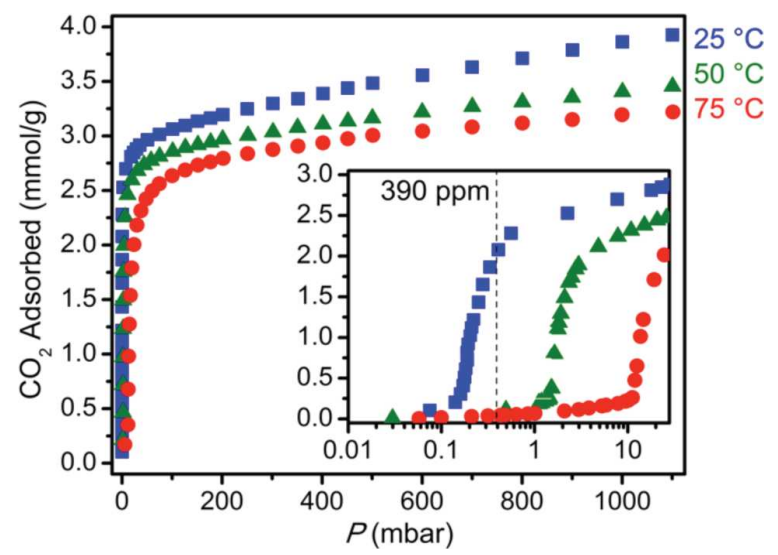

Fig.24. Adsorption of $\mathrm{CO}_{2}$ in mmen- $\mathrm{Mg}_{2}$ (dobpdc) at $25{ }^{\circ} \mathrm{C}$ (blue squares), $50{ }^{\circ} \mathrm{C}$ (green triangles), and $75^{\circ} \mathrm{C}$ (red circles). Inset: The isotherms at very low pressures exhibit a step that shifts to higher pressures at higher temperatures. The dashed, vertical line marks the current partial pressure of $\mathrm{CO}_{2}$ in air (390 ppm). Reprinted with the permission from ref. 136, Copyright 2012 American Chemical Society.

The papers presented in the above section demonstrate several strategies to enhance $\mathrm{CO}_{2}$ uptake and selectivity.

\subsection{Hydrocarbon separation.}

The purification of hydrocarbon mixtures via adsorptive technologies presents an opportunity to enhance the quality of methane and small hydrocarbons for use as an energy source and chemical feedstock. MOFs present themselves as prospective materials capable of 
achieving sufficient separation between similar hydrocarbons for reasons analogous to their use in $\mathrm{CO}_{2}$ separation [7,138-145]. Few MOFs exploit multifunctionality to separation hydrocarbons. The Shi group [146] first introduced the concept of using multiple functional sites on a MOF to enhance hydrocarbon selectivity by synthesizing two MOFs, Cu-TDPAT and Cu-TDPAH $\left\{\left[\mathrm{Cu}_{3}(\mathrm{TDPAH})\left(\mathrm{H}_{2} \mathrm{O}\right)_{3}\right] \cdot 13 \mathrm{H}_{2} \mathrm{O} \cdot 8 \mathrm{DMA}\right\}\left(\mathrm{H}_{6} \mathrm{TDPAH}=2,5,8\right.$-tris(3,5-dicarboxylphenylamino)-sheptazine acid) (simultaneously reported by Eddaoudi and co-workers [134]), to selectively separate C2 hydrocarbons over methane (Fig.25). At $298 \mathrm{~K}$ and $1 \mathrm{~atm}, \mathrm{Cu}-\mathrm{TDPAT}$ exhibits extra high adsorption of $\mathrm{C}_{2} \mathrm{H}_{2}, \mathrm{C}_{2} \mathrm{H}_{4}$, and $\mathrm{C}_{2} \mathrm{H}_{6}$ with $177.7 \mathrm{~cm}^{3} \mathrm{~g}^{-1}, 164.4 \mathrm{~cm}^{3} \mathrm{~g}^{-1}, 154.4 \mathrm{~cm}^{3} \mathrm{~g}^{-1}$, respectively (Fig.26) while only adsorbing only $28.3 \mathrm{~cm}^{3} \mathrm{~g}^{-1}$ of $\mathrm{CH}_{4}$ with under the same conditions. IAST calculations predict selectivities of $127.1: 1,85.0: 1$ and $12.1: 1$ for $\mathrm{C}_{2} \mathrm{H}_{2} / \mathrm{CH}_{4}$, $\mathrm{C}_{2} \mathrm{H}_{4} / \mathrm{CH}_{4}$ and $\mathrm{C}_{2} \mathrm{H}_{6} / \mathrm{CH}_{4}$, respectively. A theoretical investigation reveals the binding of $\mathrm{C} 2 \mathrm{~s}$ results from multipoint interactions between the guest molecule, the Lewis base sites of the ligands and OMSs of the copper paddlewheels (Fig.27). This work demonstrates the capability to enhance hydrocarbon uptake and selectivity using multipoint interactions between a framework and target analyte.

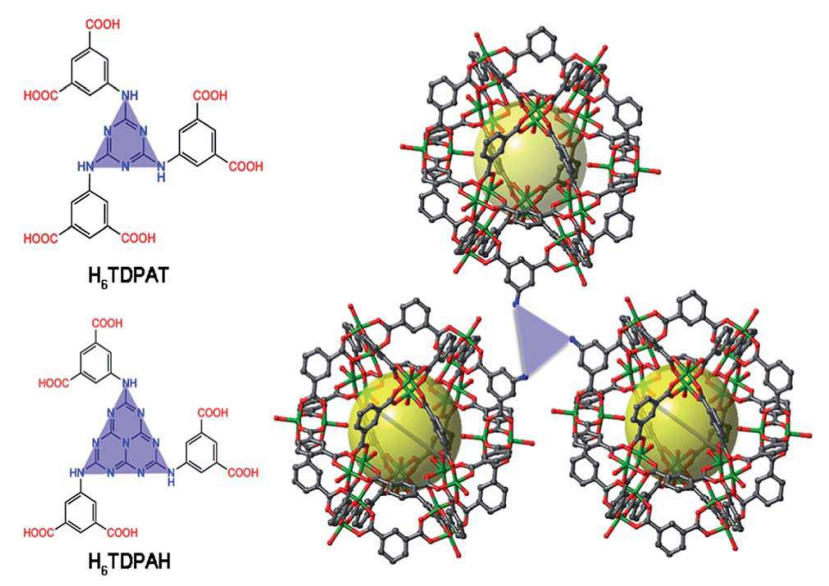


Fig.25. N-rich ligands $\left(\mathrm{H}_{6}\right.$ TDPAT and $\mathrm{H}_{6}$ TDPAH) and a portion of the $(3,24)$-connected rht-net built on TDPAT and TDPAH. Cu: green; C: gray; O: red; $\mathrm{N}$ : blue; $\mathrm{H}$ atoms are omitted for clarity. Reprinted with the permission from ref. 146, Copyright 2014 Royal Society of Chemistry.

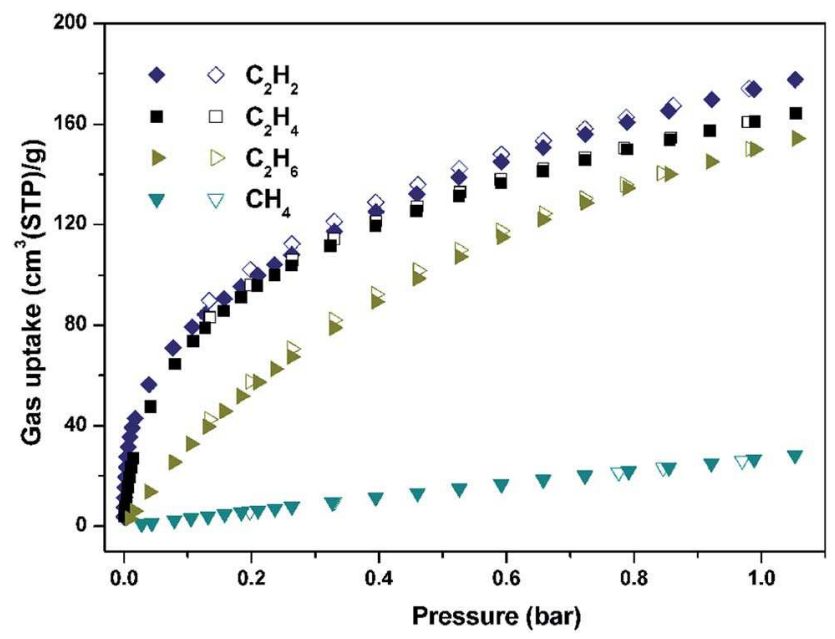

Fig.26. $\mathrm{C}_{2} \mathrm{H}_{2}, \mathrm{C}_{2} \mathrm{H}_{4}, \mathrm{C}_{2} \mathrm{H}_{6}$ and $\mathrm{CH}_{4}$ sorption isotherms at $298 \mathrm{~K}$. (adsorption: closed symbols; desorption: open symbols). Reprinted with the permission from ref. 146, Copyright 2014 Royal Society of Chemistry.

a)

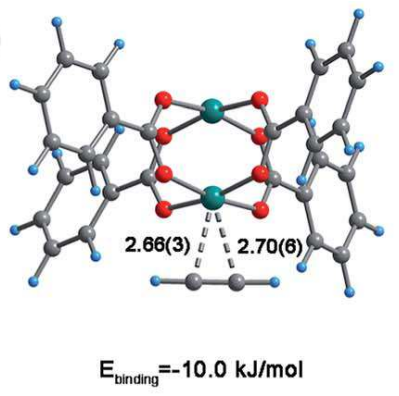

d)

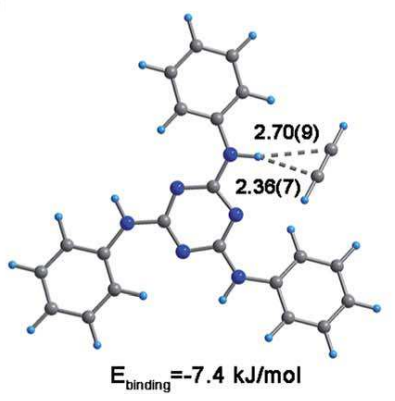

b)

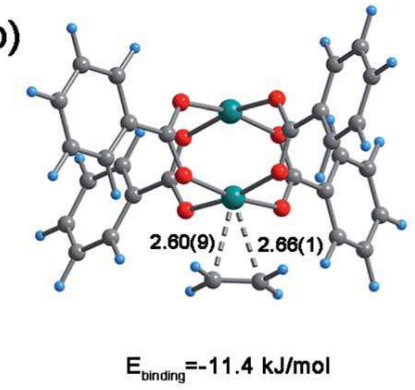

e)

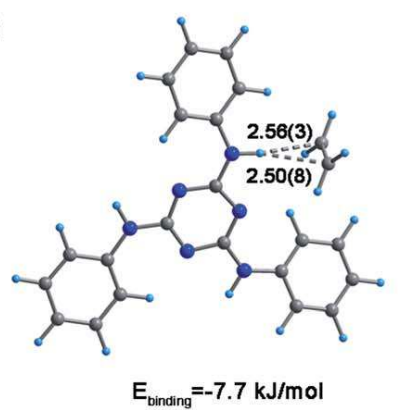

c)

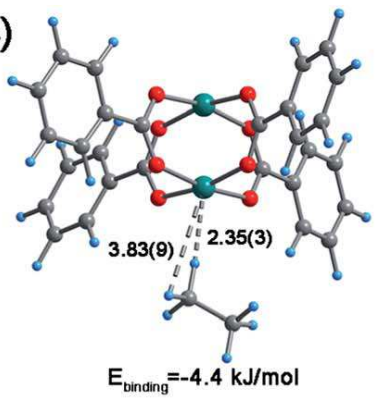

f)

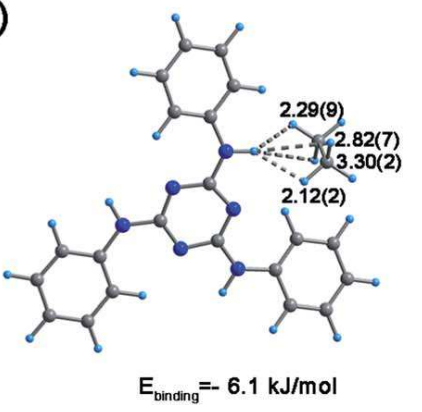


Fig.27. Discrete Fourier transform optimized geometry for $\mathrm{C} 2 \mathrm{~s}$. Close contact distances (in ${ }^{\circ} \mathrm{A}$ ) are marked. Green, red, gray, blue and light blue represent $\mathrm{Cu}, \mathrm{O}, \mathrm{C}, \mathrm{N}$ and $\mathrm{H}$ atoms, respectively. Reprinted with the permission from ref. 146, Copyright 2014 Royal Society of

Chemistry.

Recently, the Schröder group [147] used a hydroxyl-functionalized porous MOF NOTT$300\left[\mathrm{Al}_{2}(\mathrm{OH})_{2}(\mathrm{BPTCA})\right]\left(\mathrm{H}_{4} \mathrm{BPTCA}=\right.$ biphenyl-3,3',5,5'-tetracarboxylic acid) to selectively adsorb unsaturated hydrocarbons. The uptakes for $\mathrm{C}_{2} \mathrm{H}_{2}, \mathrm{C}_{2} \mathrm{H}_{4}$ in NOTT-300 were measured to be 6.34 and $4.28 \mathrm{mmol} \mathrm{g}^{-1}$ at $293 \mathrm{~K}$ and 1 bar, respectively. While it can only adsorb $0.85 \mathrm{mmol}$ $\mathrm{g}^{-1} \mathrm{C}_{2} \mathrm{H}_{6}$ and $0.29 \mathrm{mmol} \mathrm{g}^{-1} \mathrm{CH}_{4}$ under the same condition. The adsorption selectivity of $\mathrm{C}_{2} \mathrm{H}_{4} / \mathrm{C}_{2} \mathrm{H}_{6}, \mathrm{C}_{2} \mathrm{H}_{2} / \mathrm{CH}_{4}$ and $\mathrm{C}_{2} \mathrm{H}_{4} / \mathrm{CH}_{4}$ were calculated, using IAST, to be $48.7,>1.000$ and $\sim 380$, respectively, suggesting a high binding ability of NOTT-300 selective toward unsaturated hydrocarbons. Schröder et al. further studied binding sites of hydrocarbon molecules in NOTT300 by combining neutron scattering, synchrotron X-ray, neutron diffraction, and computational modelling. These study reveals simultaneous and cooperative hydrogen-bonding, $\pi \cdots \pi$ stacking interactions and intermolecular dipole interactions in the binding of acetylene and ethylene, resulting in the high adsorption selectivity.

Our group [148] recently reported effective $\mathrm{C}_{2} \mathrm{H}_{4} / \mathrm{C}_{2} \mathrm{H}_{6}$ separation at higher temperatures, exploiting two functional OMSs and $\pi$-complexation. Current methods for ethylene/ethane separations requires cryodistillation, an energy intensive process, with up to $75 \%$ of the cost derived from compression, heating, dehydration, recovery and refrigeration systems. Using MIL$101-\mathrm{Cr}$ as a substrate, we grafted sulfonic acid onto the framework. The MOF-101-Cr- $-\mathrm{SO}_{3} \mathrm{H}$ exhibits a high density of open metal sites still existing in the metal clusters. We then introduced $\mathrm{Ag}(\mathrm{I})$ ion sites via $\mathrm{Ag}(\mathrm{I})$ exchange, successfully achieving MIL-101-Cr-SO ${ }_{3} \mathrm{Ag}$ (Scheme 15), 
which was also simultaneously reported by Bao, Chen, and co-workers [149]. We expected the addition of $\mathrm{Ag}^{+}$ions to enhance the materials ability for $\pi$-complexation between ethylene and the framework. MIL-101-Cr-SO $\mathrm{SO}_{3} \mathrm{Ag}$ exhibits superior adsorption selectivity $\left(\mathrm{S}_{\mathrm{ads}}=9.7\right)$ for an equimolar mixture of ethylene and ethane at high temperatures, $318 \mathrm{~K}$, and $100 \mathrm{kPa}$ (Fig.28). The selectivity of MIL-101-Cr-SO $\mathrm{SO}_{3} \mathrm{Ag}$ surpasses MIL-101-Cr- $\mathrm{SO}_{3} \mathrm{H}$, zeolite NaX, MOFs such as MgMOF-74, FeMOF-74, CoMOF-74 and HKUST-1, and functionalized PAFs. Theoretical calculations (Fig.29) indicate the OMS and $\mathrm{Ag}(\mathrm{I})$ sites contribute as the main binding sites for $\mathrm{C}_{2} \mathrm{H}_{4}$ molecules. The use of $\pi$-complexation in association with OMS opens a new avenue to enhance ethylene/ethane separation at high temperatures.

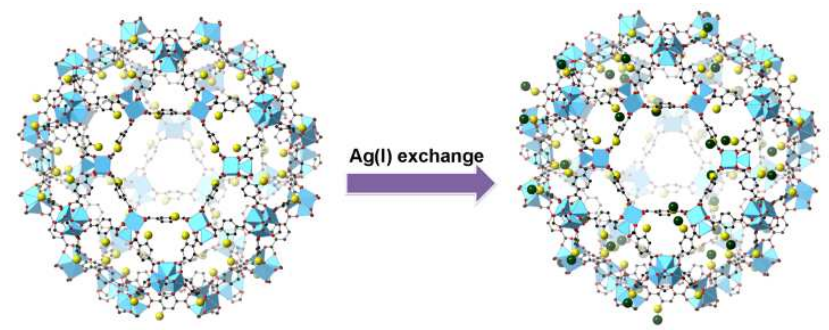

Scheme 15. Schematic illustration of $\mathrm{Ag}(\mathrm{I})$ exchange in MIL-101-Cr-SO $\mathrm{S}_{3} \mathrm{H}$ to afford MIL-101$\mathrm{Cr}-\mathrm{SO}_{3} \mathrm{Ag}$. Reprinted with the permission from ref. 148, Copyright 2015 Royal Society of Chemistry.

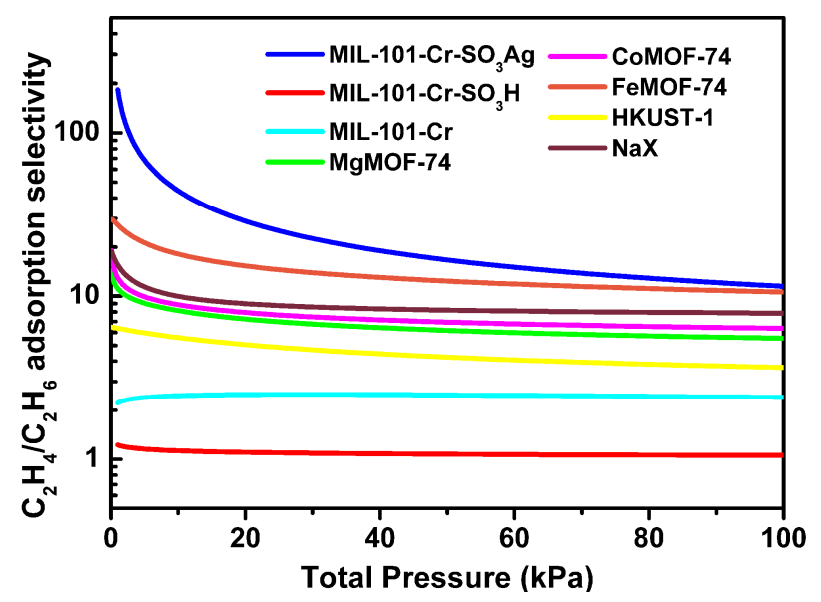


Fig.28. Comparison of the IAST calculations for $\mathrm{C}_{2} \mathrm{H}_{4}-\mathrm{C}_{2} \mathrm{H}_{6}$ adsorption selectivities for MIL$101-\mathrm{Cr}-\mathrm{SO}_{3} \mathrm{Ag}$ with $\mathrm{MIL}-101-\mathrm{Cr}-\mathrm{SO}_{3} \mathrm{H}$ and other porous materials at $318 \mathrm{~K}$. Reprinted with the permission from ref. 148, Copyright 2015 Royal Society of Chemistry.
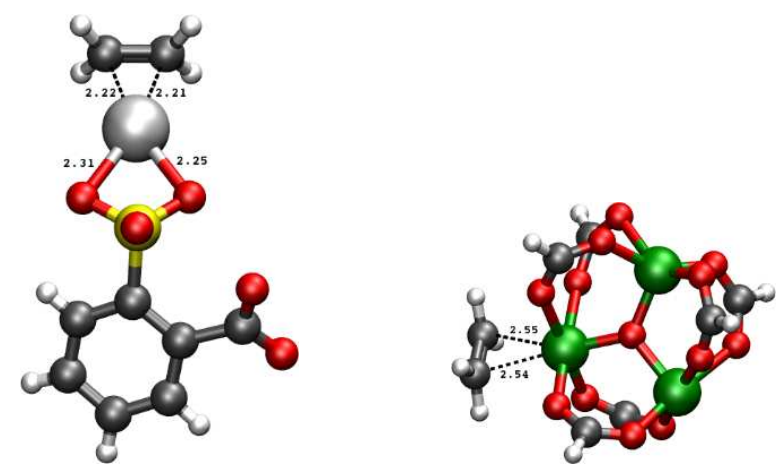

Fig.29. The optimized position of an ethylene molecule within (a) $\left(\mathrm{C}_{6} \mathrm{H}_{3}\left(\mathrm{CO}_{2}\right)_{2}\right) \mathrm{SO}_{3} \mathrm{Ag}$ and (b) $\left[\mathrm{Cr}_{3} \mathrm{O}\left(\mathrm{O}_{2} \mathrm{CH}\right)_{6}\right]^{+}$clusters. Reprinted with the permission from ref. 148, Copyright 2015 Royal Society of Chemistry.

\section{Application of MFS-MOFs in optic.}

Since energy conversion easily occurs among the organic ligands, metal cluster, and guest species, the optic properties of MOFs often result from the roles of different components. A number of other reviews discuss optics applications and properties of MOFs [25-27,150,151]. In this section, we aim to discuss several examples of multiple functional sites enhancing optical properties in MOFs. In 2011, Hupp, Nguyen and coworkers [152] synthesized a multifunctional MOF BOP $\mathrm{Zn}_{2}$ (ZnTCPP)(DPBDPM) using 5,10,15,20-tetrakis(4-carboxyphenyl)porphyrin ( $\mathrm{H}_{4} \mathrm{TCPP}$ ) and dipyridyl boron dipyrromethene (DPBDPM) and a controlled MOF BOB $\left[\mathrm{Zn}_{2}(\mathrm{DBTCPB})(\mathrm{DPBDPM})\right] \quad\left(\mathrm{H}_{2} \mathrm{DBTCPB} \quad=\quad\right.$ 1,4-dibromo-2,3,5,6-tetrakis $(4-$ carboxyphenyl)benzene. The authors constructed the framework using two ligands to enhance the range of light absorption, covering the entire visible region. Furthermore, judicious selection and synthesis of ligands ensures overlap between the emission spectrum of dipyridyl boron dipyrromethene and the absorption spectrum of Zn-TCPP; thus, the energy transfer and 
conversion easily occurs between the ligands of BOP (Fig.30). The two chromophoric components together result in a dark-colored BOP MOF crystals, capable of absorbing light across the entire visible spectrum (Fig.31). This work opened the gateway to combine porphyrin ligands with other photo-active ligands to tune the optical properties of MOFs.

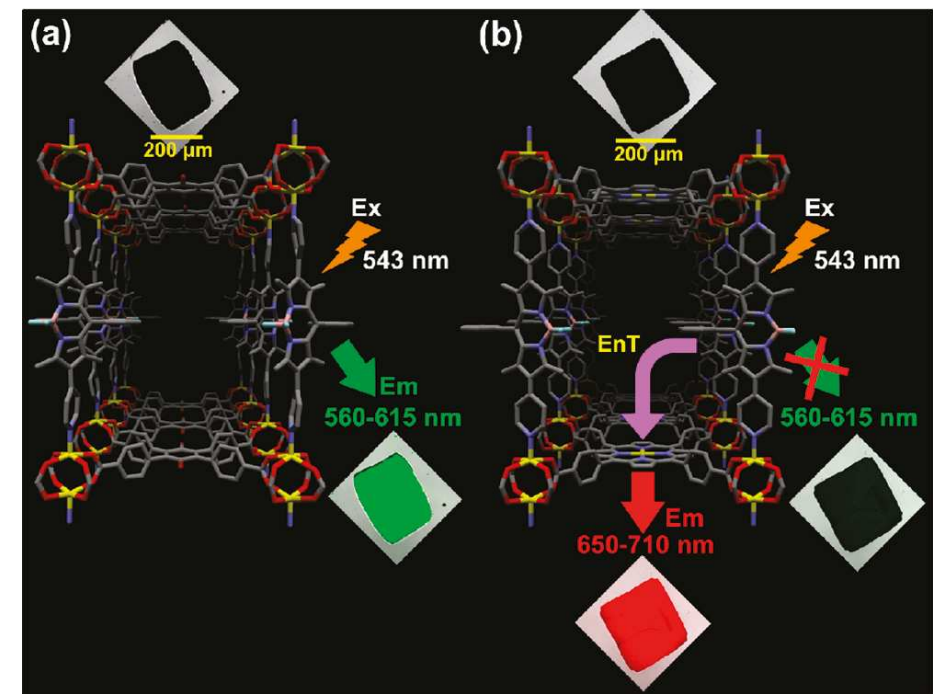

Fig.30. Confocal laser scanning microscopy images of crystals of: (a) BOB MOF and (b) BOP MOF. For illustrative purposes, when the crystals are shown as black, there is no emission. To denote emission in the "green" and "red" ranges, the remaining crystals are artificially colored green and red, respectively. Reprinted with the permission from ref. 152, Copyright 2011 American Chemical Society.
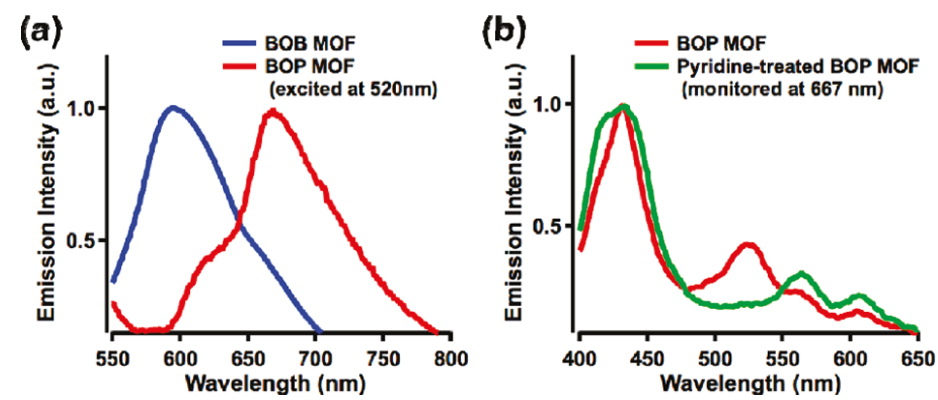

Fig.31. (a) Emission spectra of BOB and BOP MOFs. Spectra were obtained by excitation at $520 \mathrm{~nm}$. (b) Excitation spectra of BOP and pyridine-treated BOP MOF. Spectra were obtained 
by scanning the excitation wavelength from 400 to $650 \mathrm{~nm}$, with fixed emission detection at 667 nm. Reprinted with the permission from ref. 152, Copyright 2011 American Chemical Society.

Chen, Qian and coworkers [153] reported a temperature dependent luminescent MOF, $\mathrm{Eu}_{0.0069} \mathrm{~Tb}_{0.9931}$-DMBDC (DMBDC = 2,5-dimethoxy-1,4-benzenedicarboxylate), in 2012. When compared with controls based on the single lanthanide metal counterpart, the energy transfer behaviors in $\mathrm{Eu}_{0.0069} \mathrm{~Tb}_{0.9931}$-DMBDC from $\mathrm{Tb}^{3+}$-to- $\mathrm{Eu}^{3+}$ enhance the intensity of $\mathrm{Eu}^{3+}$ emission linearly with the increase of temperature (Fig.32). In addition, because $\mathrm{Tb}^{3+}$ and $\mathrm{Eu}^{3+}$ within $\mathrm{Eu}_{0.0069} \mathrm{~Tb}_{0.9931}$-DMBDC emit different colors, green at $545 \mathrm{~nm}$ and red at $613 \mathrm{~nm}$, respectively, direct observation of temperature change occurs instantly (Fig.33). The discrete multicomponent system allows $\mathrm{Eu}_{0.0069} \mathrm{~Tb}_{0.9931}$-DMBDC to behave as two distinct emissions based luminescent thermometers. This work demonstrates the feasibility of using multi-metal systems as optical sensors based off the synergetic or discrete behavior of the metals involved.
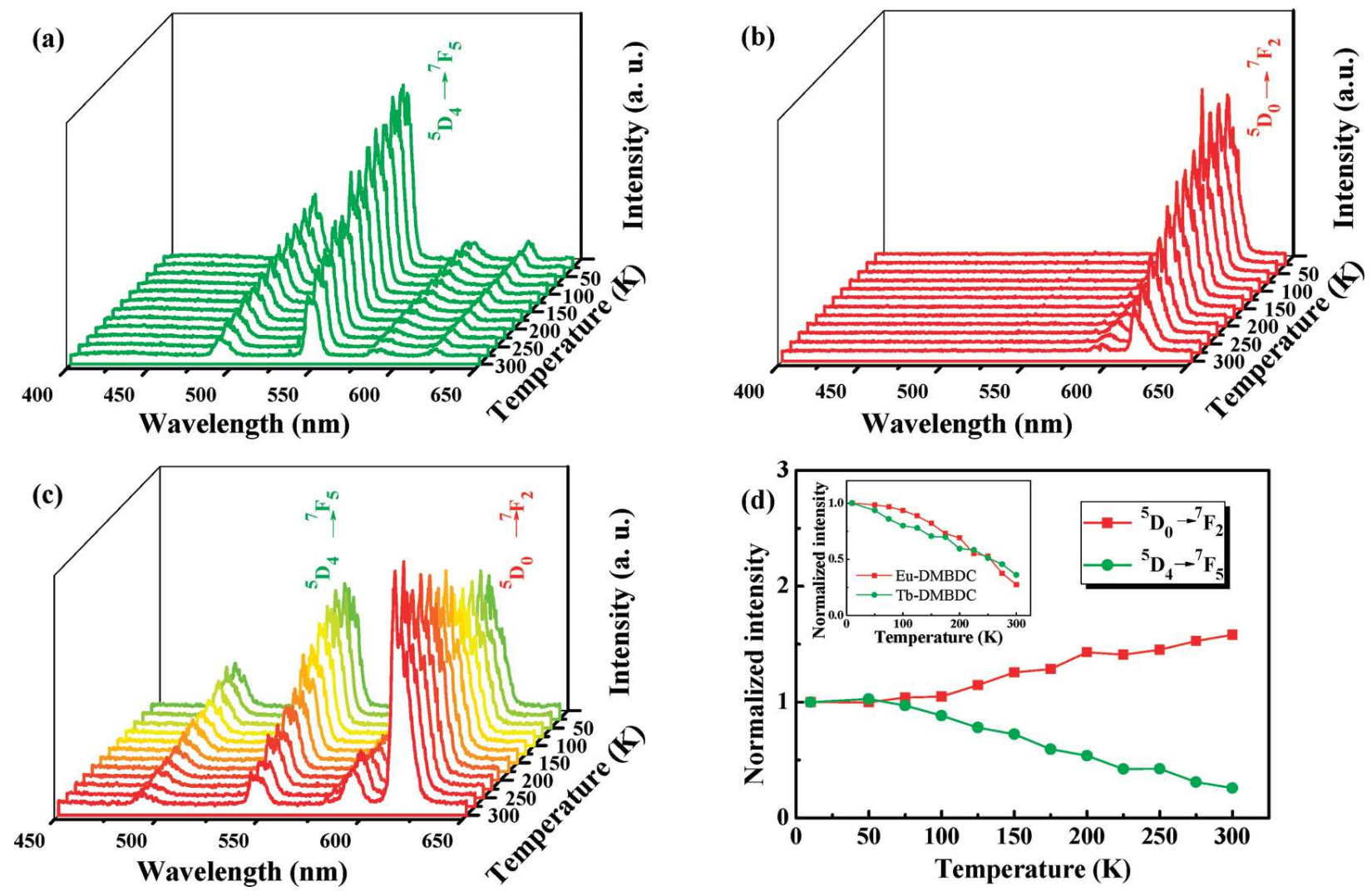
Fig.32. Emission spectra of (a) Tb-DMBDC, (b) Eu-DMBDC, (c) $\mathrm{Eu}_{0.0069} \mathrm{~Tb}_{0.9931}-\mathrm{DMBDC}$ recorded between 10 and $300 \mathrm{~K}$ (excited at $355 \mathrm{~nm}$ from the third harmonic of a Nd:YAG laser), and (d) temperature dependence of integrated intensities of the ${ }^{5} \mathrm{D}_{4} \rightarrow{ }^{7} \mathrm{~F}_{5}(534-562 \mathrm{~nm})$ and ${ }^{5} \mathrm{D}_{0}$ $\rightarrow{ }^{7} \mathrm{~F}_{2}(605-633 \mathrm{~nm})$ transitions for $\mathrm{Eu}_{0.0069} \mathrm{~Tb}_{0.9931}$-DMBDC. (Inset) Temperature-dependent integrated intensity of the ${ }^{5} \mathrm{D}_{4} \rightarrow{ }^{7} \mathrm{~F}_{5}$ transition of Tb-DMBDC and ${ }^{5} \mathrm{D}_{0} \rightarrow{ }^{7} \mathrm{~F}_{2}$ transition of EuDMBDC. Reprinted with the permission from ref. 153, Copyright 2012 American Chemical Society.

(a)
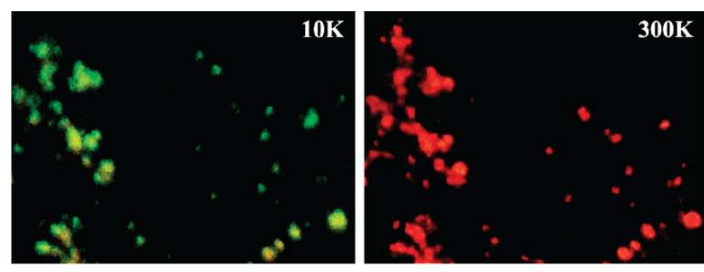

(b)

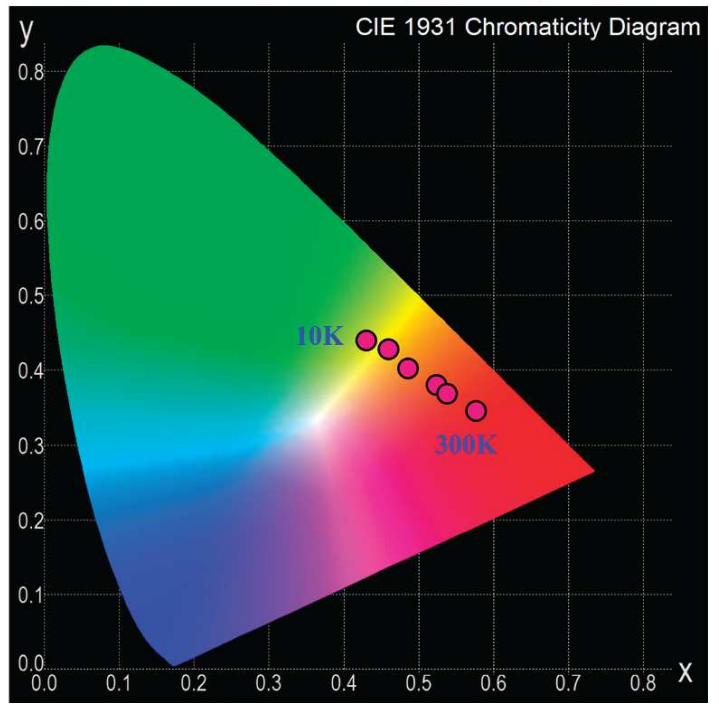

Fig.33. (a) Photograph of the luminescent $\mathrm{Eu}_{0.0069} \mathrm{~Tb}_{0.9931}$-DMBDC at $10 \mathrm{~K}$ (left) and $300 \mathrm{~K}$ (right), excited at $312 \mathrm{~nm}$. (b) CIE chromaticity diagram showing the luminescence color of $\mathrm{Eu}_{0.0069} \mathrm{~Tb}_{0.9931}$-DMBDC at different temperatures. Reprinted with the permission from ref. 153, Copyright 2012 American Chemical Society. 
In 2014, Qian, Cui and coworkers [154] prepared two lanthanide based MOF film, CPM$5 \supset \mathrm{Tb}^{3+}\left\{\mathrm{CPM}-5=\left[\left(\mathrm{CH}_{3}\right)_{2} \mathrm{NH}_{2}\right]\left[\operatorname{In}_{3} \mathrm{O}(\mathrm{BTC})_{2}\left(\mathrm{H}_{2} \mathrm{O}\right)_{3}\right]_{2}\left[\operatorname{In}_{3}(\mathrm{BTC})_{4}\right]\right\}$ and MIL-100(In)つTb $\mathrm{Tb}^{3+}$ $\left\{\right.$ MIL-100 $\left.(\mathrm{In})=\mathrm{In}_{3} \mathrm{O}(\mathrm{OH})\left(\mathrm{H}_{2} \mathrm{O}\right)_{2}[\mathrm{BTC}]_{2}\right\}(\mathrm{BTC}=1,3,5$-benzenetricarboxylate $)$ The two MOF films show the ligand-to-metal energy transfer, and also energy back transfer from metal-to ligand; thus, prolonging the triplet-state lifetime of ligands (Scheme 16). The authors showed molecular oxygen results in the deactivation of the triplet-state organic ligands, resulting in a quenching of emission (Fig.34).

a)
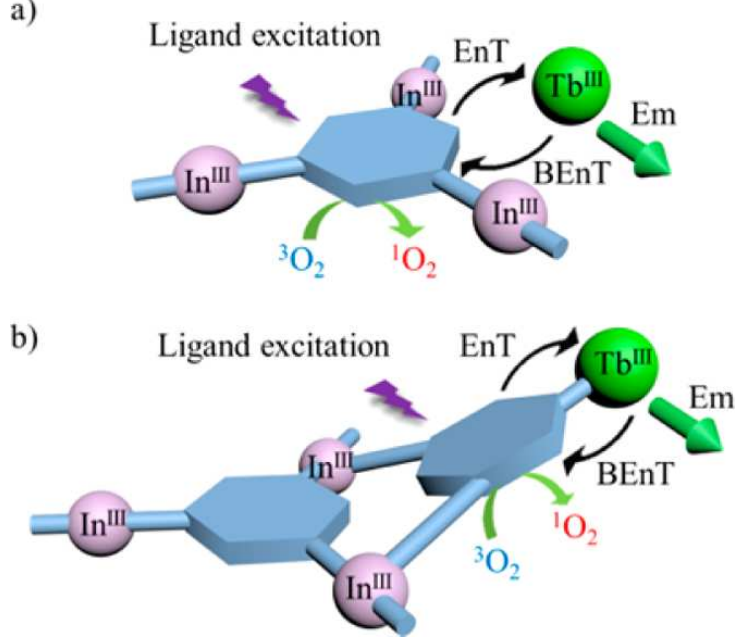

Scheme 16. Energy Transfer Processes and $\mathrm{O}_{2}$ Quenching Processes of (a) CPM-5دTb $\mathrm{Tb}^{3+}$ and (b) MIL-100(In)つ $\mathrm{Tb}^{3+}$. Reprinted with the permission from ref. 154, Copyright 2014 American Chemical Society. 

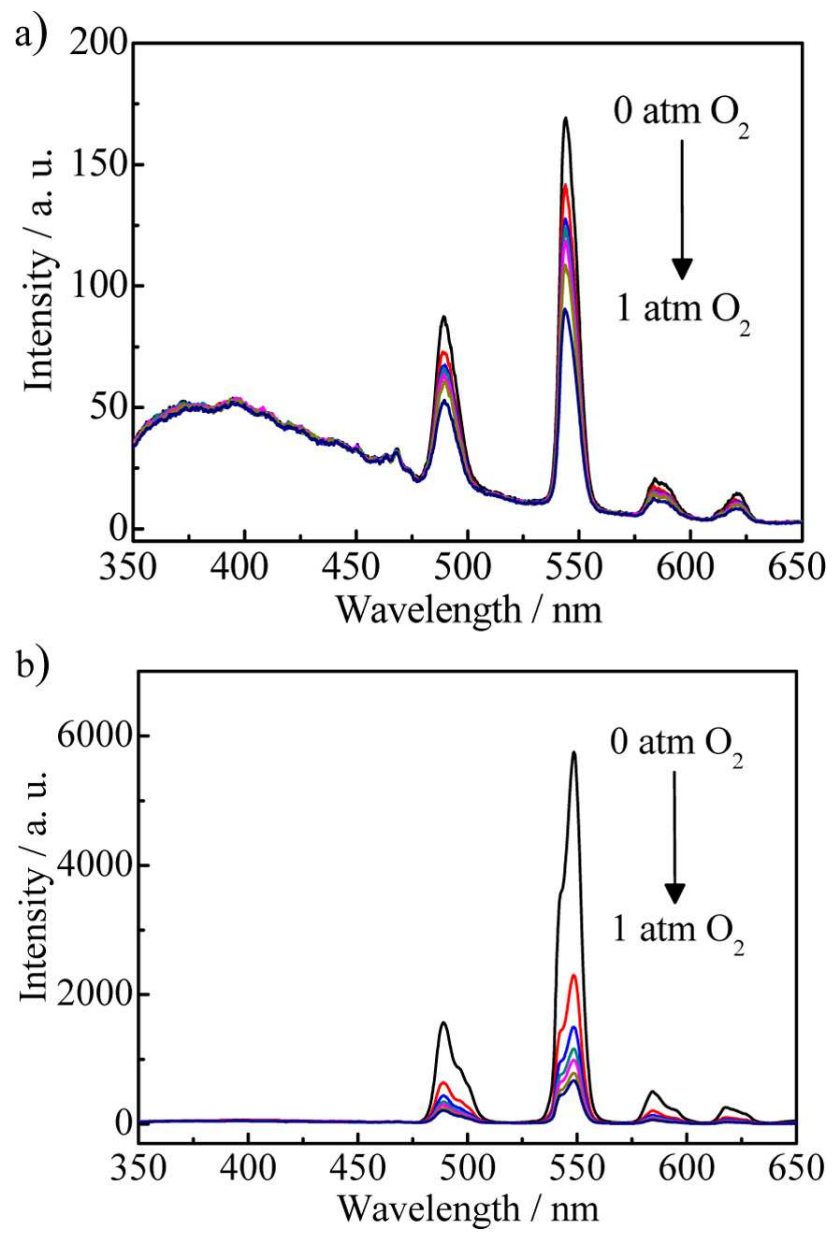

Fig.34. Emission spectra of activated (a) CPM-5つTb ${ }^{3+}$ and (b) MIL-100(In)つ $\mathrm{Tb}^{3+}$ films under different oxygen partial pressure $\mathrm{Po}_{2}$. Reprinted with the permission from ref. 154, Copyright 2014 American Chemical Society.

\section{Application of MFS-MOFs in proton conduction.}

The advancement of fuel cell technology, based off the concept of converting chemical energy into electrical energy, reaches a bottleneck when looking for an efficient, high performance proton conducting materials. Current research focuses on exploiting two separate mechanisms for proton conduction, either within a hydrogen-bonded network or via selfdiffusion of proton carriers [155-156]. MOFs offer two different avenues for tuning proton conductivity, through the accommodation of guest molecules or the functionalization of the 
framework. Proton conductivities of most MOF materials reflect a combined effect with contributions from multiple functional sites. The Shimizu group [28] and Kitagawa group [157] recently published two review articles discussing proton conduction in MOFs. Therefore, we will examine several prototypical examples to illustrate the effect of multiple functional sites in proton conductivity.

Kitagawa and coworkers [158] reported a proton-conductive $\mathrm{MOF}\left(\mathrm{NH}_{4}\right)_{2}(\operatorname{adp})$ $\left[\mathrm{Zn}_{2}(\mathrm{ox})_{3}\right] \cdot 3 \mathrm{H}_{2} \mathrm{O}(\mathrm{adp}=$ adipic acid; ox $=$ oxalate $)\left(\right.$ Fig.35) that introduced $\mathrm{NH}_{4}{ }^{+}$counter ions and adipic acid as guest molecules. The MOF exhibits a well arranged hydrogen-bond network of $\mathrm{COOH}, \mathrm{H}_{2} \mathrm{O}$, and $\mathrm{NH}_{4}{ }^{+}$resulting in a superprotonic conductivity of $8 \times 10^{-3} \mathrm{~S} \mathrm{~cm}^{-1}$ at ambient temperature and $98 \%$ relative humidity $(\mathrm{RH})$ conditions.
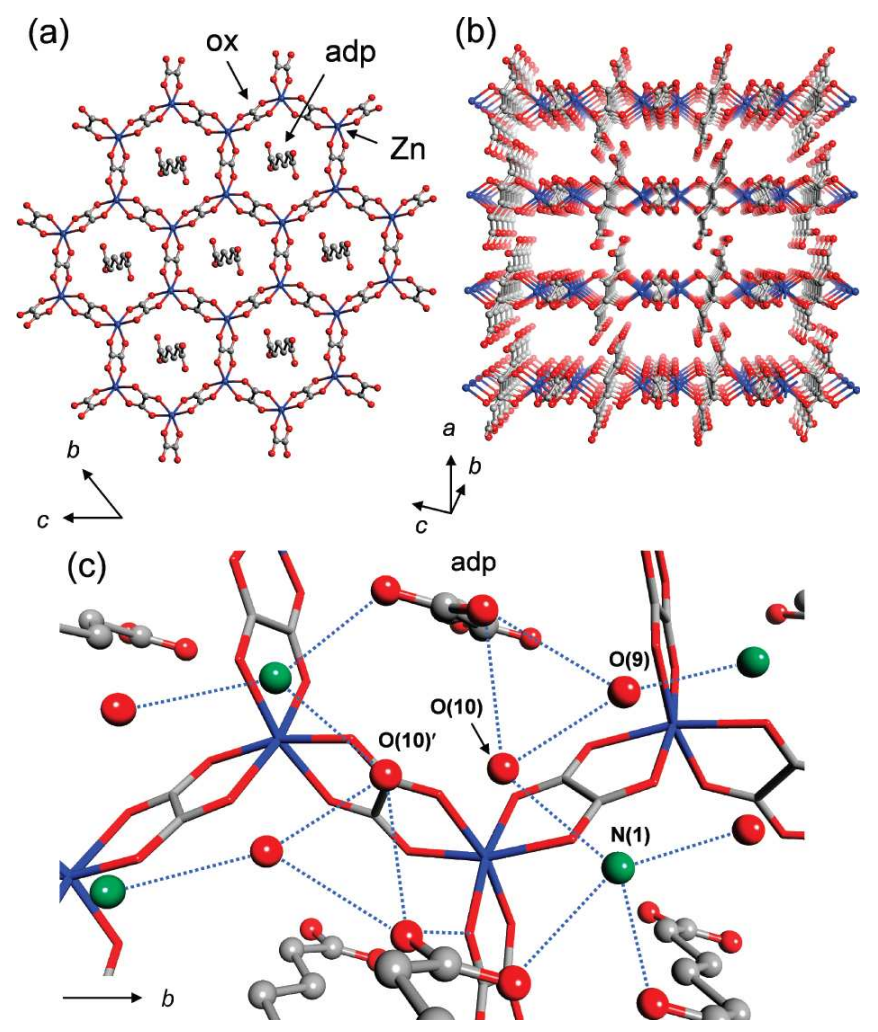

Fig.35. (a) Honeycomb layer structure of $\left(\mathrm{NH}_{4}\right)_{2}(\mathrm{adp})\left[\mathrm{Zn}_{2}(\mathrm{ox})_{3}\right] \cdot 3 \mathrm{H}_{2} \mathrm{O}$. (b) Perspective view along the b-axis. Guest molecules are omitted. (c) Hydrogen-bond arrangements of - $\mathrm{COOH}, \mathrm{H}_{2} \mathrm{O}$, 
and $\mathrm{NH}_{4}{ }^{+}$in the interlayer. Hydrogen bonds are shown as blue dotted lines. The colors of red, green, gray, and blue correspond to oxygen, nitrogen, carbon, and zinc atoms, respectively. Reprinted with the permission from ref. 158, Copyright 2009 American Chemical Society.

Two years later, Kitagawa and coworkers [159] reported a composite aluminum-based MOF (Fig.36). The authors introduced histamine molecules into the framework. Those histamine molecules exhibit three proton-hopping sites and resulting MOFs composites exhibits high proton conductivity of over $10^{-3} \mathrm{~S} \mathrm{~cm}^{-1}$ at $150{ }^{\circ} \mathrm{C}$ in a completely anhydrous environment.

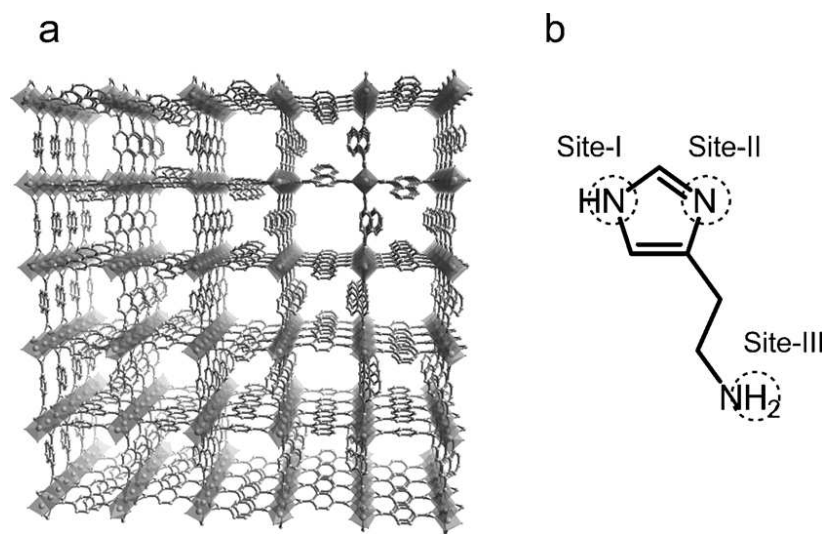

Fig.36. (a) Crystal structure of $[\mathrm{Al}(\mathrm{OH})(\mathrm{ndc})]_{\mathrm{n}}$. (b) Schematic view of histamine with three proton-hopping sites. Reprinted with the permission from ref. 159, Copyright 2011 WILEYVCH Verlag GmbH \& Co. KGaA, Weinheim.

In 2014, Ghosh and coworkers [160] reported a proton-conducting MOF $\left.\left[\left(\mathrm{Me}_{2} \mathrm{NH}_{2}\right)_{3}\left(\mathrm{SO}_{4}\right)\right]_{2}\left[\mathrm{Zn}_{2}(\mathrm{ox})_{3}\right]\right\}_{\mathrm{n}}$ that operates in both humid and anhydrous environments (Fig.37). The MOF system, constructed by $\left[\mathrm{Zn}_{2}(\mathrm{Ox})_{3}\right]_{\mathrm{n}}^{2-}$ anionic framework and $\left[\left(\mathrm{Me}_{2} \mathrm{NH}_{2}\right)_{3} \mathrm{SO}_{4}\right]_{n}^{+}$cationic supramolecular net, results from electrostatic and hydrogen-bonding interactions between sulfate anions and dimethyl ammonium cations. The MOF exhibits a conductivity of $1.0 \times 10^{-4} \mathrm{~S} \mathrm{~cm}^{-1}$ at $150{ }^{\circ} \mathrm{C}$ under anhydrous conditions and $4.2 \times 10^{-2} \mathrm{~S} \mathrm{~cm}^{-1}$ at $25{ }^{\circ} \mathrm{C}$ and humid conditions $(98 \% \mathrm{RH})$. The activation energy, $0.129 \mathrm{eV}$, indicates the 
Grotthuess mechanism transports protons. The resulting high proton conductivity of $\left.\left[\left(\mathrm{Me}_{2} \mathrm{NH}_{2}\right)_{3}\left(\mathrm{SO}_{4}\right)\right]_{2}\left[\mathrm{Zn}_{2}(\mathrm{ox})_{3}\right]\right\}_{\mathrm{n}}$ originates from proton transfer along the hydrogen-bonded dimethyl ammonium cations and sulfate anions. Although briefly discussed in this review paper, multifunctional components of MOFs can be exploited to enhance the proton conductivity within MOFs material systems.
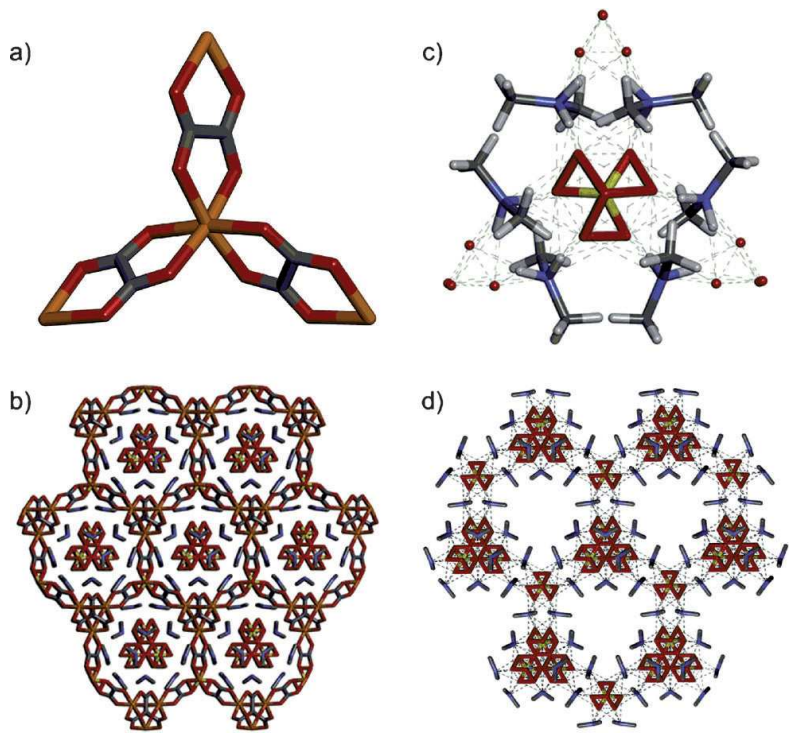

Fig.37. (a) The tris-chelated $D_{3}$-symmetric $\left[\mathrm{Zn}_{2}(\mathrm{ox})_{3}\right]^{2-}$ subunit. (b) Crystal structure of $\left\{\left[\left(\mathrm{Me}_{2} \mathrm{NH}_{2}\right)_{3}\left(\mathrm{SO}_{4}\right)\right]_{2}\left[\mathrm{Zn}_{2}(\mathrm{ox})_{3}\right]\right\}_{\mathrm{n}}$ (1). (c) Hydrogen-bonding interactions between dimethyl ammonium cations and sulfate anions in compound 1. d) $3 \mathrm{D}$ supramolecular $\left[\left(\mathrm{Me}_{2} \mathrm{NH}_{2}\right)_{3} \mathrm{SO}_{4}\right]^{+}{ }_{\mathrm{n}}$ net formed by hydrogen bonding between dimethyl ammonium cations and sulfate anions. Reprinted with the permission from ref. 160, Copyright 2014 WILEY-VCH Verlag GmbH \& Co. KGaA, Weinheim. 


$$
\overbrace{\text { mmen }}^{\mathrm{N}_{\mathrm{H}}} \overbrace{}^{\mathrm{H}}
$$
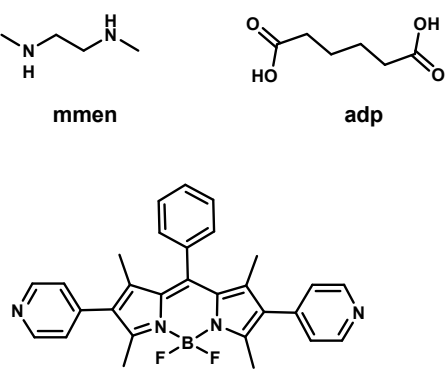

DPBDPM<smiles>O=C(O)c1ccc(C(=O)O)cc1</smiles>

BDC

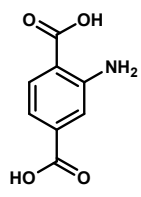

bdc- $\mathrm{NH}_{2}$
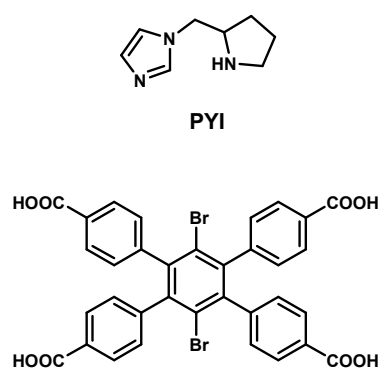

$\mathrm{H}_{2}$ DBTCPB
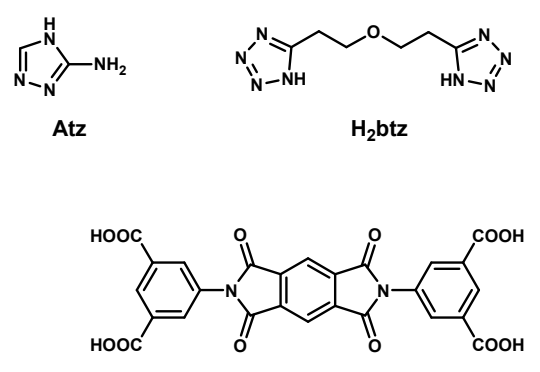

$\mathrm{H}_{4}$ BDCPPI

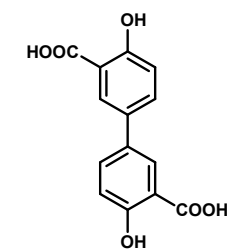

$\mathrm{H}_{4}$ dobpdc
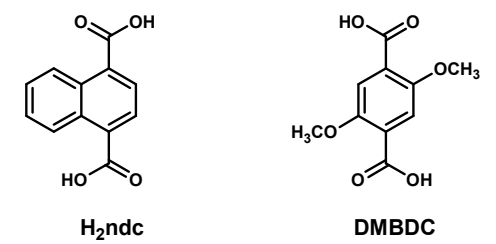

DMBDC
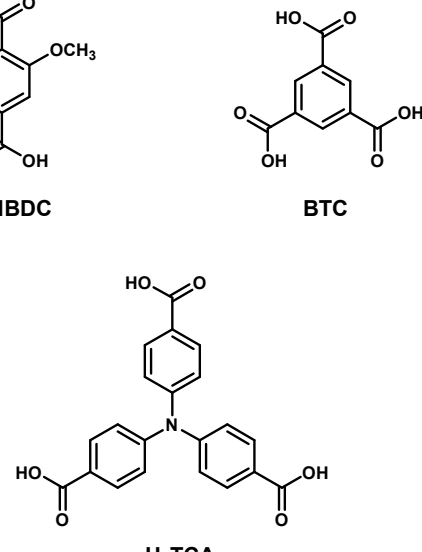

$\mathrm{H}_{4}$ BPTCA

$\mathrm{H}_{3}$ TCA
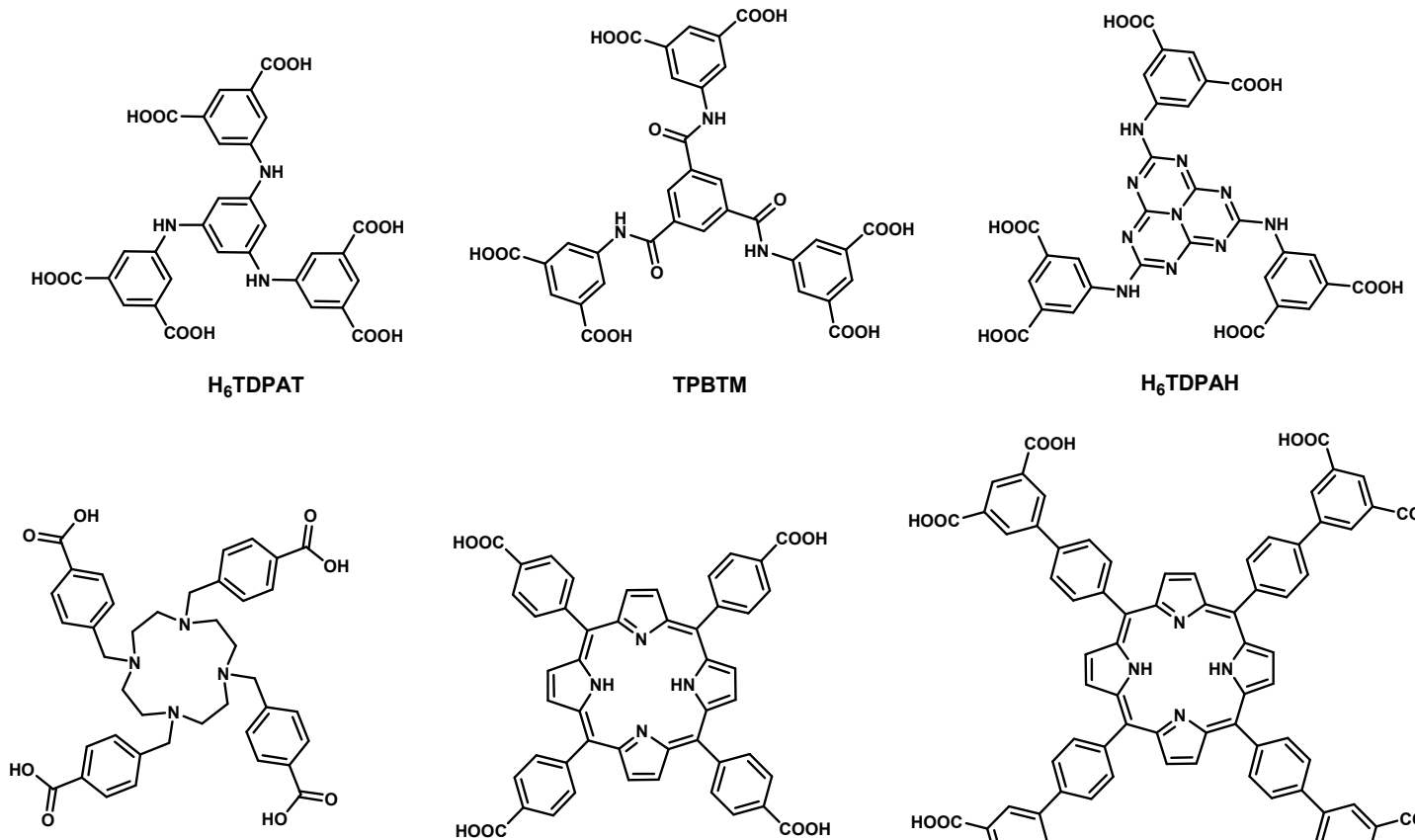

$\mathrm{H}_{4}$ tactmb

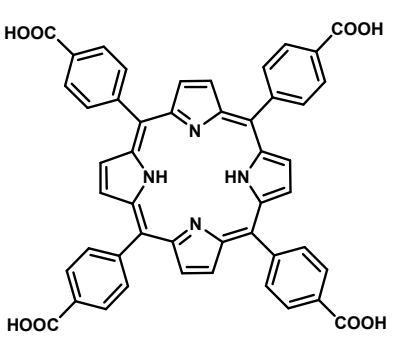

$\mathrm{H}_{4}$ TCPP

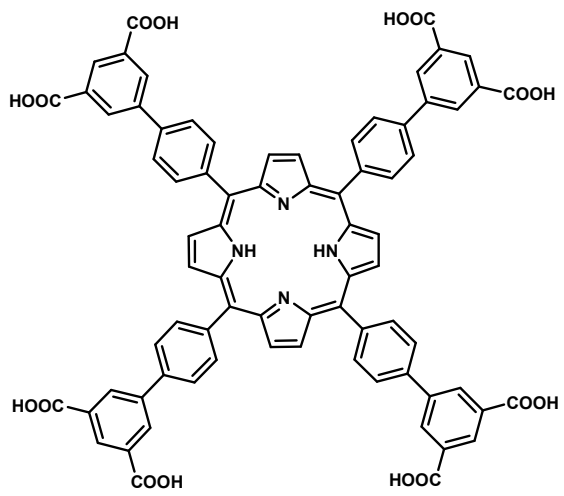

$\mathrm{H}_{10}$ tdcbpp

Scheme 17. Structural drawings of functional ligands. 


\section{Conclusion and outlook}

MFS-MOFs remain a small, but growing area of research within the MOF community. As an overarching goal, MOF research aims to elucidate structure-to-function. Viewing MOFs as a versatile platform for research opens the doors to a vast expanse of research and prospect. The first few decades of MOF research created a vast library or structures and properties available to reference; however, the current paradigm applies prior knowledge to engineer materials with novel properties using a bottoms-up approach. The ability to control the welldefined, crystalline structures of MOFs allows us to manipulate the local environment around active centers and surfaces. The inclusion of multiple functional sites within a single system expands the utility of MOFs materials. Combining functionalities brings about even more promise for MOFs to have a significant impact on society, although all domains of MSF-MOFs requires further research and development before they become practical in an industrial or large scale setting.

This review demonstrates the vast scope of work MSF-MOFs encompass. We aim to provide a holistic and systematic overview of the rapid growth MSF-MOFs has seen in recent years. Within the review, we highlight possible applications for MFS-MOFs: heterogeneous catalysis, gas adsorption and separation, optics, and proton-conducting materials. Specifically, we detail strategies and techniques developed thus far to include multiple functional sites within a single framework with the hopes these strategies are enhanced and applied to develop novel systems. We find those strategies fall into a few broader classifications: formation of MFS entirely on the organic components of MOFs, synthesis of MFS on both the organic and inorganic components of MOFs, inclusion of functional guest molecules, and the use of multiple metal functional sites. 
Heterogeneous catalysis seems the most extensively studied application for MSF-MOFs. A number of systems show promise as catalysts for a series of cascade reactions, allowing simple, one-pot processes. These processes show high efficiency and selectivity due to the high density of active sites contained within a confined nanospace. Taking inspiration from nature, applying understandings developed from studying enzymes that catalyze cascade reaction, could significantly expand the scope of reactions MSF-MOFs are capable of performing.

Beyond catalysis, MFS-MOFs show great promise in gas storage because of the increased density of gas binding sites. The crystalline nature and well-developed engineering strategies create significant opportunity to systematically design and synthesize frameworks with functional sites that behave cooperatively, enhancing the uptake capacity and selectivity towards specific molecules or gases.

The other applications mentioned in this review, for optics and proton conduction, do show great potential, however, remained relatively underappreciated at this time. To truly appreciate the potential of MSF-MOFs, we need to focus on elucidating cooperative behaviors of functional sites. We must expand our chemical knowledge of these systems and how separate functional sites can behave cooperatively to perform desired processes.

In summary, MFS-MOFs present themselves as a unique class of functional porous materials and we have barely scratched the surface in our ability to apply these materials to solve environmental and economic issues. MFS-MOFs will continue to draw interest and inquiry by both academia and industry because of the unique and distinctive features they possess. The young, blossoming field fails to paint a comprehensive picture of the crop MSF-MOFs will produce. 


\section{Acknowledgments}

The authors acknowledge the National Science Foundation (DMR-1352065) and University of South Florida for financial support of this work.

\section{References}

[1] H.-C. Zhou, J. R. Long, O. M. Yaghi, Chem. Rev. 112 (2012) 673.

[2] H. Furukawa, K. E. Cordova, M. O’Keeffe, O. M. Yaghi, Science 341 (2013) 1230444-1.

[3] G. Férey, Chem. Soc. Rev. 37 (2008) 191.

[4] S. Kitagawa, R. Kitaura, S.-i. Noro, Angew. Chem. Int. Ed. 43 (2004) 2334.

[5] L.J. Murray, M. Dinca, J. R. Long, Chem. Soc. Rev. 38 (2009) 1294.

[6] J.-R. Li, J. Sculley, H.-C. Zhou, Chem. Rev. 112 (2012) 869.

[7] H. Wu, Q. Gong, D. H. Olson, J. Li, Chem. Rev. 112 (2012) 836.

[8] Q.-L. Zhu, Q. Xu, Chem. Soc. Rev. 43 (2014) 5468.

[9] J.-P. Zhang, X.-C. Huang, X.-M. Chen, Chem. Soc. Rev. 38 (2009) 2385.

[10] W.-Y. Gao, M. Chrzanowski, S. Ma, Chem. Soc. Rev. 43 (2014) 5841.

[11] M. O’Keeffe, O. M. Yaghi, Chem. Rev. 112 (2012) 675.

[12] W. Lu, Z. Wei, Z.-Y. Gu, T.-F. Liu, J. Park, J. Park, J. Tian, M. Zhang, Q. Zhang, T. Gentle III, M. Bosch, H.-C. Zhou, Chem. Soc. Rev. 43 (2014) 5561.

[13] H.-L. Jiang, T. A. Makal, H.-C. Zhou, Coord. Chem. Rev. 257 (2013) 2232.

[14] V. Guillerm, D. Kim, J. F. Eubank, R. Luebke, X. Liu, K. Adil, M. S. Lah, M. Eddaoudi, Chem. Soc. Rev. 43 (2014) 6141.

[15] M. Eddaoudi, D. F. Sava, J. F. Eubank, K. Adil, V. Guillerm, Chem. Soc. Rev. 44 (2015) 228. 
[16] S. Ma, H.-C. Zhou, Chem. Commun. 46 (2010) 44.

[17] K. Sumida, D. L. Rogow, J. A. Mason, T. M. McDonald, E. D. Bloch, Z. R. Herm, T.-H. Bae, J. R. Long, Chem. Rev. 112 (2012) 724.

[18] M. P. Suh, H. J. Park, T. K. Prasad, D.-W. Lim, Chem. Rev. 112 (2012) 782.

[19] Y. He, W. Zhou, G. Qian, B. Chen, Chem. Soc. Rev. 43 (2014) 5657.

[20] S. Qiu, M. Xue, G. Zhu, Chem. Soc. Rev. 43 (2014) 6116.

[21] J. Y. Lee, O. K. Farha, J. Roberts, K. A. Scheidt, S. T. Nguyen, J. T. Hupp, Chem. Soc. Rev. 38 (2009) 1450.

[22] M. Yoon, R. Srirambalaji, K. Kim, Chem. Rev. 112 (2012) 1196.

[23] J. Liu, L. Chen, H. Cui, J. Zhang, L. Zhang, C.-Y. Su, Chem. Soc. Rev. 43 (2014) 6011.

[24] L. Ma, C. Abney, W. Lin, Chem. Soc. Rev. 38 (2009) 1248.

[25] M. D. Allendorf, C. A. Bauer, R. K. Bhakta, R. J. T. Houk, Chem. Soc. Rev. 38 (2009) 1330.

[26] Z. Hu, B. J. Deibert, J. Li, Chem. Soc. Rev. 43 (2014) 5815.

[27] L. E. Kreno, K. Leong, O. K. Farha, M. Allendorf, R. P. Van Duyne, J. T. Hupp, Chem. Rev. $112(2012) 1105$.

[28] P.Ramaswamy, N. E. Wong, G. K. H. Shimizu, Chem. Soc. Rev. 43 (2014) 5913.

[29] J. M. Taylor, R. K. Mah, I. L. Moudrakovski, C. I. Ratcliffe, R. Vaidhyanathan, G. K. Shimizu, J. Am. Chem. Soc. 132 (2010) 14055.

[30] J. A. Hurd, R. Vaidhyanathan, V. Thangadurai, C. I. Ratcliffe, I. L. Moudrakovski, G. K. H. Shimizu, Nat. Chem. 1 (2009) 705.

[31] T. Yamada, K. Otsubo, R. Makiura, H. Kitagawa, Chem. Soc. Rev. 42 (2013) 6655.

[32] P. Horcajada, R. Gref, T. Baati, P. K. Allan, G. Maurin, P. Couvreur, G. Férey, R. E. Morris, C. Serre, Chem. Rev. 112 (2012) 1232. 
[33] P. Horcajada, T. Chalati, C. Serre, B. Gillet, C. Sebrie, T. Baati, J. F. Eubank, D. Heurtaux, P. Clayette, C. Kreuz, J.-S. Chang, Y. K. Hwang, V. Marsaud, P.-N. Bories, L. Cynober, S. Gil, G. Fe'rey, P. Couvreur, R. Gref, Nat. Mater. 9 (2010) 172.

[34] J. D. Rocca, D. Liu, W. Lin, Acc. Chem. Res. 44 (2011) 957.

[35] S. M. Cohen, Chem. Rev. 112 (2012) 970.

[36] P. Deria, J. E. Mondloch, O. Karagiaridi, W. Bury, J. T. Hupp, O. K. Farha, Chem. Soc. Rev. 43 (2014) 5896.

[37] J. D. Evans, C. J. Sumby, C. J. Doonan, Chem. Soc. Rev. 43 (2014) 5933.

[38] Z. Wang, S. M. Cohen, Chem. Soc. Rev. 38 (2009) 1315.

[39] K. K. Tanabe, S. M. Cohen, Chem. Soc. Rev. 40 (2011) 498.

[40] B. Li, Y. Zhang, D. Ma, T. Ma, Z. Shi, S. Ma, J. Am. Chem. Soc. 136 (2014) 1202.

[41] Z. Zhang, L. Wojtas, M. Eddaoudi, M. J. Zaworotko, J. Am. Chem. Soc. 135 (2013) 5982.

[42] Z. Zhang, W.-Y. Gao, L. Wojtas, S. Ma, M. Eddaoudi, M. J. Zaworotko, Angew. Chem. Int. Ed. 51 (2012) 9330.

[43] M. H. Alkordi, Y. Liu, R. W. Larsen, J. F. Eubank, M. Eddaoudi, J. Am. Chem. Soc. 130 (2008) 12639.

[44] V. Lykourinou, Y. Chen, X.-S. Wang, L. Meng, T. Hoang, L.-J. Ming, R. L. Musselman, S. Ma, J. Am. Chem. Soc. 133 (2011) 10382.

[45] Y. Chen, V. Lykourinou, C. Vetromile, T. Hoang, L.-J. Ming, R. W. Larsen, S. Ma, J. Am. Chem. Soc. 134 (2012) 13188.

[46] Y. Chen, V. Lykourinou, T. Hoang, L.-J. Ming, S. Ma, Inorg. Chem. 51 (2012) 9156. 
[47] H. Deng, S. Grunder, K. E. Cordova, C. Valente, H. Furukawa, M. Hmadeh, F. Gándara, A. C. Whalley, Z. Liu, S. Asahina, H. Kazumori, M. O’Keeffe, O. Terasaki, J. Fraser Stoddart, O. M. Yaghi, Science 336 (2012) 1018.

[48] A. Dhakshinamoorthy, H. Garcia, Chem. Soc. Rev. 41 (2012) 5262.

[49] M. Meilikhov, K. Yusenko, D. Esken, S. Turner, G. V. Tendeloo, R. A. Fischer, Eur. J. Inorg. Chem. (2010) 3701.

[50] H. R. Moon, D.-W. Lim, M. P. Suh, Chem. Soc. Rev. 42 (2013) 1807.

[51] G. Férey, C. Mellot-Draznieks, C. Serre, F. Millange, J. Dutour, S. Surblé, I. Margiolaki, Science 309 (2005) 2040.

[52] J. Song, Z. Luo, D. K. Britt, H. Furukawa, O. M. Yaghi, K. I. Hardcastle, C. L. Hill, J. Am. Chem. Soc. 133 (2011) 16839.

[53] C.-Y. Sun, S.-X. Liu, D.-D. Liang, K.-Z. Shao, Y.-H. Ren, Z.-M. Su, J. Am. Chem. Soc. 131 (2009) 1883.

[54] H. Deng, C. J. Doonan, H. Furukawa, R. B. Ferreira, J. Towne, C. B. Knobler, B. Wang, O. M. Yaghi, Science 327 (2010) 846.

[55] Y.-F. Song, L. Cronin, Angew. Chem. Int. Ed. 47 (2008) 4635.

[56] Z. Wang, S. M. Cohen, Angew. Chem. Int. Ed. 47 (2008) 4699.

[57] M. Kim, J. F. Cahill, K. A. Prather, S. M. Cohen, Chem. Commun. 47 (2011) 7629.

[58] Y.-B. Zhang, H. Furukawa, N. Ko, W. Nie, H. J. Park, S. Okajima, K. E. Cordova, H. Deng, J. Kim, O. M. Yaghi, J. Am. Chem. Soc. accept.

[59] K. M. Koeller, C. H. Wong, Chem. Rev. 100 (2000) 4465.

[60] Y. Zhang, B. Li, S. Ma, Chem. Commun. 50 (2014) 8507. 
[61] S. Huh, H.-T. Chen, J. W. Wiench, M. Pruski, V. S.-Y. Lin, Angew. Chem. Int. Ed. 44 (2005) 1826.

[62] N. R. Shiju, A. H. Alberts, S. Khalid, D. R. Brown, G. Rothenberg, Angew. Chem. Int. Ed. $50(2011) 9615$.

[63] S. Shylesh, A. Wagner, A. Seifert, S. Ernst, W. R. Thiel, Chem. Eur. J. 15 (2009) 7052.

[64] F. Vermoortele, R. Ameloot, A.Vimont, C. Serre, D. De Vos, Chem. Commun. 47 (2011) 1521.

[65] R. Srirambalaji, S. Hong, R. Natarajan, M. Yoon, R. Hota, Y. Kim, Y. H. Ko, K. Kim, Chem. Commun. 48 (2012) 11650.

[66] T. Toyao, M. Fujiwaki, Y. Horiuchi, M. Matsuoka, RSC Adv. 3 (2013) 21582.

[67] Y. Fu, D. Sun, Y. Chen, R. Huang, Z. Ding, X. Fu, Z. Li, Angew. Chem. Int. Ed. 51 (2012) 3364.

[68] T. Toyao, M. Saito, Y. Horiuchi, M. Matsuoka, Catal. Sci. Technol. 4 (2014) 625.

[69] W.-Y. Gao, Y. Chen, Y. Niu, K. Williams, L. Cash, P. J. Perez, L. Wojtas, J. Cai, Y.-S. Chen, S. Ma, Angew. Chem. Int. Ed. 53 (2014) 2615.

[70] W.-Y. Gao, L. Wojtas, S. Ma, Chem. Commun. 50 (2014) 5316.

[71] B. Li, Y. Zhang, D. Ma, L. Li, G. Li, G. Li, Z. Shi, S. Feng, Chem. Commun. 48 (2012) 6151.

[72] P. Wu, C. He, J. Wang, X. Peng, X. Li, Y. An, C. Duan, J. Am. Chem. Soc. 134 (2012) 14991.

[73] Y. E. Cheon, M. P. Suh, Chem. Eur. J. 14 (2008) 3961.

[74] B. Yuan, Y. Pan, Y. Li, B. Yin, H. Jiang, Angew. Chem. Int. Ed. 49 (2010) 4054.

[75] D.-W. Lim, J. W. Yoon, K. Y. Ryu, M. P. Suh, Angew. Chem. Int. Ed. 51 (2012) 9814. 
[76] Y. Li, R. T. Yang, J. Am. Chem. Soc. 128 (2006) 726.

[77] M. P. Suh, H. R. Moon, E. Y. Lee, S. Y. Jang, J. Am. Chem. Soc. 128 (2006) 4710.

[78] Y. Li, R. T. Yang, J. Am. Chem. Soc. 128 (2006) 8136.

[79] C. Wang, K. E. deKrafft, W. Lin, J. Am. Chem. Soc. 134 (2012) 7211.

[80] A. Aijaz, A. Karkamkar, Y. J. Choi, N. Tsumori, E. Ro $\square$ nnebro, T. Autrey, H. Shioyama, Q. Xu, J. Am. Chem. Soc. 134 (2012) 13926.

[81] H.-L. Jiang, B. Liu, T. Akita, M. Haruta, H. Sakurai, Q. Xu, J. Am. Chem. Soc. 131 (2009) 11302.

[82] C. Zlotea, R. Campesi, F. Cuevas, E. Leroy, P. Dibandjo, C. Volkringer, T. Loiseau, G. Férey, M. Latroche, J. Am. Chem. Soc. 132 (2010) 2991.

[83] Y. Wei, S. Han, D. A. Walker, P. E. Fuller, B. A. Grzybowski, Angew. Chem. Int. Ed. 51 (2012) 7435.

[84] A.-X. Yan, S. Yao, Y.- G. Li, Z.-M. Zhang, Y. Lu, W.-L. Chen, E.-B. Wang, Chem. Eur. J. 20 (2014) 6927.

[85] N. V. Maksimchuk, K. A. Kovalenko, S. S. Arzumanov, Y. A. Chesalov, M. S. Melgunov, A. G. Stepanov, V. P. Fedin, O. A. Kholdeeva, Inorg. Chem. 49 (2010) 2920.

[86] N.V. Maksimchuk, M.N. Timofeeva, M.S. Melgunov, A.N. Shmakov, Yu.A. Chesalov, D.N. Dybtsev, V.P. Fedin, O.A. Kholdeeva, J. Catal. 257 (2008) 315.

[87] T. Bogaerts, A. Van Yperen-De Deyne, Y.-Y. Liu, F. Lynen, V. Van Speybroeck, P. Van Der Voort, Chem. Commun. 49 (2013) 8021.

[88] Y. Pan, B. Yuan, Y. Li, D. He, Chem. Commun. 46 (2010) 2280.

[89] F. G. Cirujano, F. X. Llabrés i Xamena, A. Corma, Dalton Trans. 41 (2012) 4249.

[90] X. Li, Z. Guo, C. Xiao, T. W. Goh, D. Tesfagaber, W. Huang, ACS Catal. 4 (2014) 3490. 
[91] M. Zhao, K. Deng, L. He, Y. Liu, G. Li, H. Zhao, Z. Tang, J. Am. Chem. Soc. 136 (2014) 1738.

[92] C. Wang, K. E. deKrafft, W. Lin, J. Am. Chem. Soc. 134 (2012) 7211.

[93] Y. Horiuchi, T. Toyao, M. Saito, K. Mochizuki, M. Iwata, H. Higashimura, M. Anpo, M. Matsuoka, J. Phys. Chem. C 116 (2012) 20848.

[94] D. Sun, W. Liu, Y. Fu, Z. Fang, F. Sun, X. Fu, Y. Zhang, Z. Li, Chem. Eur. J. 20 (2014) 4780.

[95] L. Shen, W. Wu, R. Liang, R. Lin, L. Wu, Nanoscale, 5 (2013) 9374.

[96] Q. Han, C. He, M. Zhao, B. Qi, J. Niu, C. Duan, J. Am. Chem. Soc. 135 (2013) 10186.

[97] P. Buchwalter, J. Rosé, P. Braunstein, Chem. Rev. 115 (2015) 28.

[98] F. Schröder, S. Henke, X. Zhang, R. A. Fischer, Eur. J. Inorg. Chem. (2009) 3131.

[99] H.-L. Jiang, T.Akita, T. Ishida, M. Haruta, Q. Xu, J. Am. Chem. Soc. 133 (2011) 1304.

[100] X. Gu, Z.-H. Lu, H.-L. Jiang, T. Akita, Q. Xu, J. Am. Chem. Soc. 133 (2011) 11822.

[101] J. Hermannsdörfer, M. Friedrich, N. Miyajima, R. Q. Albuquerque, S. Kümmel, R. Kempe, Angew. Chem. Int. Ed. 51 (2012) 11473.

[102] Q.-L. Zhu, J. Li, Q. Xu, J. Am. Chem. Soc. 135 (2013) 10210.

[103] J. Li, Q.-L. Zhua, Q. Xu, Chem. Commun. 50 (2014) 5899.

[104] H. Dai, N.Cao, L. Yang, J. Su, W. Luo, G. Cheng, J. Mater. Chem. A 2 (2014) 11060.

[105] H. Dai, B. Xia, L. Wen, C. Du, J. Su, W. Luo, G. Cheng, Appl. Catal. B: Environ. 165 (2015) 57.

[106] N. Cao, J. Su, W. Luo, G. Cheng, Int. J. Hydrogen Energy 39 (2014) 9726.

[107] Y.-Z. Chen, Q. Xu , S.-H. Yu, H.-L. Jiang, small 11 (2015) 71.

[108] F. Ke, L. Wang, J. Zhu, Nanoscale, 7 (2015) 1201. 
[109] Y. Zhang, B. Li, K. Williams, W.-Y. Gao, S. Ma, Chem. Commun. 49 (2013) 10269.

[110] W. Lu, J. P. Sculley, D. Yuan, R. Krishna, Z. Wei, H.-C. Zhou, Angew. Chem. Int. Ed. 51 (2012) 7480 .

[111] W. Lu, D. Yuan, J. Sculley, D. Zhao, R. Krishna, H.-C. Zhou, J. Am. Chem. Soc. 133 (2011) 18126.

[112] B. A. Al-Maythalony, O. Shekhah, R. Swaidan, Y. Belmabkhout, I. Pinnau, M. Eddaoudi, J. Am. Chem. Soc. 137 (2015) 1754.

[113] W. M. Bloch, R. Babarao, M. R. Hill, C. J. Doonan, C. J. Sumby, J. Am. Chem. Soc. 135 (2013) 10441.

[114] J. J. Gassensmith, H. Furukawa, R. A. Smaldone, R. S. Forgan, Y. Y. Botros, O. M. Yaghi, J. Fraser Stoddart, J. Am. Chem. Soc. 133 (2011) 15312.

[115] Z. R. Herm, J. A. Swisher, B. Smit, R. Krishna, J. R. Long, J. Am. Chem. Soc. 133 (2011) 5664.

[116] J. An, N. L. Rosi, J. Am. Chem. Soc. 132 (2010) 5578.

[117] L.-C. Lin, J. Kim, X. Kong, E. Scott, T. M. McDonald, J. R. Long, Jeffrey A. Reimer, B. Smit, Angew. Chem. Int. Ed. 52 (2013) 4410.

[118] X. Kong, E. Scott, W. Ding, J. A. Mason, J. R. Long, J. A. Reimer, J. Am. Chem. Soc. 134 (2012) 14341.

[119] F. Debatin, A. Thomas, A. Kelling, N. Hedin, Z. Bacsik, I. Senkovska, S. Kaskel, M. Junginger, H. Müller, U. Schilde, C. Jäger, A. Friedrich, H.-J. Holdt, Angew. Chem. Int. Ed. 49 (2010) 1258.

[120] J.-B. Lin, J.-P. Zhang, X.-M. Chen, J. Am. Chem. Soc. 132 (2010) 6654.

[121] S. M. Chen, J. Zhang, T. Wu, P. Y. Feng, X. H. Bu, J. Am. Chem. Soc. 131 (2009) 16027. 
[122] Y. Liu, J.-R. Li, W. M. Verdegaal, T.-F. Liu, H.-C. Zhou, Chem. Eur. J. 19 (2013) 5637.

[123] B. Zheng, J. Bai, J. Duan, L. Wojtas, M. J. Zaworotko, J. Am. Chem. Soc. 133 (2011) 748.

[124] R. Vaidhyanathan, S. S. Iremonger, K. W. Dawson, G. K. H. Shimizu, Chem. Commun. (2009) 5230.

[125] R. Vaidhyanathan, S. S. Iremonger, G. K. H. Shimizu, P. G. Boyd, S. Alavi, T. K. Woo, Science 330 (2010) 650 .

[126] S. Couck, J. F. M. Denayer, G. V. Baron, T. Rémy, J. Gascon, F. Kapteijn, J. Am. Chem. Soc. 131 (2009) 6326.

[127] J. An, S. J. Geib, N. L. Rosi, J. Am. Chem. Soc. 132 (2010) 38.

[128] P. Cui, Y.-G. Ma, H.-H. Li, B. Zhao, J.-R. Li, P. Cheng, P. B. Balbuena, H.-C. Zhou, J. Am. Chem. Soc. 134 (2012) 18892.

[129] T. K. Prasad, D. H. Hong, M. P. Suh, Chem. Eur. J. 16 (2010) 14043.

[130] B. Li, Z. Zhang, Y. Li, K. Yao, Y. Zhu, Z. Deng, F. Yang, X. Zhou, G. Li, H. Wu, N. Nijem, Y. J. Chabal, Z. Lai, Y. Han, Z. Shi, S. Feng, J. Li, Angew. Chem. Int. Ed. 51 (2012) 1412.

[131] R. Luebke, J.F. Eubank, A.J. Cairns, Y. Belmabkhout, L. Wojtas, M. Eddaoudi, Chem. Commun. 48 (2012) 1455.

[132] Y. Yan, M. Suyetin, E. Bichoutskaia, A. J. Blake, D. R. Allan, S. A. Barnett, M. Schröder, Chem. Sci. 4 (2013) 1731.

[133] N. H. Alsmail, M. Suyetin, Y. Yan, R. Cabot, C. P. Krap, J. Lü, T. L. Easun, E. Bichoutskaia, W. Lewis, A. J. Blake, M. Schröder, Chem. Eur. J. 20 (2014) 7317.

[134] R. Luebke, Ł. J. Weseliński, Y. Belmabkhout, Z. Chen, Ł. Wojtas, M. Eddaoudi, Cryst. Growth Des. 14 (2014) 414. 
[135] X.-J. Wang, P.-Z. Li, Y. Chen, Q. Zhang, H. Zhang, X. X. Chan, R. Ganguly, Y. Li, J. Jiang, Y. Zhao, Sci. Rep. 3 (2013) 1149.

[136] T. M. McDonald, W. R. Lee, J. A. Mason, B. M. Wiers, C. S. Hong, J. R. Long, J. Am. Chem. Soc. 134 (2012) 7056.

[137] A. M. Fracaroli, H. Furukawa, M. Suzuki, M. Dodd, S. Okajima, F. Gándara, J. A. Reimer, O. M. Yaghi, J. Am. Chem. Soc. 136 (2014) 8863.

[138] Z. R. Herm, E. D. Bloch, J. R. Long, Chem. Mater. 26 (2014) 323.

[139] Z. Zhang, Z. Z. Yao, S. Xiang, B. Chen, Energy Environ. Sci. 7 (2014) 2868.

[140] C. Y. Lee, Y.-S. Bae, N. C. Jeong, O. K. Farha, A. A. Sarjeant, C. L. Stern, P. Nickias, R. Q. Snurr, J. T. Hupp, S. T. Nguyen, J. Am. Chem. Soc. 133 (2011) 5228.

[141] Y.-S. Bae, C. Y. Lee, K. C. Kim, O. K. Farha, P. Nickias, J. T. Hupp, S. T. Nguyen, R. Q. Snurr, Angew. Chem., Int. Ed. 51 (2012) 1857.

[142] S.-C. Xiang, Z. Zhang, C.-G. Zhao, K. Hong, X. Zhao, D.-R. Ding, M.-H. Xie, C.-D. Wu, M. C. Das, R. Gill, K. Mark Thomas, B. Chen, Nat. Commun. 2 (2011) 204.

[143] K. Li, D. H. Olson, J. Seidel, T. J. Emge, H. Gong, H. Zeng, J. Li, J. Am. Chem. Soc. 131 (2009) 10368.

[144] E. D. Bloch, W. L. Queen, R. Krishna, J. M. Zadrozny, C. M. Brown, J. R. Long, Science 335 (2012) 1606.

[145] S. J. Geier, J. A. Mason, E. D. Bloch, W. L. Queen, M. R. Hudson, C. M. Browncd, J. R. Long, Chem. Sci. 4 (2013) 2054.

[146] K. Liu, D. Ma, B. Li, Y. Li, K. Yao, Z. Zhang, Y. Han, Z. Shi, J. Mater. Chem. A 2 (2014) 15823. 
[147] S. Yang, A. J. Ramirez-Cuesta, R. Newby, V. Garcia-Sakai, P. Manuel, S. K. Callear, S. I. Campbell, C. C. Tang, M. Schröder, Nat. Chem. 7 (2015) 121.

[148] Y. Zhang, B. Li, R. Krishna, Z. Wu, D. Ma, Z. Shi, T. Pham, K. Forrest, B. Space, S. Ma, Chem. Commun. 51 (2015) 2714.

[149] G. Chang, M. Huang, Y. Su, H. Xing, B. Su, Z. Zhang, Q. Yang, Y. Yang, Q. Ren, Z. Bao, B. Chen, Chem. Commun. 51 (2015) 2859.

[150] Y. Cui, Y. Yue, G. Qian, B. Chen, Chem. Rev. 112 (2012) 1126.

[151] Y. Cui, B. Chen, G. Qian, Coord. Chem. Rev. 273-274 (2014) 76.

[152] C. Y. Lee, O. K. Farha, B. J. Hong, A. A. Sarjeant, S. T. Nguyen, J. T. Hupp, J. Am. Chem. Soc. 133 (2011) 15858.

[153] Y. Cui, H. Xu, Y. Yue, Z. Guo, J. Yu, Z. Chen, J. Gao, Y. Yang, G. Qian, B. Chen, J. Am. Chem. Soc. 134 (2012) 3979.

[154] Z. Dou, J. Yu, Y. Cui, Y. Yang, Z. Wang, D. Yang, G. Qian, J. Am. Chem. Soc. 136 (2014) 5527.

[155] K.-D. Kreuer, Chem. Mater. 8 (1996) 610.

[156] W. Weppner, K.-D. Kreuer, A. Rabenau, Angew. Chem. Int. Ed. 122 (1982) 208.

[157] S. Horike, D. Umeyama, S. Kitagawa, Acc. Chem. Res. 46 (2013) 2376.

[158] M. Sadakiyo, T. Yamada, H. Kitagawa, J. Am. Chem. Soc. 131 (2009) 9906.

[159] D. Umeyama, S. Horike, M. Inukai, Y. Hijikata, S. Kitagawa, Angew. Chem. Int. Ed. 50 (2011) 11706.

[160] S. S. Nagarkar, S. M. Unni, A. Sharma, S. Kurungot, S. K. Ghosh, Angew. Chem. Int. Ed. 53 (2014) 2638. 


\title{
Catalysis
}

\author{
Optic
}

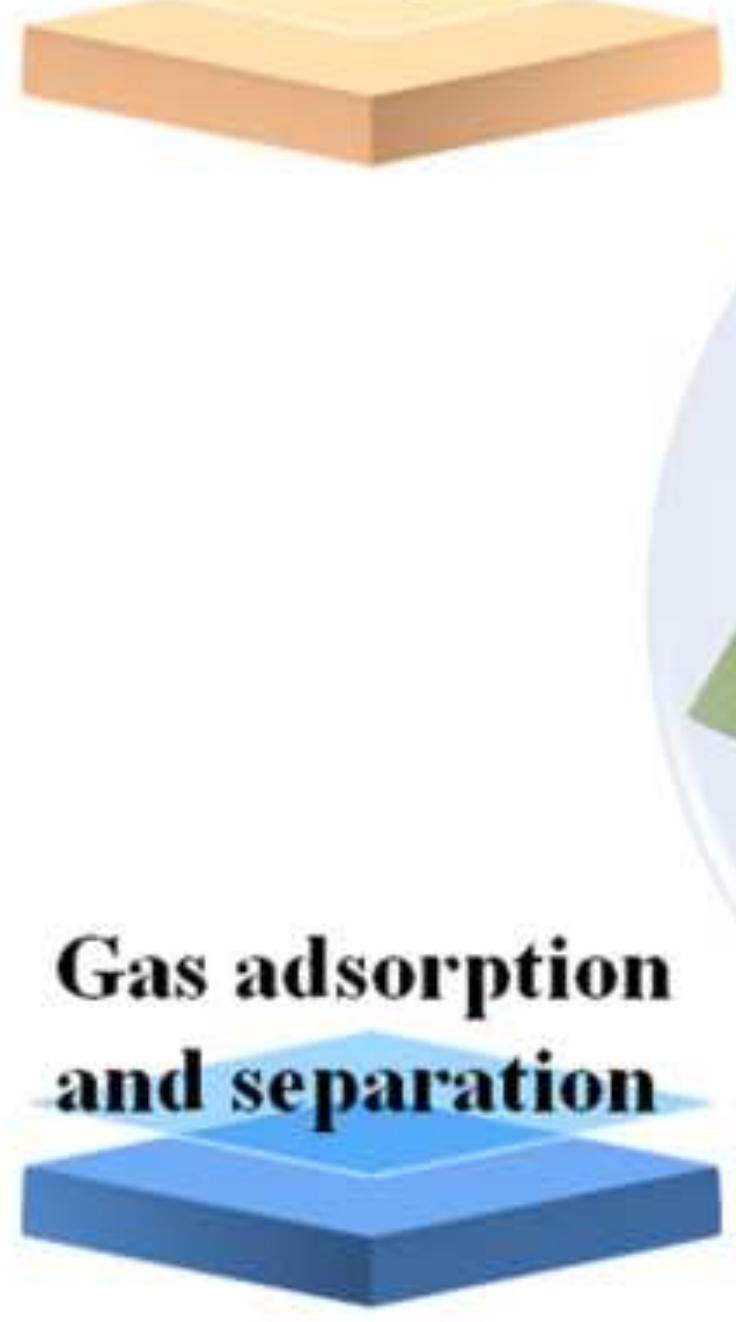

Gas adsorption and separation
Proton conduction
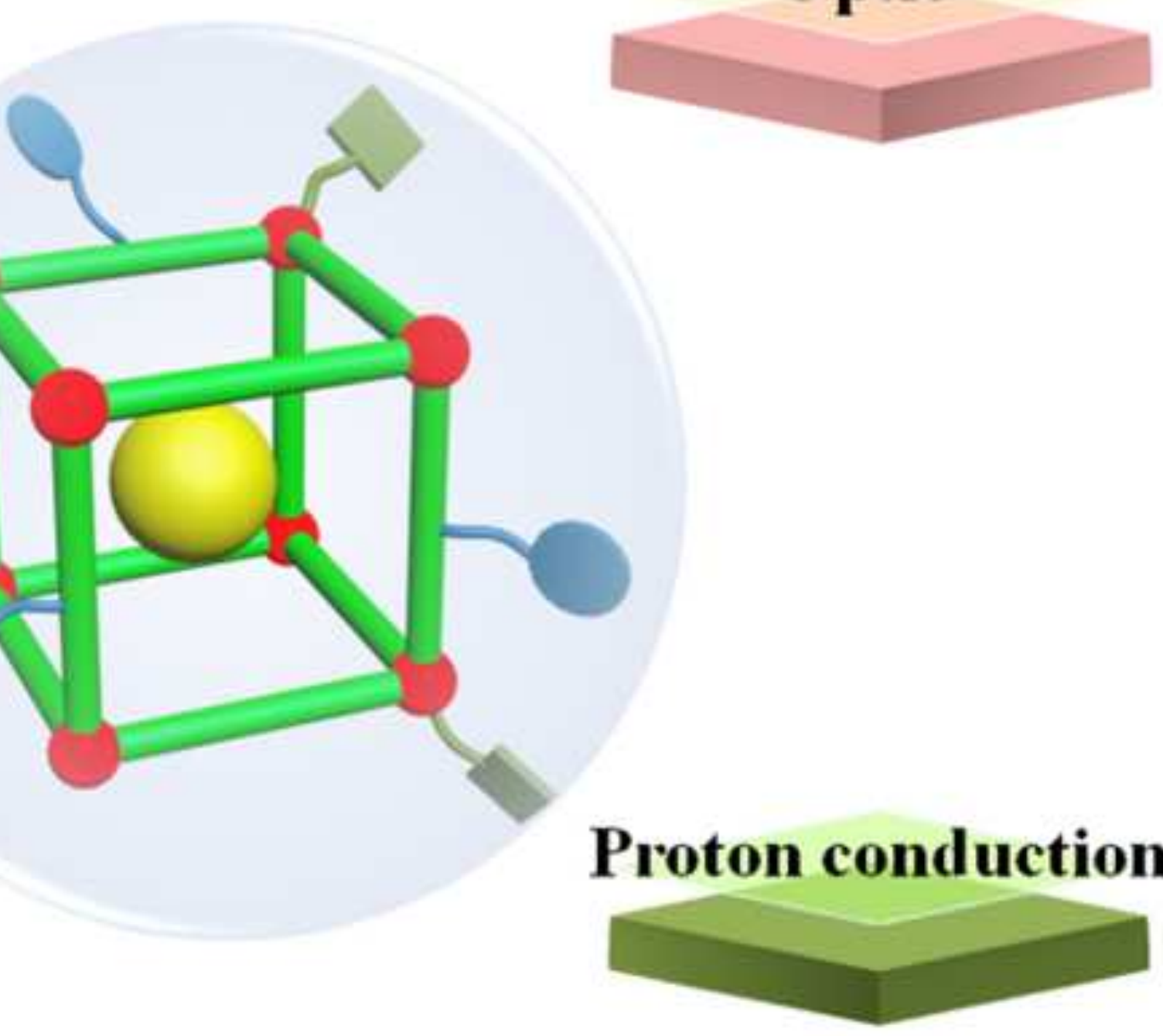

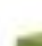

